\author{
Universidade de Brasília \\ Faculdade de Ciências da Saúde \\ Departamento de Enfermagem \\ Programa de Pós-Graduação em Enfermagem
}

MÁRCIA TIMM

Adaptação transcultural do instrumento Medical Office Survey on Patient Safety Culture sobre segurança do paciente para Atenção Primária à Saúde 


\author{
UNIVERSIDADE DE BRASÍLIA \\ FACULDADE DE CIÊNCIAS DA SAÚDE \\ DEPARTAMENTO DE ENFERMAGEM \\ PROGRAMA DE PÓS-GRADUAÇÃO EM ENFERMAGEM
}

MÁRCIA TIMM

\title{
Adaptação transcultural do instrumento Medical Office Survey \\ on Patient Safety Culture sobre segurança do paciente para
}

Atenção Primária à Saúde

Dissertação apresentada como requisito parcial para a obtenção do Título de Mestre em Enfermagem pelo Programa de Pós-Graduação em Enfermagem da Universidade de Brasília. Área de Concentração: Políticas, Práticas e Cuidado em Saúde e Enfermagem.

Linha de Pesquisa: Gestão da Atenção à Saúde e Organização dos Serviços em Saúde.

Orientadora: Professora $\mathrm{Dr}^{\mathrm{a}}$. Maria Cristina Soares Rodrigues 
Ficha catalográfica elaborada automaticamente. com os dados fornecidos pelo(a) autor(a)

\section{TIMN, MARCIA}

Adaptaç̄o tranecultural do instrumento Medical Office Survey on Patient Safety Culture wobre segurança do paciente para Atenç̄o Primiria a Saude / MARCIA TIMM; orientador Maria Criatina Soarea Rodriguea. - - Brasilia, 2015.

$$
151 \mathrm{p} \text {. }
$$

Disuertaç̄o (Meatrado - Meatrado em Enfermagem) -Univeraidade de Branilia, 2015.

1. Segurança do Paciente. 2. Cultura

Organizacional. 3. Gerenciamento de Segurança. 4. Peaquiasa em Enfermagem. 5. Bnfermagem de Atenção Primbria. I. Soarea Rodriguea, Maria Cristina, orient. II. Titulo. 
MÁRCIA TIMM

\title{
Adaptação transcultural do instrumento Medical Office Survey on Patient Safety Culture sobre segurança do paciente para
}

\author{
Atenção Primária à Saúde
}

Dissertação apresentada como requisito parcial para a obtenção do Título de Mestre em Enfermagem pelo Programa de Pós-Graduação em Enfermagem da Universidade de Brasília. Área de Concentração: Políticas, Práticas e Cuidado em Saúde e Enfermagem.

Linha de Pesquisa: Gestão da Atenção à Saúde e Organização dos Serviços em Saúde.

Aprovado em 27/08/2015

BANCA EXAMINADORA

Professora Doutora Maria Cristina Soares Rodrigues - Presidente da Banca Universidade de Brasília

Professora Doutora Helena Eri Shimizu - Membro Efetivo, Externo ao Programa Universidade de Brasília

Professora Doutora Walterlânia Silva Santos- Membro Efetivo, Interno ao Programa Universidade de Brasília

Professora Doutora Thatianny Tanferri de Brito Paranaguá- Membro Suplente Universidade de Brasília 
Dedico este trabalho à minha filha Bruna. Ao meu marido, pela ajuda e compreensão. Aos meus pais que me ensinaram a lutar e persistir para atingir os objetivos. 


\section{AGRADECIMENTOS}

Agradeço a Deus porque sem Ele nada seria possível.

Agradeço às pessoas que contribuíram para realização dessa conquista, direta ou indiretamente.

Em especial à minha orientadora, Professora Dr. ${ }^{a}$ Maria Cristina Soares Rodrigues, que esteve muito próxima nesta trajetória, acompanhando cada etapa, dedicando seu tempo e atenção com muito zelo, responsabilidade, carinho e respeito.

À minha família que me apoiou nos momentos difíceis, minha filha Bruna em especial que compartilhou a atenção e dedicação para tornar esse trabalho possível, meu marido pelo auxílio no uso dos recursos tecnológicos. Aos meus pais, todo meu amor e respeito porque a eles devo a vida, por me ensinarem a ser persistente e a enfrentar os desafios. Às minhas irmãs que me estimularam a continuar a caminhada.

Ao painel de especialistas e ao grupo de público alvo que, voluntariamente, contribuíram na análise do instrumento.

À minha amiga Poliana que, apesar da distância, me apoiou e compreendeu as minhas inquietações. 
"A menos que modifiquemos a nossa maneira de pensar, não seremos capazes de resolver os problemas causados pela forma como nos acostumamos a ver o mundo". 


\section{RESUMO}

Timm, Márcia. Adaptação transcultural do instrumento Medical Office Survey on Patient Safety Culture para uso na Atenção Primária à Saúde. 2015. 150 p. Dissertação (Mestrado) - Departamento de Enfermagem, Faculdade de Ciências da Saúde, Universidade de Brasília, Brasília, 2015.

INTRODUÇÃO: A segurança do paciente é um assunto atual e de grande destaque, está inserido nas agendas de pesquisa dos mais modernos sistemas de saúde do mundo. A cultura de segurança é uma das temáticas no contexto da segurança do paciente e a adaptação transcultural e validação do instrumento para o português do Brasil constitui o objeto de pesquisa proposto neste estudo. OBJETIVOS: traduzir, adaptar e validar o instrumento de pesquisa Medical Office Survey on Patient Safety Culture, para avaliar a cultura de segurança do paciente na Atenção Primária à Saúde no Brasil. MATERIAIS E MÉTODOS: Trata-se de um estudo metodológico de adaptação transcultural do instrumento elaborado pela Agency for Healthcare and Research in Quality, dos Estados Unidos da América. Seguiram-se as etapas de tradução, síntese I, retrotradução, síntese II, análise de especialistas, grupo de populaçãoalvo e pré-teste. A tradução para o português foi realizada por dois tradutores bilíngues português-inglês, nativos brasileiros, que conheciam o objetivo do estudo. As versões traduzidas foram comparadas para realizar a síntese I. A retrotradução foi realizada por dois tradutores bilíngues inglês-português, nativos americanos, que não conheciam o objetivo do estudo e a versão original. Realizada síntese II e comparada com a versão original para identificar discrepâncias. Na etapa de análise dos especialistas, participaram seis especialistas, que possuíam produção científica no tema da pesquisa, avaliaram o instrumento quanto à clareza e coerência do conteúdo por meio de escala Likert e sugestões de adequações. RESULTADOS: Na análise dos dados o instrumento atingiu índice de validade de conteúdo geral de 0,85. A avaliação pelo grupo de população-alvo foi realizada com amostra de seis profissionais que compõem a equipe multidisciplinar da Atenção Primária à Saúde, com amostra desde o estrato mais baixo (nível médio) até o mais alto (pós-graduação) de escolaridade, foi realizada a análise semântica do conteúdo do instrumento, as sugestões de adaptação foram analisadas e modificadas por consenso pela pesquisadora e orientadora. $\mathrm{O}$ pré-teste foi aplicado em uma amostra de 37 profissionais em quatro unidades de saúde de uma regional de saúde da Secretaria de Estado de Saúde do Distrito Federal, Brasil. Foi utilizado escala Likert para avaliar a compreensão dos itens do instrumento. CONCLUSÃO: Os resultados demonstraram que o instrumento é de fácil compreensão pela população-alvo. $\mathrm{O}$ coeficiente alfa de Cronbach geral do instrumento foi de 0,95 . Com o estudo cumpriu-se a tradução, adaptação transcultural e validação do instrumento para a língua portuguesa do Brasil com nível satisfatório de validade de conteúdo e alta confiabilidade.

Palavras-Chaves: Segurança do Paciente; Cultura Organizacional; Gerenciamento de Segurança; Pesquisa em Enfermagem; Enfermagem de Atenção Primária; Enfermagem em Saúde Pública. 


\begin{abstract}
Timm, Marcia. Cross-cultural adaptation of the instrument Medical Office Survey on Patient Safety Culture about patient's safety in primary health care. Number of sheets: 150 p. Dissertation (Mastership) - Department of Nursing, Faculty of Health Sciences, University of Brasília, Brasília, 2015.

INTRODUCTION: Patient's safety is a current issue and of great headline, it is inserted into the research agendas of the most modern health systems in the world. The culture of safety is one of the themes in the context of patient safety and validation of the Portuguese for Brazil is the object of research proposed in this study. OBJECTIVES: translating, adapting and validating the research instrument Medical Office Survey on Patient Safety Culture, to evaluate the culture of patient's safety in primary health care in Brazil. MATERIALS AND METHODS: This is a methodological study of cross-cultural adaptation of the instrument prepared by the Agency for Healthcare and Research in Quality, of the United States of America. There were followed the steps of translation, synthesis I, retro-translation, synthesis II, expert analysis, target population group and pre-test. The Portuguese translation was carried out by two bilingual Portuguese-English translators, native Brazilians who knew the purpose of the study. The translated versions were compared to perform the synthesis I. The retro-translation was carried out by two bilingual translators English-Portuguese, native Americans, who did not know the purpose of the study and the original version. Held synthesis II and compared to the original version to identify discrepancies. In the experts' analysis step, six experts participated; they had scientific production on the subject of research, evaluated the instrument regarding the clarity and coherence of the content by using Likert scale and suggestions for adjustments. RESULTS: In the analysis of the data the instrument hit general content validity index of 0.85 . The assessment by the group of the target population was held with six professionals who make up the multidisciplinary team of Primary Health Care, with sample from the lower stratum (mid-level) to the highest (postgraduate) educational level, semantic analysis of the content of the instrument was performed, and the suggestions of adaptation has been reviewed and modified by consensus by researcher and advisor. The pre-test was applied in a sample of 37 professionals in four regional health units of health of the State Secretariat of Health of the Federal District, Brazil. Likert scale was used to assessing the understanding of the items of the instrument. CONCLUSION: The results showed that the instrument is easily understood by the target population. The general Cronbach's alpha coefficient of the instrument was 0.95 . With the study fulfilled the translation, cross-cultural adaptation and validation of the instrument into Portuguese of Brazil with satisfactory level of content validity and high reliability.
\end{abstract}

Keywords: Patient Safety; Organizational Culture; Safety Management; Nursing Research; Primary Care Nursing; Public Health Nursing. 


\section{RESUMEN}

Timm, Marcia. Adaptación transcultural del instrumento Medical Office Survey on Patient Safety Culture, acerca de la seguridad del paciente en atención primaria de salud. Número de hojas: 150 p. Tesis (Maestría) - Departamento de Enfermería, Facultad de Ciencias de la Salud de la Universidad de Brasília, Brasília, 2015.

INTRODUCCIÓN: La eguridad del paciente es un tema actual y a destacar, se inserta en las agendas de investigación de los sistemas de salud más modernos del mundo. La cultura de seguridad es uno de los temas en el contexto de seguridad del paciente y la adaptación cultural y validación de los portugueses de Brasil es el objeto de la investigación propuesta en este estudio. OBJETIVOS: traducir, adaptar y validar el instrumento de investigación Medical Office Survey on Patient Safety Culture, para evaluar la cultura de la seguridad del paciente en Atención Primaria de Salud en Brasil. MATERIALES Y MÉTODOS: Se trata de un estudio metodológico de adaptación transcultural del instrumento elaborado por la Agency for Healthcare and Research in Quality, de los Estados Unidos de América. Siguió los pasos de la traducción, síntesis I, retro-traducción, síntesis II, análisis de expertos, grupo de población objetivo y pre-test. La traducción para el portugués se llevó a cabo por dos traductores bilingües de portugués-inglés, brasileños nativos que conocían el propósito del estudio. Las versiones traducidas se compararon para llevar a cabo la síntesis I. La retro-traducción fue realizada por dos traductores bilingües inglés-portugués, nativos americanos que no conocían el propósito del estudio y la versión original. Realizada la síntesis II y en comparación con la versión original para identificar discrepancias. En el análisis de los expertos, seis expertos que habían participado tenían conocimiento en la literatura científica acerca del tema de la investigación, evaluaron el instrumento con respecto a la claridad y la coherencia de los contenidos mediante escala Likert y sugerencias para realizar ajustes. RESULTADOS: En el análisis de los datos el instrumento alcanzó índice de validez de contenido general de 0.85. La evaluación por el grupo de la población objetivo se llevó a cabo con seis profesionales que conforman el equipo multidisciplinario de Atención Primaria de Salud, con la muestra del estrato más bajo (nivel medio) hasta el más alto (postgrado) nivel educativo, fue conducido el análisis semántico del contenido del instrumento, las sugerencias de adaptación han sido revisadas y modificadas por consenso por la investigadora y asesora. El pre-test fue aplicado en una muestra de 37 profesionales en cuatro unidades de salud de una regional de salud de la Secretaría de Estado de Salud del Distrito Federal, Brasil. Escala de Likert se utilizó para evaluar la comprensión de los ítems del instrumento. CONCLUSIÓN: Los resultados mostraron que el instrumento es fácilmente entendido por la población objetivo. El coeficiente alfa de Cronbach general del instrumento fue de 0.95. El estudio cumplió la traducción, adaptación transcultural y validación del instrumento para el portugués de Brasil con un nivel satisfactorio de validez de contenido y alta confiabilidad.

Palabras clave: Seguridad del Paciente; Cultura Organizacional; Gestión de la Seguridad; Investigación em Enfermería; Enfermería Pesquisa; Enfermería de Atenção Primaria; Enfermería en Salud Pública. 


\section{LISTA DE FIGURAS}

Figura 1. Modelo do queijo suíço de James Reason............................................ 25

Figura 2. Matriz de avaliação de desempenho do sistema de saúde PROADESS/MS - Fundação Oswaldo Cruz, 2011 .............................

Figura 3. Etapas do método utilizado para validação do instrumento para o português do Brasil, Brasília - DF, 2015.

\section{LISTA DE QUADROS}

Quadro 1. Estratégia de avaliação por Reichenhei.

\section{LISTA DE GRÁFICOS}

Gráfico 1. Distribuição dos participantes da pesquisa na etapa de pré-teste, por faixa etária. Brasília - DF, 2015.

\section{LISTA DE TABELAS}

Tabela 1. Resultado dos cálculos de índice de validade de conteúdo e concordância Inter avaliadores na fase de análise dos especialistas, Brasília - DF, 2015.

Tabela 2. Médias relativas à compreensão dos itens do questionário, segundo população-meta, aplicados no pré-teste - Seção A. Brasília - DF, 2015

Tabela 3. Média de compreensão dos itens do questionário aplicados no préteste, com cálculo de desvio padrão - Seção B. Brasília - DF, 2015

Tabela 4. Média de compreensão dos itens do questionário aplicados no préteste, com cálculo de desvio padrão - Seção C. Brasília - DF, 2015

Tabela 5. Média de compreensão dos itens do questionário aplicados no préteste, com cálculo de desvio padrão - Seção D. Brasília - DF, 2015....

Tabela 6. Média de compreensão dos itens do questionário aplicados no préteste, com cálculo de desvio padrão - Seção E. Brasília - DF, 2015....

Tabela 7. Média de compreensão dos itens do questionário aplicados no préteste, com cálculo de desvio padrão - Seção F. Brasília - DF, 2015.... 
Tabela 8. Média de compreensão dos itens do questionário aplicados no préteste, com cálculo de desvio padrão - Seção G. Brasília - DF, 2015....

Tabela 9. Média de compreensão dos itens do questionário aplicados no préteste, com cálculo de desvio padrão - Avaliação Global. Brasília DF, 2015 .

Tabela 10. Frequência das opções de respostas da amostra do pré-teste, seção A, item 1. Brasília - DF, 2015.

Tabela 11. Frequência das opções de respostas da amostra do pré-teste, seção A, item 2. Brasília - DF, 2015.

Tabela 12. Frequência das opções de respostas da amostra do pré-teste, seção A, item 3. Brasília - DF, 2015.

Tabela 13 Frequência das opções de respostas da amostra do pré-teste, seção A, item 4. Brasília - DF, 2015.

Tabela 14 Frequência das opções de respostas da amostra do pré-teste, seção A, item 5. Brasília - DF, 2015.....

Tabela 15 Frequência das opções de respostas da amostra do pré-teste, seção A, item 6. Brasília - DF, 2015......

Tabela 16 Frequência das opções de respostas da amostra do pré-teste, seção A, item 7. Brasília - DF, 2015......

Tabela 17 Frequência das opções de respostas da amostra do pré-teste, seção A, item 8. Brasília - DF, 2015.

Tabela 18 Frequência das opções de respostas da amostra do pré-teste, seção A, item 9. Brasília - DF, 2015.

Tabela 19 Frequência das opções de respostas da amostra do pré-teste, seção A, item 10. Brasília - DF, 2015.

Tabela 20 Frequência das opções de respostas da amostra do pré-teste, seção B, item 1. Brasília - DF, 2015 .

Tabela 21 Frequência das opções de respostas da amostra do pré-teste, seção C, item 1. Brasília - DF, 2015

Tabela 22 Frequência das opções de respostas da amostra do pré-teste, seção C, item 2. Brasília - DF, 2015 .

Tabela 23 Frequência das opções de respostas da amostra do pré-teste, seção C, item 3. Brasília - DF, 2015.

Tabela 24 Frequência das opções de respostas da amostra do pré-teste, seção C, item 4. Brasília - DF, 2015. 
Tabela 25 Frequência das opções de respostas da amostra do pré-teste, seção C, item 5. Brasília - DF, 2015 ..............................................................

Tabela 26 Frequência das opções de respostas da amostra do pré-teste, seção C, item 6. Brasília - DF, 2015.

Tabela 27 Frequência das opções de respostas da amostra do pré-teste, seção C, item 7. Brasília - DF, 2015.

Tabela 28 Frequência das opções de respostas da amostra do pré-teste, seção C, item 8. Brasília - DF, 2015.

Tabela 29 Frequência das opções de respostas da amostra do pré-teste, seção C, item 9. Brasília - DF, 2015.

Tabela 30. Frequência das opções de respostas da amostra do pré-teste, seção C, item 10. Brasília - DF, 2015.

Tabela 31. Frequência das opções de respostas da amostra do pré-teste, seção C, item 11. Brasília - DF, 2015.

Tabela 32. Frequência das opções de respostas da amostra do pré-teste, seção C, item 12. Brasília - DF, 2015.

Tabela 33. Frequência das opções de respostas da amostra do pré-teste, seção C, item 13. Brasília - DF, 2015.

Tabela 34. Frequência das opções de respostas da amostra do pré-teste, seção C, item 14. Brasília - DF, 2015.

Tabela 35. Frequência das opções de respostas da amostra do pré-teste, seção C, item 15. Brasília - DF, 2015.

Tabela 36. Frequência das opções de respostas da amostra do pré-teste, seção D, item 1. Brasília - DF, 2015.

Tabela 37. Frequência das opções de respostas da amostra do pré-teste, seção D, item 2. Brasília - DF, 2015.

Tabela 38. Frequência das opções de respostas da amostra do pré-teste, seção D, item 3. Brasília - DF, 2015.

Tabela 39. Frequência das opções de respostas da amostra do pré-teste, seção D, item 4. Brasília - DF, 2015.

Tabela 40. Frequência das opções de respostas da amostra do pré-teste, seção D, Item 5. Brasília - DF, 2015.

Tabela 41. Frequência das opções de respostas da amostra do pré-teste, seção D, item 6. Brasília - DF, 2015. 
Tabela 42. Frequência das opções de respostas da amostra do pré-teste, seção D, item 7. Brasília - DF, 2015

Tabela 43. Frequência das opções de respostas da amostra do pré-teste, seção D, item 8. Brasília - DF, 2015.

Tabela 44. Frequência das opções de respostas da amostra do pré-teste, seção D, item 9. Brasília - DF, 2015.

Tabela 45. Frequência das opções de respostas da amostra do pré-teste, seção D, item 10. Brasília - DF, 2015

Tabela 46. Frequência das opções de respostas da amostra do pré-teste, seção D, item 11. Brasília - DF, 2015

Tabela 47. Frequência das opções de respostas da amostra do pré-teste, seção D, item 12. Brasília - DF, 2015.

Tabela 48. Frequência das opções de respostas da amostra do pré-teste, seção E, item 1. Brasília - DF, 2015.

Tabela 49. Frequência das opções de respostas da amostra do pré-teste, seção E, item 2. Brasília - DF, 2015 .

Tabela 50. Frequência das opções de respostas da amostra do pré-teste, seção E, item 3. Brasília - DF, 2015.

Tabela 51. Frequência das opções de respostas da amostra do pré-teste, seção E, item 4. Brasília - DF, 2015

Tabela 52. Frequência das opções de respostas da amostra do pré-teste, seção F, item 1. Brasília - DF, 2015.

Tabela 53. Frequência das opções de respostas da amostra do pré-teste, seção F, item 2. Brasília - DF, 2015.

Tabela 54. Frequência das opções de respostas da amostra do pré-teste, seção F, item 3. Brasília - DF, 2015.

Tabela 55. Frequência das opções de respostas da amostra do pré-teste, seção F, item 4. Brasília - DF, 2015.

Tabela 56. Frequência das opções de respostas da amostra do pré-teste, seção F, item 5. Brasília - DF, 2015.

Tabela 57. Frequência das opções de respostas da amostra do pré-teste, seção F, item 6. Brasília - DF, 2015.

Tabela 58. Frequência das opções de respostas da amostra do pré-teste, seção F, item 7. Brasília - DF, 2015. 
Tabela 59. Frequência das opções de respostas da amostra do pré-teste, seção G,

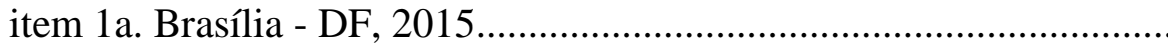

Tabela 60. Frequência das opções de respostas da amostra do pré-teste, seção G, item 1b. Brasília - DF, 2015.

Tabela 61. Frequência das opções de respostas da amostra do pré-teste, seção G, item 1c. Brasília - DF, 2015.

Tabela 62. Frequência das opções de respostas da amostra do pré-teste, seção G, item 1d. Brasília - DF, 2015.

Tabela 63. Frequência das opções de respostas da amostra do pré-teste, seção G, item 1e. Brasília - DF, 2015.

Tabela 64. Frequência das opções de respostas da amostra do pré-teste, seção G, item 2. Brasília - DF, 2015 


\section{SUMÁRIO}

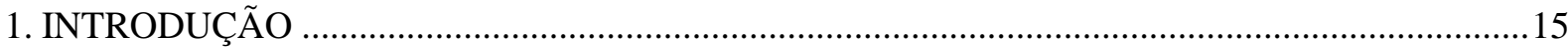

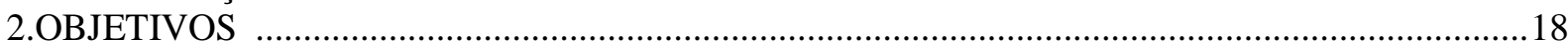

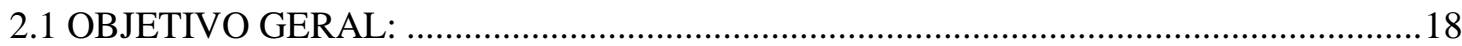

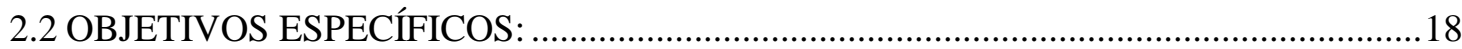

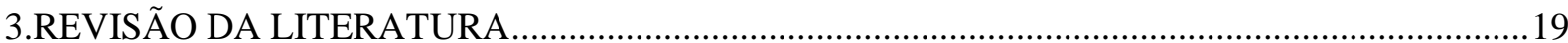

3.1 SEGURANÇA DO PACIENTE...…………………………………………………....19

3.2 CULTURA ORGANIZACIONAL E CULTURA DE SEGURANÇA DO PACIENTE ...22

3.4 A CULTURA DE SEGURANÇA DO PACIENTE NA ATENÇÃO PRIMÁRIA À SAÚDE

3.4.1 Dimensão efetividade ..........................................................................................38

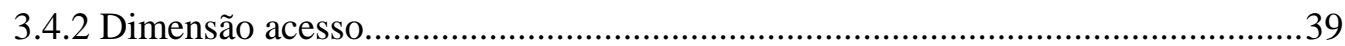

3.4.3 Dimensão eficiência ..............................................................................................40

3.4.4 Dimensão respeito aos direitos das pessoas - centrado no paciente.......................41

3.4.5 Dimensão continuidade ………………………………………………………….43

3.4.6 Dimensão adequação ............................................................................................4

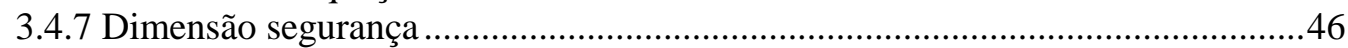

3.5 ESTRATÉGIAS PARA TORNAR OS CUIDADOS MAIS SEGUROS ……………….....48

3.6 AVALIAÇÃO DA CULTURA DE SEGURANÇA, ADAPTAÇÃO CULTURAL E VALIDAÇÃO DE INSTRUMENTOS DE MENSURAÇÃO............................................51

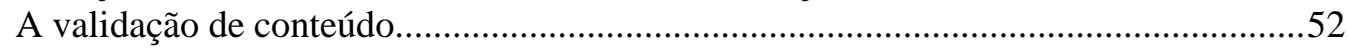

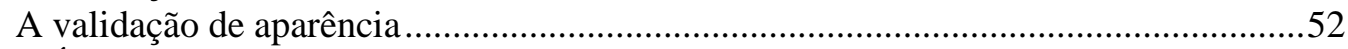

O Índice de fidedignidade ou concordância interavaliadores (interrater agrément)......53

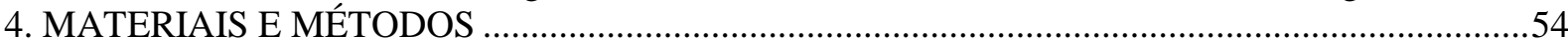

4.1 DESENHO DO ESTUDO .......................................................................................54

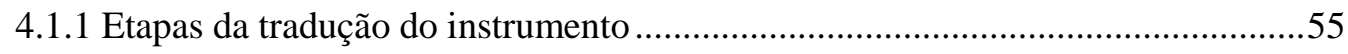

4.1.2 Validação do instrumento ...................................................................................57

4.1.3 Aplicação do pré-teste para a população-alvo ......................................................58

4.2 CONSIDERAÇÕ̃ES ÉTICAS ……………………………………………………....6

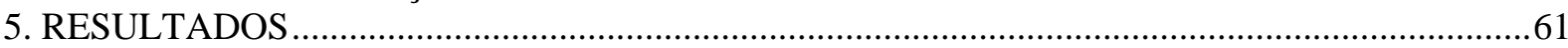

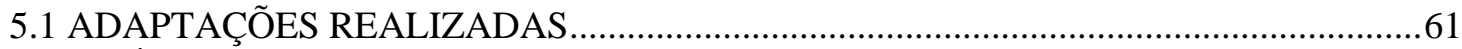

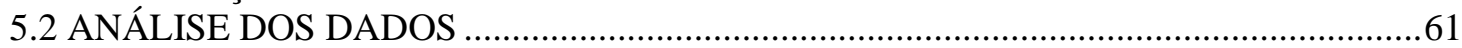

5.2.1 Índice de Validade de Conteúdo e Concordância Interavaliadores .......................61

5.2.2 Adaptações do instrumento sugeridas pelos especialistas .......................................64

5.2.3 Adaptações sugeridas pelo grupo de população-alvo ………………………….....64

5.2.4 Pré-teste …………………………………………………………………....65

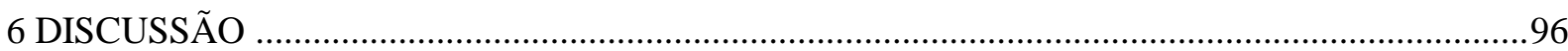

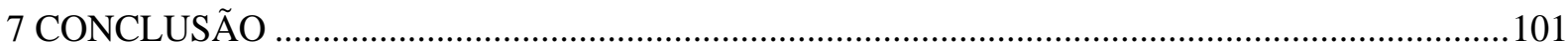

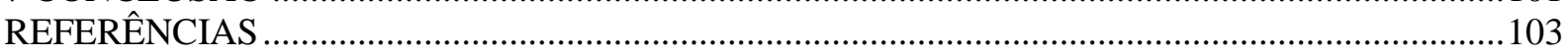

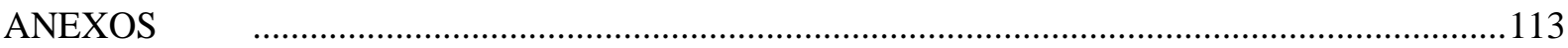

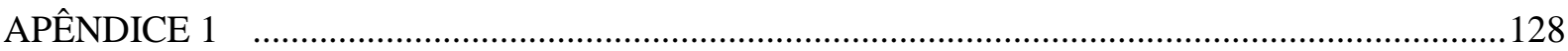

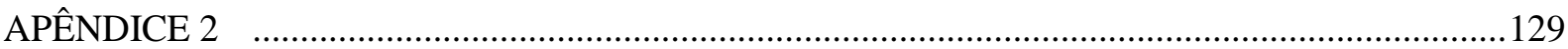

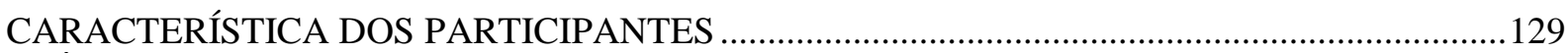

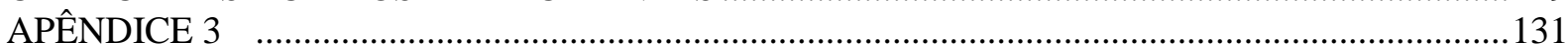

COMPARAÇÃO DA PRIMEIRA SÍNTESE T1-2 E APÓS AVALIAÇÃO DOS ESPECIALISTAS.131

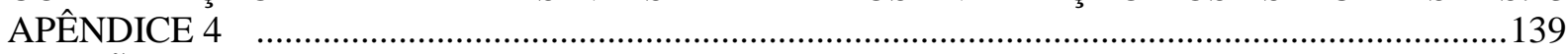

VERSÃO FINAL DO INSTRUMENTO TRADUZIDO E ADAPTADO …………………………....139 


\begin{abstract}
APRESENTAÇÃO
A motivação em estudar o tema Segurança do Paciente surgiu a partir da realização da disciplina Segurança de Medicamentos no Cuidado em Saúde do Programa de Pós-Graduação em Enfermagem da UnB, cursada em 2011, na condição de aluna especial, ministrada pela professora Maria Cristina Soares Rodrigues. Nessa oportunidade, tive o primeiro contato com o assunto, quando identifiquei a importância da segurança do paciente no cuidado e o desempenho das atividades como enfermeira assistencial.

A referida disciplina foi como uma "semente plantada", que foi se desenvolvendo, se definindo, criando forma para a acepção de um pré-projeto de pesquisa a ser desenvolvido em meu curso de mestrado. Inicialmente, não tinha muita clareza quanto ao objeto do estudo, porque o interesse era desenvolver uma pesquisa direcionada à minha atuação profissional, que tivesse relevância social, que fosse aplicável e pudesse contribuir para a melhoria da qualidade da assistência ao paciente.

$\mathrm{Na}$ fase de elaboração do projeto, já estava atuando na chefia de enfermagem de um centro de saúde no Distrito Federal. Assim, sedimentou-se em mim a importância desse tema para a assistência e gestão, entretanto, quando fiz um levantamento bibliográfico preliminar identifiquei escassez de publicações referentes ao tema no Brasil, o que configurava um campo a ser investigado.

A Segurança do Paciente é um tema amplo, está inserido em todos os níveis de atenção e está diretamente relacionado com a qualidade da assistência em saúde. Assim sendo, optei por estudar a cultura de segurança na atenção primária, que é um dos ramos da segurança do paciente. As referências estudadas traziam questionários como principal forma de investigar a cultura de segurança. Pelo fato de não encontrar um questionário validado para ser utilizado na atenção primária, surgiu o interesse em validar um instrumento para aplicação nesse nível de atenção. Deste modo, escolhi pela tradução e adaptação de um questionário já testado e validado em outros países, em contrapartida da elaboração de um novo instrumento, pois possibilitaria a comparação com estudos internacionais, e pelo fato de ser um instrumento já testado e amplamente aplicado em outras línguas, fato que fornece consistência ao estudo.
\end{abstract}

Atualmente, estou na gerência de uma clínica da família e identifico um grande potencial de aplicabilidade do estudo, inicialmente como instrumento para identificar a atual 
cultura de segurança no serviço. Ademais, agrega conceitos e fundamentação teórica de diversos estudos nacionais e internacionais para compor um corpo de conhecimento na área de Segurança do Paciente na Atenção Primária à Saúde, que possibilitam propor estratégias de melhoria da segurança e qualidade, bem como na implantação do Núcleo de Segurança do Paciente e ações de educação permanente em serviço. Como forma de divulgação e visibilidade do estudo, o produto originado nesta pesquisa foi apresentando no Congresso de Medicina de Família e Comunidade, em Natal, Rio Grande do Norte, em julho de 2015, na modalidade de apresentação oral. Além disso, foi elaborado um artigo submetido em periódico com Qualis Capes da Área de Enfermagem estrato A2.

Nessa trajetória acadêmico-científica, vivenciada de forma persistente e apaixonada, na construção do "Eu pesquisador", apresento o trabalho gerado nos próximos capítulos, na expectativa de ter contribuído para o avanço da ciência em saúde e enfermagem brasileira. 


\section{INTRODUÇÃO}

Muitos países já reconheceram que a segurança do paciente é importante e estão construindo estratégias para melhorar a qualidade e segurança dos cuidados (WHO, 2011). O Institute of Medicine alertou para o problema da segurança nas instituições de saúde em relatório publicado em 2000 intitulado "To Err is Human: Buliding a Safer Health System" (KOHN et al., 2000). No entanto, Nightingale (1863) já trazia em seu livro Notes on Hospitals que "Pode parecer estranho enunciar que a principal exigência em um hospital seja não causar dano aos doentes". "Não causar dano ao paciente" constitui, provavelmente, a definição mais sucinta de segurança do paciente (GAAL et al., 2011).

Segurança do Paciente consiste em evitar e prevenir danos ou eventos adversos aos pacientes, resultantes dos processos de cuidados de saúde prestados (REIS et al., 2012). Evento Adverso é definido como lesão ou dano resultante da assistência à saúde, já o desfecho adverso é a consequência de um cuidado de saúde, da morbidade/mortalidade que um paciente sofre em função de sua doença de base. Em saúde, nem todos os erros culminam em eventos adversos e nem todos os eventos adversos são resultantes de erros (HARADA; PEDREIRA, 2013). Dentre os eventos adversos, a maioria dos incidentes ocorre em quatro principais áreas, quais sejam: diagnóstico, prescrição de medicamentos, comunicação entre profissionais de saúde e pacientes, e fatores organizacionais (ESMAIL, 2013). Um incidente de segurança do paciente é um evento ou circunstância que poderia resultar, ou resultou, em dano desnecessário para o paciente (PORTUGAL, 2011).

A segurança do paciente é um assunto atual e de grande destaque, está inserido nas agendas de pesquisa dos mais modernos sistemas de saúde. A cultura de segurança é uma das temáticas no contexto da segurança do paciente. Para que haja assistência comprometida com a segurança do paciente, é preciso promover o debate e informação sobre o assunto, no sentido de estabelecer cultura de segurança nas instituições de saúde.

O conceito de cultura de segurança surgiu com base em pesquisas com foco em segurança e prevenção de acidentes em indústrias de alta confiabilidade e críticas a erros, como a aviação, fabricação química e usinas nucleares (SORRA; DYER, 2010), e posteriormente foi adaptado para área da saúde. De acordo com Sorra et al. (2008) a cultura de segurança de uma organização é o produto dos valores individuais e do grupo, atitudes, percepções, competências e padrões de comportamento que determinam o compromisso, estilo e proficiência da gestão da saúde e segurança de uma organização. 
A avaliação da cultura de segurança permite identificar e gerir prospectivamente questões relevantes à segurança em suas rotinas de trabalho (REIS et al., 2012). Para estabelecer cultura de segurança positiva e fazer melhorias na prática geral, evidências sugerem que o primeiro passo é avaliar e compreender a atual cultura de segurança (ZWART et al., 2011). Eklöf et al. (2014) defendem que o sistema de normas para a aceitação de riscos são negativos para a segurança em saúde, e a cultura é o que melhor representa os interesses dos pacientes, cuidadores e sociedade. Os autores também ressaltam que o ambiente de trabalho influencia na segurança do cuidado. Assim, a maneira pela qual os profissionais da saúde são treinados e socializados reflete nos resultados, uma vez que a cultura é transferida de forma gradual ao longo do tempo.

Nos últimos anos, as pesquisas em segurança do paciente, em relação aos cuidados primários, têm evoluído bastante (GAAL et al., 2011), embora ainda exista a percepção de que o nível de Atenção Primária seja considerado de baixa tecnologia e que a segurança não seja um problema (LINNEAUS EURO-PC, 2014). Contrariando essa falsa percepção, inevitavelmente, os erros existem, sejam estes relacionados com os profissionais ou relacionado com o sistema. É uma constante na prática clínica e podem ocorrer em qualquer fase do processo da prestação de cuidados (MENDES; BARROSO, 2014). Na medida em que a Atenção Primária utiliza menos tecnologia “dura", como máquinas-ferramentas, requer mais tecnologia "leve", que é o trabalho "vivo" em ato na produção. A ideia de tecnologia está muito vinculada não só a equipamento tecnológico, mas também a um certo saber fazer, e a um ir fazendo. A gestão dessa relação de processo de trabalho enfrenta situações de alta complexidade, em termos qualitativos, os quais caracterizam o conjunto das instituições do ponto de vista produtivo, em particular as da saúde (MERHY; ONOCKO, 1997).

Portanto, os eventos adversos são comuns também na Atenção Primária à Saúde, em que é realizado maior número de atendimentos (BONDEVIK et al, 2014). Os pacientes recebem prescrições, medicamentos ou vacinas e não permanecem no serviço, portanto, há dificuldade em identificar eventos adversos, ou mesmo garantir a continuidade do tratamento de forma correta pelo paciente. O potencial para eventos adversos é espantoso, mas a base de conhecimento sobre a segurança do paciente, nesse contexto, é ínfima (ESMAIL, 2013). Por essas razões, tem havido crescente interesse em fatores relacionados à segurança do paciente também fora do ambiente hospitalar (BONDEVIK et al, 2014).

As questões relacionadas com a segurança do paciente (ou a falta dela) em cuidados de saúde primários constituem um problema maior, à semelhança do que acontece em contexto hospitalar, e, como tal, necessita de adequada e urgente intervenção (MENDES; MOURA, 
2014). Observa-se a necessidade de ampliar a cultura de segurança na Atenção Primária à Saúde, a fim de habilitar pacientes e profissionais para reconhecerem e gerenciar os eventos adversos, sendo sensíveis à sua capacidade compartilhada para a mudança, reduzindo erros e tensões entre profissionais e população (MARCHON; MENDES JÚNIOR, 2014).

A Organização Mundial da Saúde (OMS) convocou um grupo internacional de especialistas, na tentativa de apoiar o desenvolvimento de uma base de evidências mais abrangente, para discutir, debater, e aconselhar sobre as direções para preencher lacunas de conhecimento em torno dos cuidados primários seguros, que também serviria para catalisar a investigação nestas áreas a nível internacional (CRESSWELL et al., 2013).

Ao explorar o tema da cultura de segurança, identificou-se escassa produção científica no Brasil. Em revisão publicada por Reis et al. (2013) identificou-se que a maioria dos estudos que avaliam a cultura de segurança em organizações utiliza questionários como instrumento de coleta de dados. Nesse estudo os autores não localizaram pesquisas em segurança do paciente na Atenção Primária em países em desenvolvimento e concluíram que estudos muito úteis têm sido realizados na área, mas, por outro lado, métodos com mais rigor e definições mais claras e coerentes de termos comuns precisam ser utilizados para auxiliar na comparabilidade dos mesmos. Da mesma forma, estudos brasileiros relacionado à ocorrência de eventos adversos na Atenção Primária à Saúde são escassos. Outra revisão realizada por Halligan e Zecevic (2011) aponta que a maioria dos estudos utiliza métodos quantitativos para medir a cultura de segurança e propõe melhorias por meio da implementação de intervenções multifacetárias destinadas a avaliar várias dimensões.

Dessa forma, faz-se necessário investigar a cultura de segurança na perspectiva das equipes multidisciplinares, inseridas em um contexto organizacional, para compor um corpo de conhecimento, identificando a visão dos profissionais a respeito da segurança do paciente, suscitando, assim, o debate e reflexão sobre o assunto, a fim de subsidiar a implantação de ações que melhorem a segurança do paciente e a qualidade da assistência em serviços de Atenção Primária à Saúde e que possa ser utilizado como fundamentação para estudos futuros. A adaptação transcultural e validação do instrumento para o português do Brasil constitui o objeto da pesquisa proposto neste estudo. Questionários adaptados e validados para a realidade brasileira podem contribuir no processo de avaliação e compreender a atual cultura de segurança na Atenção Primária à Saúde no país. 


\section{OBJETIVOS}

\subsection{OBJETIVO GERAL:}

- Validar o instrumento Medical Office Survey on Patient Safety Culture para investigação da cultura da segurança do paciente na Atenção Primária à Saúde.

\subsection{OBJETIVOS ESPECÍFICOS:}

- Traduzir e adaptar o instrumento para avaliar a cultura de segurança do paciente na Atenção Primária à Saúde no Brasil;

- Analisar o instrumento de pesquisa em pré-teste aplicado em quatro serviços de saúde da Atenção Primária à Saúde de uma regional de saúde da Secretaria de Estado de Saúde do Distrito Federal. 


\section{REVISÃO DA LITERATURA}

Na revisão da literatura, serão abordados conceitos e ponderações importantes sobre a temática, com breve apresentação de contexto histórico e o cenário na atualidade. Os principais tópicos serão a segurança do paciente, a cultura de segurança, a cultura organizacional, a cultura de segurança na Atenção Primária e a segurança do paciente interrelacionada com a qualidade dos serviços, como dimensão ordenadora na reorganização do processo de trabalho nesse contexto, sendo ainda levantados alguns aspectos favoráveis para a melhoria.

\subsection{SEGURANÇA DO PACIENTE}

Diversas personalidades ao longo da História tiveram preocupação com a segurança do paciente, Hipócrates já falava em não causar dano ao paciente, Ignaz Phillip em 1847 chamava atenção para a importância da higiene das mãos e Florence Nightingale foi a primeira líder em segurança do paciente a fazer análise estatística para mensurar os resultados da assistência e reduzir óbitos preveníveis (WACHTER, 2013; BRANCO FILHO, 2014).

Segundo Vincent (2009), a segurança do paciente pode ser definida como o ato de evitar, prevenir e melhorar os resultados adversos ou as lesões originadas no processo de atendimento médico-hospitalar.

A redução do dano ao paciente tem sido identificada como uma das principais áreas que necessitam de melhoria, com grande impacto no resultado e no financiamento do sistema de saúde. O dano associado ao cuidado de saúde é definido como o dano resultante ou associado a planos ou ações tomadas durante a prestação de cuidados de saúde, e não de uma doença ou lesão subjacente (PORTUGAL, 2011).

No relatório do Institute of Medicine dos Estados Unidos da América, publicado em 1999, estimou-se que 44 a 98 mil americanos morram anualmente em decorrência de erros associados aos cuidados em saúde (KOHN et al, 2000). O relatório do Institute of Medicine, quando foi lançado, tinha uma ambiciosa meta de reduzir os eventos adversos em $50 \%$ em 5 anos. No entanto, os eventos adversos com danos permanecem frequentes nas instituições de saúde (BRANCO FILHO, 2014).

Na Atenção Primária à Saúde, não se dispõe de dados para conhecer a frequência dos eventos adversos no Brasil, a maioria das investigações são no contexto hospitalar. Estudo Ibero-Americano de eventos Adversos em cinco países da América Latina (Argentina, Costa Rica, Colômbia, México e Peru) mostrou que 10,5\% dos pacientes hospitalizados sofrem 
algum tipo de eventos adversos, e destes, 58,9\% poderiam ter sido evitados; dentre os eventos adversos, os mais frequentes foram relacionados à infecção nosocomial, seguido por procedimentos realizados, cuidados e medicação (Estudo Ibero-Americano de eventos Adversos, 2010). Em outro estudo, de revisão, identificou-se que a maior parte dos incidentes avaliados não atingiu o paciente e quando atingiu foi de pouca gravidade (a frequência de incidentes variou entre 50 e $83 \%$ ). A medicação foi o tipo de evento adverso mais frequente na Atenção Primária à Saúde, segundo os estudos selecionados (MARCHON; MENDES JÚNIOR, 2014).

A segurança do paciente é um problema em todos os países que prestam serviços de saúde, tanto em serviços privados quanto públicos. Os pacientes são prejudicados por erros de prescrição ou administração de medicamentos, falha na identificação do paciente, o mau uso da tecnologia, falha na comunicação entre os profissionais de saúde ou atraso no recebimento do tratamento (WHO, 2011). Para prevenir e/ou evitar os eventos adversos, é fundamental conhecê-los, antecipá-los e, quando ocorrem, notificá-los, discuti-los, partilhá-los e aprender com eles (MENDES; BARROSO, 2014).

Os eventos adversos geram altos custos ao sistema de saúde, com grande desperdício de recursos financeiros para tratá-los. Esses valores poderiam ser mais bem utilizados em um processo de melhoria do próprio sistema (BRANCO FILHO, 2014). A segurança reside nos sistemas e também nas pessoas, e, por isso, deve ser ativamente procurada e estimulada. Tentar evitar danos não é suficiente, o caminho consiste em reduzir os erros de todos os tipos e procurar a alta confiabilidade como um componente essencial do atendimento de alta qualidade (VINCENT, 2009).

Diversas agências e instituições ao redor do mundo têm como foco a segurança do paciente e exercem importante papel em busca da melhoria da segurança do paciente e qualidade dos serviços, dentre elas está a Agency for Health Care Research and Quality, a Joint Commission, o Institute of Medicine e o Institute for Healthcare Improvement, este fundado em 1991 e sediado em Cambriedge, Massachusetts nos Estados Unidos da América.

O projeto Learning from International Networks about Errors and Understanding Safety in Primary Care (LINNEAUS) reúne um grupo de pesquisadores de sete países Estados Unidos da América, Reino Unido, Canadá, Holanda, Alemanha, Austrália e Nova Zelândia - composta por médicos, cientistas sociais, pesquisadores de saúde e gestores, que tem como foco a Atenção Primária à Saúde.

Mundialmente há a Organização Mundial da Saúde e, na América Latina e Caribe, a Organização Pan-Americana da Saúde. No Brasil há o Ministério da Saúde, em conjunto com 
a Agência Nacional de Vigilância Sanitária (ANVISA) e também o Centro Colaborador para Qualidade e Segurança do Paciente - PROQUALIS, criado em 2009, vinculado ao Instituto de Comunicação e Informação Cientifica e Tecnológica em Saúde/Fundação Oswaldo Cruz.

De acordo com Montserrat-Capella et al. (2013), a segurança do paciente já entrou na agenda política do Brasil desde a mobilização da ANVISA/Ministério da Saúde junto à Organização Mundial da Saúde para que os objetivos desejados fossem alcançados. No país, marco importante do compromisso com a assistência segura na atenção à saúde foi a instituição do Programa Nacional de Segurança do Paciente, a partir de $1^{\circ}$ de abril de 2013, cujo objetivo é prevenir e reduzir a incidência de eventos adversos e o monitoramento e prevenção de danos na assistência á saúde (MINISTÉRIO DA SAÚDE, 2013).

Apesar disso, entre a criação de uma norma ou legislação e a efetividade na prática da segurança do paciente e qualidade da assistência, existe um longo caminho a percorrer, observa-se que a implementação das ações encontra-se em fase inicial e a passos lentos em nosso país. De acordo com Mendes e Barroso (2014), a promoção de uma cultura de segurança do paciente não pode ser uma atividade paralela dos programas ministeriais, dos parágrafos estatutários das instituições de saúde, dos organogramas dos gestores e até das bases de dados dos responsáveis do risco, mas sim a base de trabalho para toda a prática clínica.

Os dados quanto ao número de eventos adversos no Brasil não são conhecidos, mas em outros países, com base em variedade de estudos, identificou-se que pelo menos 1 em cada 10 (ou até 1 em 3) hospitalizações é marcada por um evento adverso, e cerca de metade desses eventos adversos são evitáveis. Cerca de um terço deles causa dano real ao paciente (WACHTER, 2013). Marchon e Mendes Júnior (2015), realizaram estudo de tradução e adaptação, para o português do Brasil, do questionário Primary Care International Study of Medical Errors (PCISME), elaborado para identificar incidentes ocorridos com paciente na Atenção Primária à Saúde.

A revisão retrospectiva de prontuário tem sido considerada o método de coleta de dados mais adequado (Gold standard) para a avaliação de eventos adversos (BRANCO FILHO, 2014), porém, há de se considerar que no Brasil as informações registradas no prontuário, pelos profissionais, nem sempre são completas. Estudo realizado para avaliar a qualidade dos registros de enfermagem no prontuário identificou que $26,7 \%$ foram considerados ruins, $64,6 \%$ foram considerados regulares e $8,7 \%$ bons (SETZ; D'INNOCENZO, 2009). Outro estudo que avaliou a qualidade de prontuários de pacientes na Atenção Primária identificou que os registros de características do processo de atendimento, 
em mulheres, hipertensas e diabéticas ficaram longe das proposições do Ministério da Saúde para a Estratégia Saúde da Família (VASCONCELLOS et al., 2008).

\subsection{CULTURA ORGANIZACIONAL E CULTURA DE SEGURANÇA DO PACIENTE}

A cultura de segurança refere-se às crenças e aos valores que existem em uma organização e também às crenças dos profissionais e ao valor esperado de seu trabalho, fatores que irão influenciar sua atitude e comportamento (TSAI, 2011). De acordo com Sorra e Dyer (2010), cultura de segurança são os valores de gestão e de pessoal, crenças e normas sobre o que é importante em uma organização de saúde, como os membros da organização devem se comportar, que atitudes e ações são adequadas e inadequadas, quais processos e procedimentos são recompensados e punidos no que diz respeito à segurança do paciente.

O conceito de cultura de segurança emergiu da cultura organizacional (VINCENT, 2009). Dessa forma, optou-se por tratar de ambos em um mesmo capítulo, por considerar que são indissociáveis.

O crescente interesse pela cultura organizacional, que teve seu ápice na década de 1980, deu-se devido à percepção de que as teorias existentes não dispunham de instrumentos e métodos que permitissem compreender a natureza complexa das organizações, particularmente em contextos de mudança, em que se busca melhoria de desempenho ou aumento de competitividade (REIS, 2014).

Outro termo utilizado muitas vezes como sinônimo da cultura de segurança é clima de segurança. Para Vincent (2009) clima de segurança é normalmente usado quando se discutem as medidas da cultura de segurança de base. "[...] clima de segurança é a manifestação superficial da cultura da segurança."

Hoffmann et al. (2013) aplicaram um instrumento de clima de segurança na Alemanha e observaram que uma equipe menor obteve percepção mais positiva, dos fatores de trabalho em equipe e do clima de segurança nos processos clínicos, em comparação com equipes maiores. Os autores ainda afirmam que, quando a segurança do paciente é abordada no contexto dos cuidados primários em medicina de família, o clima de segurança é uma medida de resultado importante para ações de melhoria.

Paese e Sasso (2013) publicaram estudo realizado para avaliar o clima de segurança na Atenção Primária com equipes de saúde da família no Brasil. Nesse estudo foi utilizando o questionário de atitudes de segurança Safety Attitudes Questionnaire, que compreende nove atitudes: satisfação do trabalho, condições de trabalho, cultura do trabalho em equipe, comunicação, gerência do centro de saúde, segurança do paciente, reconhecimento do 
estresse, educação permanente e erro. Os resultados deste estudo revelaram que as atitudes Condições de Trabalho, Cultura da Segurança do Paciente, Comunicação e Gerência do Centro de Saúde obtiveram maior destaque para a cultura de segurança do paciente na Atenção Primária à Saúde.

O erro médico e os danos causados aos pacientes têm sido descritos e estudados por mais de um século. Entretanto, com exceção de poucos pioneiros, os profissionais de saúde parecem não ter percebido a extensão e a gravidade do problema, ou não estão preparados para aceitá-lo (VINCENT, 2009). No início do movimento, para a segurança do paciente, o maior foco era medir e diminuir a incidência de erros, no entanto, cada vez mais especialistas em segurança preferem enfatizar eventos adversos evitáveis ou danos evitáveis em vez de erros (WACHTER, 2013).

Os erros se apresentam com forma e mecanismos semelhantes ao longo de amplo espectro de atividades mentais. Assim, é possível identificar formas comparáveis de erros nas mais diversas atividades, tais como a fala, a percepção, as ações, julgamento, solução de problemas e similares (NASCIMENTO, 2014).

Faz-se necessário diferenciar erro de violação para entender os processos envolvidos na ocorrência de um erro. Um erro constitui a falha na execução de uma ação planejada de acordo com o desejado ou o desenvolvimento incorreto de um plano. Os erros podem manifestar-se em uma ação praticada errada (comissão) ou por não conseguir praticar a ação certa (omissão), quer seja na fase de planejamento ou na fase de execução (PORTUGAL, 2011). Um exemplo de omissão consiste na não realização de mudança de decúbito de um paciente acamado no período de tempo recomendado ou prescrito. A violação de normas prescritas é definida como a etapa inicial de um processo progressivo, que irá culminar em erro (NASCIMENTO, 2014). “Os erros são, por definição, não intencionais, ao passo que as transgressões são habitualmente intencionais, apesar de raramente maliciosas, e em determinado contexto podem tornar-se rotineiras ou automáticas (PORTUGAL, 2011)"”.

Os eventos adversos são comumente associados ao erro humano individual, mas devem-se considerar como desencadeadores as condições de trabalho, os aspectos estruturais e a complexidade das atividades desenvolvidas (OLIVEIRA et al, 2014). A abordagem tradicional para os erros relacionados à assistência à saúde tem sido acusar e/ou punir o profissional que prestou a assistência, enquanto o movimento moderno conclui que a segurança depende da criação de sistemas que antecipem os erros e também os previnam ou interceptem antes que causem dano (WACHTER, 2010). Predomina a percepção de que falhas na segurança do paciente resultam apenas em ações punitivas para o profissional, 
impedindo que o assunto seja discutido de modo positivo por meio de uma ação conjunta entre os pares, visando à melhoria do cuidado em saúde e à redução de riscos ao paciente (RIGOBELLO et al., 2012).

Um estudo realizado em hospitais de Ribeirão Preto, estado de São Paulo, reitera que os profissionais têm receio em relação às medidas punitivas relacionadas à notificação de eventos adversos, o que deve ser considerado ponto de atenção e melhoria (FRANÇOLIN et al, 2015). Se o manejo de eventos adversos estiver baseado na punição e culpa, isso poderá causar omissão dos relatos desses eventos, dificultando a construção de uma cultura institucional voltada para a segurança do paciente (FRANÇOLIN et al, 2015). Trabalhar em profundidade a segurança clínica das organizações sanitárias requer conhecer os erros atuais, o que exige mudança de pensamento e o uso de registros adequados (QUES et al, 2010).

Nascimento (2014) apresenta os mecanismos básicos na ocorrência de erros, com base nos estudos de Reason (2003). Nesse modelo identificaram-se três mecanismos de erro: 1. Deslize e lapso com base na habilidade; 2. Engano com base nas normas; 3. Engano com base no conhecimento. Segundo Mendes e Barroso (2014), em análise cuidadosa sobre os fatores desencadeantes do erro, observa-se série de incidentes, mesmo numa prática segura, que, quando influenciados pelo ambiente de trabalho e pela cultura organizacional podem produzir maus resultados. Dessa forma, o erro humano deve ser encarado de dois modos diferentes: o do indivíduo e o da organização.

Inicialmente o erro era visto como uma abordagem individual, ou seja, atos inseguros de indivíduos que trabalham na ponta do sistema, com base em processo mental fora do padrão desejado, tais como: esquecimento, desatenção, descuido, pouca motivação, negligência e imprudência. Mais recentemente o erro está sendo tratado em uma abordagem sistêmica, que tem como premissa básica a falibilidade dos seres humanos e, portanto, erros são esperados mesmo nas organizações de excelência. Essa abordagem não enfatiza a perversidade humana, nem a culpabilização e a responsabilização do indivíduo como única causa do erro (NASCIMENTO, 2014).

De acordo com Watcher (2013), o modelo do queijo suíço de James Reason, elaborado com base em inúmeras investigações sobre acidentes em áreas como a aviação comercial e a energia nuclear, tem sido amplamente utilizado para ilustrar que, em organizações complexas, um erro em uma única "ponta" raramente é suficiente para causar danos. Aponta ainda que é necessário concentrar menos no objetivo (inútil) de tentar aperfeiçoar o comportamento humano e mais no objetivo de diminuir os buracos do queijo suíço. O modelo do queijo suíço ilustra as falhas no sistema em prevenir o erro (Figura 1). 


\section{Modelo do Queijo Suiço}

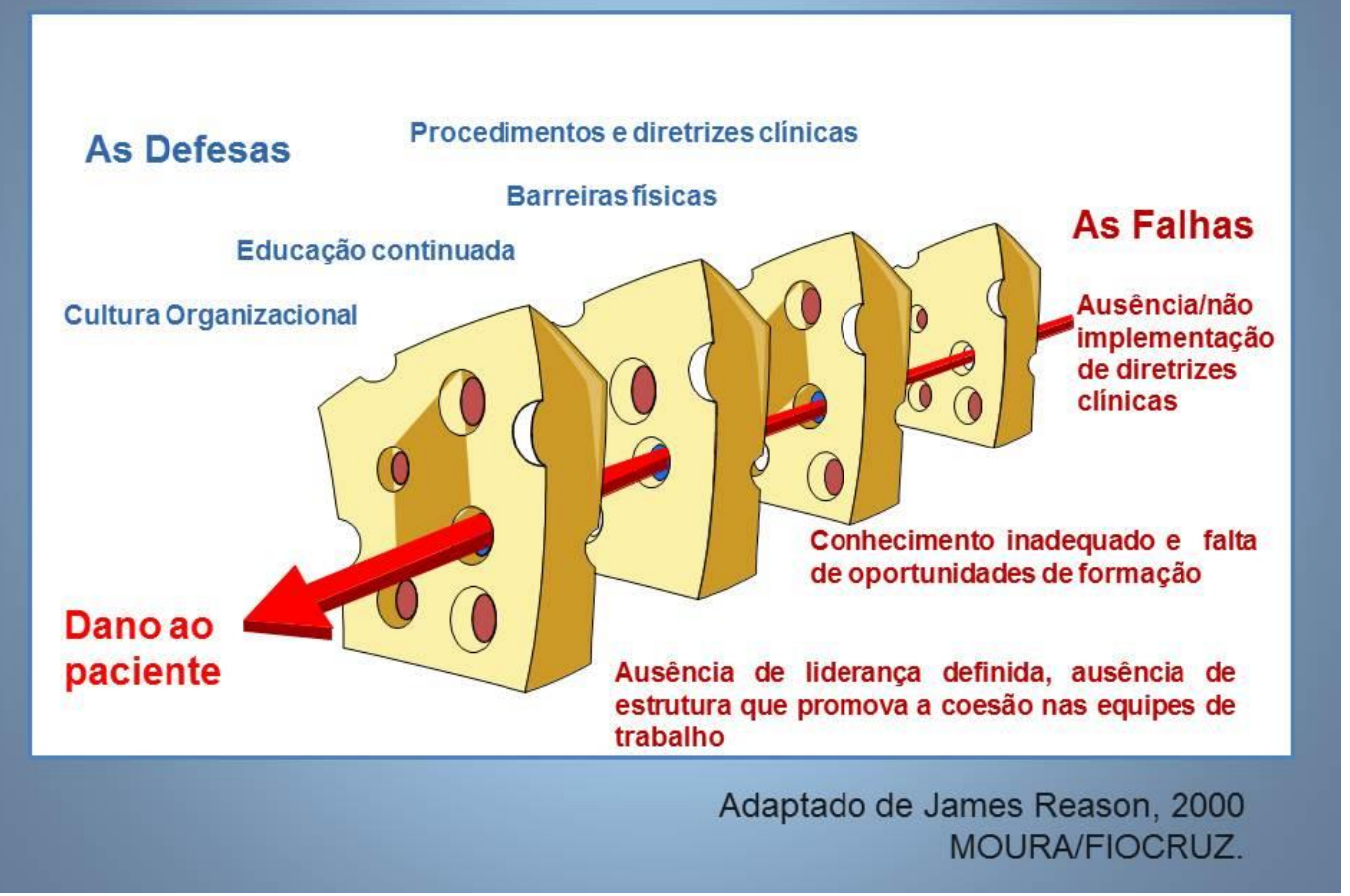

Fonte: MOURA/FIOCRUZ.

É importante que a cultura organizacional apoie o aprendizado e o desenvolvimento (PROQUALIS/MS, 2012). Aprender somente com os próprios erros seria lento, doloroso, desnecessariamente e de alto custo para os pacientes. As experiências têm de ser reunidas e condensadas para que os profissionais de saúde possam aprender também com os erros dos outros (VINCENT, 2009). A segurança do paciente evoluiu desde o primeiro relatório, os reguladores e acreditadores incentivam as organizações de cuidados de saúde a adotar "práticas seguras" e prevenir eventos adversos, que são considerados em grande parte evitáveis (SHEKELLE, 2013).

Algumas estratégias na identificação e prevenção de eventos adversos com dano, segundo Branco Filho (2014) são:

1) dano com uma causa identificável e modificável;

2) evento adverso em que uma adaptação de um processo irá evitar a recorrência no futuro (exemplo: uso de ferramenta como análise de causa-raiz que identifica causa do dano e propõe a modificação no processo);

3) dano com uma diretriz existente que não foi respeitada (exemplo: prevenção de tromboembolismo venoso que é recomendado por uma diretriz e não é seguida).

Ter um ambiente de trabalho livre de culpa e uma cultura não punitiva é vital para lidar com os erros e a promoção da cultura de segurança do paciente, com mecanismos de informação que previnam e corrijam falhas no sistema e erros humanos, pois permite aos 
profissionais de saúde relatar e aprender com os erros, ao invés de buscar a culpabilidade individual ou organizacional (WHO, 2011; AMMOURI et al, 2015). A segurança não pode centrar numa pessoa, num equipamento ou num serviço, ela emerge da interação de todos os componentes de um sistema. Melhorar a segurança depende da compreensão e análise dessa interação (MENDES; BARROSO, 2014).

Para que o erro não se torne banalizado, conciliando-se o movimento atual de não culpabilização e mantendo-se a responsabilização na medida necessária, surgiu o conceito de cultura justa, que distingue entre o erro humano (por exemplo, cometer deslizes) e o comportamento de risco (por exemplo, tomar atalhos) e o comportamento imprudente (por exemplo, "ignorar" os passos de segurança necessários) (NASCIMENTO, 2014).

Para Vincent (2009), uma cultura completamente não acusatória parece inviável, porque restringe proteções que estimulam um comportamento seguro. Em uma cultura franca e justa, o aspecto da responsabilidade pessoal é preservado e exige uma resposta mais compreensiva e cuidadosa quando o erro e a lesão iatrogênica ocorrem.

Com o frequente aumento na identificação de erros e eventos adversos relacionados aos cuidados de saúde, houve o consequente aumento de processos judiciais. Wachter (2013) levantou alguns pontos principais em relação à judicialização da medicina, apresentados no quadro a seguir:

Pontos principais

- Nos Estados Unidos da América, o sistema de má prática médica é governado pela lei de responsabilidade civil, a qual compensa as vítimas lesadas com recursos dos prestadores de cuidado de saúde culpados.

- A arbitrariedade, os altos custos administrativos e a tendência a atribuir culpa individual sem procurar soluções sistêmicas estão entre as críticas ao sistema de judicialização da medicina.

- Uma tendência recente importante tem sido a promoção da abertura da informação aos pacientes após eventos adversos e erros, com pedido de desculpas e ofertas de acordos.

- O limite às recompensas por dor e sofrimento pode ajudar a limitar o tamanho delas e a diminuir a tendência dos advogados a aceitarem casos sob essa condição, mas não melhoram as falhas fundamentais do sistema.

- Recentemente, tem-se promovido nos Estados Unidos da América os sistemas sem culpa ou tribunais de saúde, nos quais o paciente é compensado com base em suas lesões, sem que seja necessário atribuir culpa. Experiências internacionais preliminares com esses sistemas têm sido positivas. Fonte: Wachter, 2013 (Adaptado). 
Para Vincent (2009) não basta apenas apelar para o pensamento sistêmico e uma cultura justa, é necessário que, de alguma forma, as responsabilidades sejam assumidas e alguma ação seja tomada. O autor apresenta, ainda, algumas questões para análise dos incidentes: as ações foram intencionais? Houve intensão de causar lesão? Há alguma evidência de problema médico? Algum protocolo normalmente adotado não foi seguido? Porém, as questões levantadas pelo autor na identificação do incidente e investigação apontam para a busca de culpados.

A segurança do paciente não constitui problemática individual, tampouco de categoria profissional, mas de processo que envolve uma transformação a nível institucional (MENDES; BARROSO, 2014). Os contextos organizacionais e institucionais — incluindo as lideranças, o comportamento profissional e a cultura - podem ter impacto profundo sobre as perspectivas das iniciativas de melhoria (PROQUALIS/MS, 2012).

Estudos mais aprofundados podem auxiliar a ação dos gestores para a realização do planejamento e desenvolvimento de estratégias organizacionais com o objetivo de melhorar a qualidade do cuidado na Atenção Primária à Saúde (MARCHON; MENDES JÚNIOR, 2014). Com a análise da cultura organizacional de um serviço específico é possível identificar as características da instituição, quais são suas metas e o que a gestão pode realizar com seus pontos fortes e fracos para alcançar a qualidade e desenvolver uma cultura focada na segurança do paciente (CAMARGO TOBIAS et al., 2014). Deve-se assegurar que os objetivos de melhoria estejam alinhados com os objetivos da organização como um todo (PROQUALIS/MS, 2012).

Em estudo qualitativo realizado por Ques et al. (2010) para elencar as barreiras e fortalezas em torno da segurança do paciente, identificaram-se como principais barreiras: a posição corporativa dos profissionais, a organização e infraestrutura com uma grande variabilidade, a excessiva pressão assistencial, a escassa protocolização e ausência de liderança autêntica em segurança, a falta de indicadores confiáveis e aceitos, a falta de comunicação e de cultura de segurança e, por último, a carência de formação específica em segurança.

Alguns autores relacionam fatores que potencializam e outros que prejudicam a segurança do paciente. Como potencialidades da promoção de segurança resultam os esforços e comprometimento diário de equipes multiprofissionais, instituições e serviços de atenção à saúde, públicos e privados, com mudança organizacional, fomento da cultura de segurança, de processos e sistemas organizados, avaliados e aprimorados continuamente quanto à prevenção e redução de danos (QUES et al, 2010; OLIVEIRA et al, 2014). 
Para Paese e Sasso (2013) quando os elos de confiança estão firmados, as necessidades e os erros são expostos mais claramente pelos profissionais e a instituição consegue intervir nos processos de trabalho e na formação permanente, empoderando os profissionais para garantir uma cultura da segurança e uma assistência mais segura.

São também aspectos favoráveis a preocupação e o desenvolvimento contínuos, com o objetivo de desempenhar boas práticas assistenciais recomendadas por agências nacionais e internacionais em busca de melhores resultados, a disponibilidade de materiais, a formação e desenvolvimento profissional, do aprimoramento da relação dos profissionais com os pacientes, a pesquisa e planejamento estratégico, e uma política nacional de segurança no cuidado à saúde (QUES et al., 2010; OLIVEIRA et al., 2014).

Como barreiras para a segurança do paciente, são mencionadas a falta de materiais, de manutenção de equipamentos e os cuidados não realizados devido à demanda excessiva (OLIVEIRA et al., 2014). Dentre os aspectos de fragilidade, evidencia-se a existência da cultura do medo de que os erros sejam inscritos nas fichas funcionais, fato que possivelmente motiva a subnotificação dos eventos adversos (FRANÇOLIN et al., 2015). De acordo com Ques et al., (2010) a grande capacidade de adaptação a novos métodos de trabalho pelos profissionais de enfermagem e maior conscientização do pessoal sanitário possibilitará a denúncia dos eventos adversos, relacionados com a segurança, sem valor punitivo para o profissional de saúde.

Muitas vezes, a organização do trabalho assistencial se realiza de forma hierárquica em vez de interdisciplinar, com ausência de grupos de trabalho que objetivem a melhora da segurança clínica e satisfação do usuário, também faltam equipes interdisciplinares (QUES et al., 2010). O trabalho em equipe deve ser fortalecido como um núcleo básico, uma vez que nele possivelmente reside um potencial decisivo para a eficácia do modelo atual de saúde da Atenção Primária (RODRÍGUEZ-COGOLLO et al., 2014).

Hinrichsen et al. (2011) ressaltam a importância da existência da cultura de gestão de riscos, assim como a formação de uma comissão, composta por uma equipe multidisciplinar, para o monitoramento de situações adversas decorrentes das práticas assistenciais. Outro aspecto importante consiste em trabalhar em direção a objetivos comuns e utilizar uma linguagem comum a todos. Para assegurar a sustentabilidade das ações, os resultados positivos devem ser transformados em normas, protocolos e procedimentos, garantindo sua integração nas atividades de rotina (PROQUALIS/MS, 2012).

É papel dos gestores e líderes promoverem melhor integração com os profissionais da assistência direta para o planejamento e desenvolvimento de ações conjuntas de gestão 
compartilhada para a qualidade do serviço (OLIVEIRA et al., 2014). Quando há boa interação entre o líder e os subordinados, haverá cooperação e motivação dos subordinados para cumprir a missão e os objetivos atribuídos pela organização, o que, por sua vez, aumenta a satisfação no trabalho (TSAI, 2011).

Ressalta-se a importância de lideranças fortes associadas a uma cultura de participação, direção e controle, mas com flexibilidade em relação às necessidades locais no momento da implementação das ações de prevenção de incidentes e eventos adversos, tendose em vista que esses ocorrem de forma imprevista e perturbam o desenvolvimento normal do sistema. A gestão desses eventos passa pela sua identificação, registro, análise, discussão e prevenção, numa cultura de responsabilidade, retroalimentação crítica em relação ao desempenho, mas sem culpabilização (PROQUALIS/MS, 2012; MENDES; BARROSO, 2014;).

As instituições devem refletir criticamente sobre o papel que os gestores devem desempenhar, uma vez que as decisões estratégicas incluem a gestão de pessoas, precisam incentivar e capacitar os profissionais para prevenção, notificação e manejo efetivos desses riscos durante a realização e a avaliação da assistência prestada, o planejamento das instalações, a elaboração dos procedimentos operacionais, a escolha dos equipamentos, bem como todas as outras decisões que definem a estrutura do sistema (OLIVEIRA et al., 2014; FRANÇOLIN et al, 2015).

Talvez seja mais adequado caracterizar o líder da melhoria como um facilitador, e não como uma autoridade (PROQUALIS/MS, 2012). Portanto, esforços contínuos devem ser priorizados na prática, desde a alta direção até os profissionais da assistência direta, no intuito de promover estrutura física, humana e organizacional em qualidade e quantidade que garanta a promoção da cultura de segurança e a satisfação dos colaboradores, pacientes e familiares (OLIVEIRA et al., 2014).

O papel do facilitador envolve a capacidade de permitir que os outros contribuam com seus pontos de vista, conhecimentos e ideias, criando redes, facilitando a cooperação e a colaboração, gerando confiança entre os outros profissionais, promovendo o entusiasmo e mantendo o ímpeto (PROQUALIS/MS, 2012). Tal investimento deve levar em consideração aspectos direcionados para o gerenciamento de pessoas, jornadas de trabalho exequíveis, remuneração adequada e estabelecimento de bom relacionamento interpessoal por meio de incentivo à comunicação efetiva e ao trabalho em equipe (OLIVEIRA et al., 2014).

Estratégias têm sido propostas para minimizar o problema e prevenir danos. Por meio da promoção da visão organizacional e da comunicação junto à equipe, é possível influenciar 
o comportamento e atitude no trabalho (TSAI, 2011). É esperado dos gerentes uma postura proativa, fornecendo à equipe feedback e comunicação sobre o erro identificado na unidade, com recomendações para melhorar a segurança do paciente e prevenir que erros ocorram (AMMOURI et al., 2015). Organizações com uma cultura de segurança positiva são caracterizadas pela comunicação fundamentada na confiança mútua, pela percepção comum da importância da segurança e confiança na efetividade de medidas preventivas (Reis, 2014).

É importante identificar de que forma os contextos organizacionais e institucionais podem representar ameaças persistentes para as atividades de melhoria, especialmente quando envolvem mudanças no contingente de pessoal ou tensões organizacionais que minam o tempo e o entusiasmo dedicado às atividades (PROQUALIS/MS, 2012).

A escassa disponibilidade de tempo, durante o horário laboral, para trabalhar temas referentes à segurança do paciente e capacitar outros profissionais, e a falta de tempo real para realizar atividades e procedimentos, se somam à ocupação do tempo de trabalho dedicado às tarefas, dificultando a identificação de complicações (QUES et al, 2010).

Em pesquisa realizada com residentes de medicina sobre cultura de segurança com aplicação do instrumento Medical Office Survey on Patient Safety Culture (MOSP) adaptado para o espanhol, o "ritmo e volume de trabalho" e "formação de pessoal" foram apontados como as dimensões com maior potencial de melhoria (RODRÍGUEZ-COGOLLO et al, 2014). Um dos fatores que dificulta o desenvolvimento de ação em prol da segurança é a grande pressão assistencial que sofre os profissionais (QUES et al., 2010).

O primeiro desafio para melhoria é identificar e reconhecer o problema, para tanto, é fundamental usar dados concretos para demonstrar a sua existência (DIXON-WOODS et al., 2011). Os riscos levantados são inquietantes, pois evidenciam a qualidade da assistência; entretanto, após o seu levantamento, devem ser analisados para elucidar as possíveis causas, direcionando reflexões e educação permanente à equipe (OLIVEIRA et al., 2014).

Essa melhoria depende da necessária mudança de cultura dos profissionais para a segurança, do uso de indicadores de qualidade, da existência de um sistema de registros, alinhados à política de segurança do paciente instituída nacionalmente (OLIVEIRA et al., 2014). Também é fundamental que haja a disseminação dos conceitos da cultura de segurança do paciente para que haja uma melhor introspecção desta em todas as fases de cuidados (HINRICHSEN et al., 2011). Para superar os desafios relacionados ao processo de melhoria, é importante coordenar ações em múltiplos níveis de atenção, procurando influenciar diversos grupos de interesse, em busca de melhoria duradoura na assistência à saúde, que incentive os 
profissionais e promova o seu envolvimento nas ações de melhoria da qualidade (PROQUALIS/MS, 2012).

A comunicação de incidentes pode ser vista como uma ferramenta que concentra a atenção na segurança e têm influências em vários níveis organizacionais, práticas individuais e em equipe, conhecimentos e atitudes. Os efeitos positivos sobre a consciência e o conhecimento dos trabalhadores provavelmente são tão importantes para a segurança como a melhoria dos processos (ANDERSON et al., 2013).

Destaca-se a importância de incentivo por parte da instituição à realização de notificações, a coleta de dados completos e a retroalimentação são elementos essenciais do processo de melhoria, pois, assim, estratégias de controle podem ser desenvolvidas a fim de evitar novas ocorrências, influenciando diretamente na qualidade da assistência (PROQUALIS/MS, 2012; FRANÇOLIN et al., 2015).

Procedimentos de gestão de riscos são rigorosamente adotados na aviação, considerando que a segurança dos passageiros envolve, também, a segurança do piloto e da tripulação, por outro lado no cenário da saúde, esse aspecto era visto como algo que não afetava a segurança do trabalhador. Colla et al. (2005) ao compararem as indústrias de alto risco com os serviços de saúde, relataram que, no ambiente de saúde, as práticas inseguras são experimentadas pelo cliente e não pelo empregado, e estes são reembolsados por um terceiro, mas, frequentemente, não implicam custos para o empregador.

De acordo com Branco Filho (2014), muitos desses custos são compartilhados com os pagadores (governos, seguradoras e planos de saúde), ou seja, os hospitais conseguem transferir os custos a terceiros, absorvendo pequena parte desses e gerando pouco incentivo financeiro para melhoria da qualidade e segurança do paciente.

Mas esse cenário está mudando, foi publicado um artigo por Rosenthal (2007) que trazia a nova regra que os Centers for Medicare and Medicaid Services dos Estados Unidos da América implementaram no reembolso do pagamento dos hospitais para o atendimento de pacientes individuais com complicações evitáveis. As condições pelas quais o hospital não seria reembolsado são: objetos deixados durante a cirurgia, embolia pulmonar, incompatibilidade sanguínea, infecção urinária relacionada a cateter, úlcera por pressão, infecção associada a cateter vascular, mediastinite pós-cirurgia cardíaca e queda do leito.

Nas organizações com um padrão de alta confiabilidade, a exemplo das organizações prestadoras de cuidados de saúde, o registro do erro com base numa perspectiva de aprendizagem deve ser incentivado como uma atitude proativa, preventiva e sistemática de toda a equipe de saúde pela aprendizagem que daí advém, sobretudo, pela mais valia que a 
organização adquire, evitando a sua recorrência e aumentando a credibilidade da organização e dos seus profissionais (MENDES; BARROSO, 2014). Outra estratégia importante consiste em envolver os próprios profissionais de saúde que lidam diretamente com o paciente, perguntando-lhes o que eles desejariam melhorar em seu serviço. (PROQUALIS/MS, 2012).

É necessário um trabalho ativo para promover a credibilidade. Isso, provavelmente, significa trabalhar com grupos profissionais variados nos seus próprios termos, alinhando o projeto aos valores de cada grupo e às suas noções sobre as melhores práticas (PROQUALIS/MS, 2012). A existência de equipes diretivas que motivem a promoção de mudanças institucionais precisa de liderança clara por parte de um grupo de profissionais formados, sendo a figura do enfermeiro essencial na segurança do paciente, isso exigirá a criação de um comitê interno em cada um dos centros, com contribuições interdisciplinares em equipes multidisciplinares (QUES et al., 2010). Desta forma, é necessário que os enfermeiros estejam comprometidos em fornecer uma assistência de qualidade. Em vários tipos de cuidado de saúde existe variação na qualidade, porque há evidências insuficientes para o estabelecimento de consenso sobre a melhor forma de tratar o problema, o estado de risco ou a necessidade de promover a saúde (LUNNEY et al., 2011).

Assim, a avaliação da cultura de segurança é vista como o ponto de partida para iniciar o planejamento de ações que busquem mudanças para reduzir a incidência de eventos adversos e, consequentemente, para garantir cuidados de saúde seguros (REIS et al., 2013). Por outro lado, a transformação cultural é um processo complexo, com múltiplos fatores que influenciam o seu sucesso. Portanto, é imprescindível a adoção de soluções aplicáveis a todos os membros da organização, que possam ser facilmente integradas na rotina clínica e fluxo de trabalho, aumentando a adesão e a sustentabilidade (THOMAS; GALLA, 2012).

Uma cultura de segurança é, essencialmente, uma cultura em que todos estão conscientes do seu papel e da sua contribuição para a organização e são responsáveis pelas consequências das suas ações (MENDES; BARROSO, 2014). A importância do papel do enfermeiro na segurança do paciente já foi bem estabelecida. Dentre os fatores que sabidamente afetam os resultados relacionados à segurança do paciente estão o número de enfermeiros num serviço, o nível de educação dos enfermeiros e um ambiente de trabalho favorável (KIRWAN et al., 2013).

No Reino Unido executivos de saúde e segurança listaram características que constituem uma "boa" cultura de segurança na companhia (WATERSON, 2014):

- Gerentes regularmente visitam o local de trabalho e discutem assuntos com a força de trabalho; 
- A organização fornece regularmente informações claras sobre segurança;

- Os funcionários podem levantar uma preocupação de segurança, sabendo que a companhia vai levar a sério e vai dizer quais medidas estão tomando a respeito disso;

- A segurança é sempre a prioridade da companhia e o trabalho pode ser interrompido se não sentirmos segurança;

- A companhia investiga todos os acidentes e quase acidentes, faz algo a respeito e fornece feedback;

- A companhia mantem-se atualizada com novas ideias de segurança;

- Podem-se obter equipamentos de segurança e treinar se necessário, com orçamento para isso;

- Todos são incluídos nas decisões que afetam a segurança e regularmente são questionados sobre isso;

- Raramente qualquer um na companhia adota atalhos ou riscos desnecessários;

- Os funcionários podem ser abertos e honestos sobre segurança, a companhia não procura alguém para culpar;

- A moral é geralmente alta.

Outro aspecto relevante refere-se à formação curricular em segurança do paciente. Em estudo sobre a compreensão dos alunos de cursos de graduação em enfermagem e medicina, observou-se que a maior parte dos alunos acredita que, depois da ocorrência do erro, uma estratégia efetiva de prevenção seria trabalhar com mais cuidado, o que reflete uma visão voltada ao indivíduo e não à cultura de segurança (YOSHIKAWA et al., 2013).

Destaca-se a insuficiente formação relacionada aos temas de segurança, falta de formação específica sobre riscos associados a processos, inadequada gestão do conhecimento nessa área e escassa formação sobre pesquisas bibliográficas e de evidências (QUES et al., 2010).

Neste sentido, poderia considerar estratégias diferentes para corrigir esse déficit, entre os quais devem ser observados: a promoção do desenvolvimento da cultura de segurança do paciente no currículo da especialidade; o aumento à informação e o conhecimento dos profissionais em formação sobre os fatores que influenciam a segurança do paciente, para incentivar uma atitude crítica; e uma análise mais aprofundada dos fatores que influenciam, como a pressão no trabalho, priorizando a reorganização das atividades, evitando a sobrecarga da assistência e, se necessário, ajustando o planejamento de recursos (RODRÍGUEZCOGOLLO et al., 2014). 


\subsection{A CULTURA DE SEGURANÇA DO PACIENTE NA ATENÇÃO PRIMÁRIA À SAÚDE}

Nas instituições de saúde, a cultura de segurança está emergindo como um dos requisitos essenciais para prevenir a ocorrência de incidentes, por meio da gestão de riscos onde os profissionais comunicam os erros e agem de forma proativa, buscando redesenhar os processos para evitar novos incidentes (CAMARGO TOBIAS et al., 2014). A abordagem da cultura de segurança precisa de múltiplos enfoques que permitam aprofundar, de forma compreensiva e dinâmica, a interação dos diferentes processos (QUES et al., 2010). A cultura da segurança do paciente é uma estrutura multifatorial, que visa promover uma abordagem de sistemas para prevenir e reduzir danos aos pacientes (AMMOURI et al., 2015).

A atenção primária é aquele nível de um sistema de serviço de saúde que oferece a entrada no sistema, fornece atenção sobre a pessoa no decorrer do tempo para todas as condições e coordena ou integra a atenção fornecida em outros níveis (STARFIELD, 2002). $\mathrm{Na}$ prestação de cuidados primários as habilidades interpessoais são fundamentais, explorar questões relacionadas com a segurança do paciente nesta área estabelece desafios específicos. Há pouca pesquisa para nos ajudar a compreender as questões de segurança do paciente neste contexto (ESMAIL, 2013). No campo da Atenção Primária à Saúde, há espaço para estudos sobre a segurança do paciente, visto que, a grande maioria dos cuidados em saúde acontece na Atenção Primária à Saúde (MARCHON; MENDES JÚNIOR, 2014). É comumente reconhecido que, nas unidades de saúde, geralmente não há cultura de segurança (SÁNCHEZ et al., 2013).

A Atenção Primária é muito mais heterogênea em seus arranjos organizacionais. As modalidades de organização entre cuidados primários e secundários são diferentes e complexas e há uma multiplicidade de locais onde a Atenção Primária é realizada (no consultório, na unidade de saúde, pelo telefone e nas casas dos pacientes) (ESMAIL, 2013). No setor de atendimento primário, diferentes práticas se organizam de diferentes formas, com diferentes níveis de disponibilidade para os pacientes, diferentes graus de responsabilidade compartilhada e apoio recíproco, e assim por diante. Resumindo a cultura é "o modo como fazemos a coisa por aqui” (VINCENT, 2009).

Pesquisas sugerem que os eventos adversos e erros não são incomuns em cuidados primários, aonde um grande número de interações pode representar um problema significativo. No Reino Unido, 85\% dos contatos com os serviços de saúde são da Atenção Primária e há 300 milhões de consultas de clínica geral a cada ano. Isso significa que cerca de 
750 mil pacientes consultam o seu médico de clínica geral por dia. Mais de $70 \%$ de todas as prescrições são emitidas fora do hospital (LINNEAUS EURO-PC, 2014).

Os profissionais de saúde na Atenção Primária, muitas vezes, têm menos controle sobre o gerenciamento dos cuidados prestados em comparação com as internações hospitalares, onde os pacientes são monitorados continuamente (WHO, 2008). A problemática dos eventos adversos é multifatorial e está associada aos processos existentes no sistema como um todo e à atuação dos diversos profissionais envolvidos, como médicos, farmacêuticos e equipe de enfermagem (CARVALHO; CASSIANI, 2012).

Em revisão sistemática realizada por Makeham et al. (2008), os principais incidentes de segurança do paciente na Atenção Primária descritos foram devidos ao tratamento (31\%), erros de medicação (8\%), incidentes de diagnóstico (34\%), a incapacidade de supervisionar ou de monitorar (16\%), desempenho inadequado (15\%), falha ou atraso no encaminhamento $(4 \%)$ e outros erros $(26 \%)$.

Outra revisão sistemática realizada por Marchon e Mendes Júnior (2014), sobre segurança do paciente na Atenção Primária, abordou os fatores contribuintes de incidentes relatados nos diversos estudos, que foram: falhas na comunicação interprofissional e com o paciente; falhas na gestão, como falta de insumos medico-cirúrgicos e de medicamentos, profissionais pressionados para serem mais produtivos em menos tempo, falhas em prontuários, falhas na recepção dos pacientes, planta física da unidade de saúde inadequada, descarte inadequado de resíduos da unidade de saúde, tarefas excessivas e falhas no cuidado.

As falhas no cuidado são diversas na Atenção Primária, como: falhas no tratamento medicamentoso (principalmente erro na prescrição); falha no diagnóstico; demora na realização do diagnóstico; demora na obtenção de informações e interpretação dos achados laboratoriais; falhas em reconhecer a urgência da doença ou suas complicações; déficit de conhecimento profissional (MARCHON; MENDES JÚNIOR, 2014). Evidências demonstram que a falta de comunicação entre os prestadores de cuidados de saúde é um dos principais contribuintes para erros (AMMOURI et al., 2015).

De acordo com Gama e Saturno (2013, p.33):

\footnotetext{
“A segurança do paciente tem interseções com quase todas as demais dimensões de qualidade. Quando as intervenções em segurança do paciente focam a prevenção de situações e procedimentos potencialmente nocivos, coincidem claramente aspectos e atuações anteriormente vinculados a outras dimensões de qualidade, particularmente aspectos essenciais da qualidade técnico-científica, somente com a ressalva de que as possíveis falhas aumentam o risco de iatrogenia, efeitos adversos ou dano desnecessário."
} 
Visando à melhoria do desempenho e à qualidade dos serviços na Atenção Primária à Saúde, o Ministério da Saúde criou, em 2011, o Programa Nacional de Melhoria do Acesso e da Qualidade da Atenção Básica (PMAQ-AB), no qual os indicadores estão relacionados aos grupos prioritários, como gestantes, pacientes diabéticos e hipertensos, e os padrões de qualidade incluem aspectos da infraestrutura, organização do trabalho, capacidade para atendimento de casos agudos, satisfação dos usuários, entre outros.

Os quatro elementos estruturais relevantes à Atenção Primária são acessibilidade, variedade de serviços, população eletiva e continuidade. A Atenção Primária aborda os problemas mais comuns da comunidade, desde a prevenção, a cura até a reabilitação para maximizar a saúde e o bem estar (STARFIELD, 2002).

Identifica-se a carência de indicadores que analisem e avaliem a segurança dos pacientes no âmbito mundial (QUES et al., 2010). Com o objetivo de propor uma metodologia de avaliação de desempenho no Brasil, foi desenvolvido o Projeto de Avaliação de Desempenho de Sistemas de Saúde (PROADESS), o qual identifica oito dimensões: efetividade; acesso; eficiência; respeito aos direitos das pessoas, aceitabilidade; continuidade; adequação e segurança (PROADESS/MS, 2011).

No intento de evidenciar a segurança do paciente como dimensão ordenadora da reorganização do processo de trabalho na Atenção Primária, elegeu-se o modelo de avaliação de desempenho de sistemas de saúde apresentado na figura 2 - PROADESS/MS (2011). Considerando-se que a segurança do paciente tem interseções com praticamente todas as dimensão deste modelo, serão apresentados os conceitos das dimensões e possíveis estratégias de mudança do processo de trabalho relacionado com a segurança do paciente para cada uma das dimensões que apresentam correlação. 


\section{Matriz de Dimensões da Avaliação de Desempenho do Sistema de saúde}

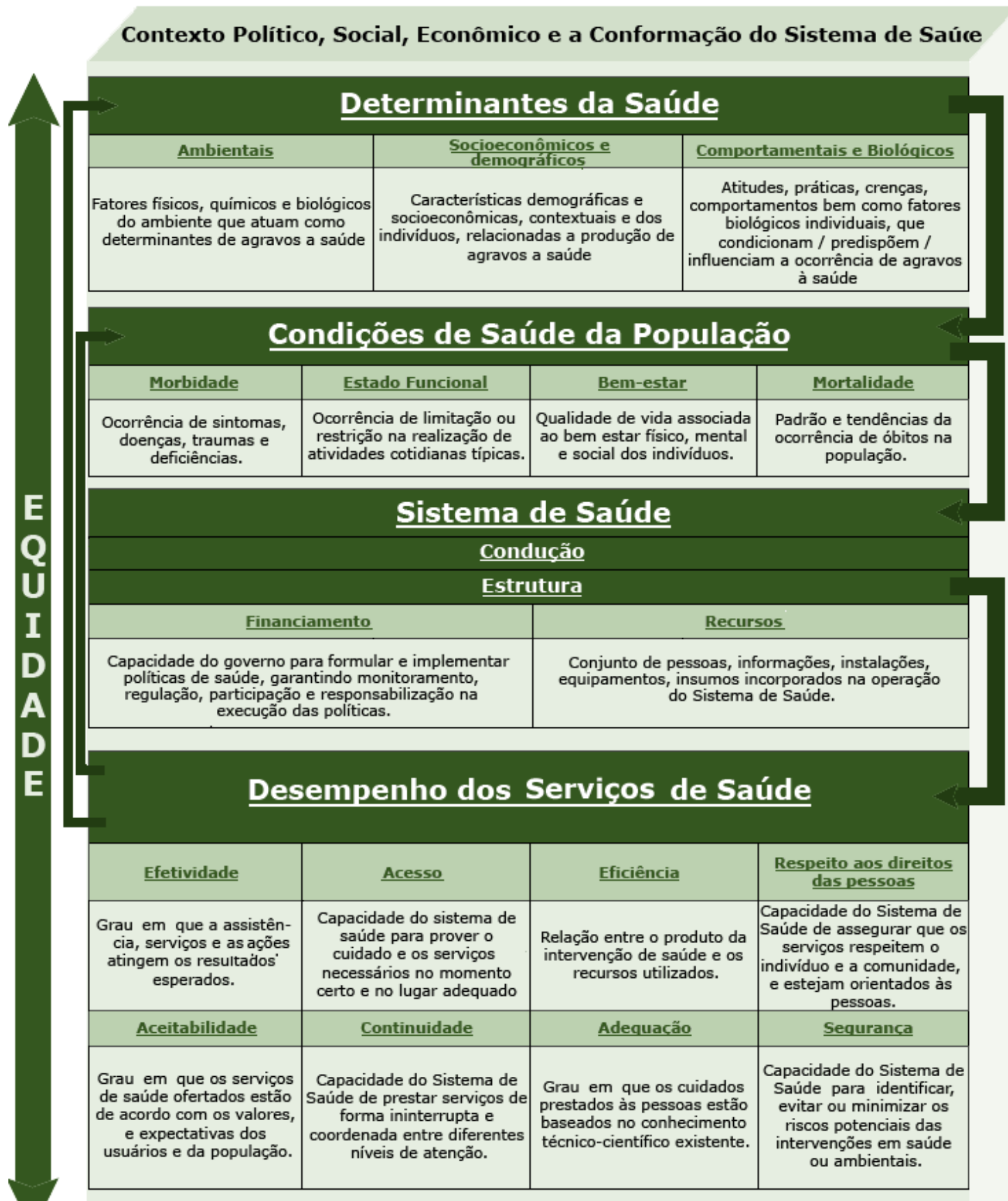

Nota: Equidade é o eixo que conta transversalmente todas as dimensões. Portanto, todas elas devem ser analisadas segundo essa perspectiva, utilizando as variáveis e indicadores mais apropriados a cada uma delas.

Fonte: Fundação Oswaldo Cruz, PROADESS/MS - 2011

Figura 1. Matriz de avaliação de desempenho do sistema de saúde - PROADESS/MS Fundação Oswaldo Cruz, 2011 


\subsubsection{Dimensão efetividade}

A definição para efetividade adotada pelo PROADESS/MS (2011), é o grau com que a assistência, serviços e ações atingem os resultados esperados. O cuidado efetivo/necessário é aquele para o qual existem evidências científicas razoavelmente robustas indicando que ele responde melhor do que qualquer outra alternativa e que os benefícios para os pacientes excedem os riscos de possíveis danos (TRAVASSOS; CALDAS, 2013). Para aumentar a probabilidade de êxito das intervenções de melhoria, é importante contar com uma boa base de evidências científicas (PROQUALIS/MS, 2012).

No contexto da Atenção Primária, um exemplo de efetividade é a cobertura vacinal, quando a maioria dos pacientes que tem indicação recebe a vacina e esta se demonstra efetiva na prevenção das doenças transmissíveis. Em relação à segurança do paciente, um exemplo da efetividade sem causar danos é a aplicação da vacina com a indicação e idade correta, via correta, seguindo o calendário vacinal, respeitando o intervalo correto entre vacinas que possam interagir. Nesse contexto, uma estratégia de mudança de processo de trabalho é a instituição da dupla checagem, para interceptar possíveis erros.

A dupla checagem consiste em checar o procedimento por duas pessoas de forma independente, na prática, essa estratégia é relativamente fácil de aplicar, um profissional realiza a avaliação do cartão de vacina e seu aprazamento, da mesma forma o profissional responsável pela aplicação checa novamente todas as informações do cartão e da vacina antes do procedimento. De acordo com Wachter (2010), mesmo quando a dupla checagem é exigida pela política da instituição, é fundamental assegurar que elas sejam realmente independentes.

De acordo com Viacava et al. (2012), os indicadores de efetividade são as taxas de internações evitáveis e de mortes evitáveis: a) aquelas evitáveis por serem decorrentes de agravos passíveis de prevenção por meio da Atenção Primária em Saúde e outras políticas sociais, agravos referentes fundamentalmente a estilos de vida; b) as mortes por causas prevenidas por meio de detecção precoce e tratamento oportuno (neoplasias malignas, dentre outras); c) as mortes evitáveis por agravos sensíveis ao cuidado médico-assistencial adequado.

Para enfrentar o problema da carência de recursos no cuidado de saúde, considera-se necessário melhorar a segurança, a efetividade e as experiências vividas pelos pacientes (PROQUALIS/MS, 2012). Nesse contexto é necessário analisar se a forma com que está sendo realizada a promoção da saúde e prevenção na Atenção Primária é efetiva, ou o foco é no tratamento da doença já instalada. 
A melhora nesses indicadores está relacionada às mudanças na lógica da prestação do serviço, como modificação na abordagem do usuário, melhorando o vínculo, sem postura hierarquizada, e proporcionando o empoderamento para que este faça as escolhas em relação à prevenção e controle dos fatores de risco, considerando-se os determinantes e condicionantes sociais e a cultura.

A efetividade das ações da Atenção Primária são difíceis de avaliar devido aos diversos fatores relacionados que interferem nos resultados, por exemplo, em uma população com baixo nível educacional, baixa renda, somado a problemas sociais e psicológicos (como uso de drogas, condições de moradia, desemprego, conflitos familiares, famílias desestruturadas etc). Por exemplo, um paciente diabético pode até compreender que precisa ter uma alimentação mais saudável e fracionada, mas se sua renda não lhe proporciona a possibilidade de escolhas, assim essa orientação pode não ser aplicável.

\subsubsection{Dimensão acesso}

O acesso pode ser dividido de duas formas: a acessibilidade externa (antes do contato com o serviço de saúde) e interna (já dentro do serviço de saúde) também se relaciona com a segurança quando prejudica a prestação da atenção de forma oportuna e a tempo, pois os atrasos no atendimento aumentam o risco de complicações (GAMA; SATURNO, 2013).

A definição de acesso segundo o PROADESS/MS (2011) é a capacidade das pessoas em obter os serviços necessários no lugar e momento certo.

No campo político, a equidade e a universalidade do acesso a todos os níveis de atenção são princípios que devem nortear as políticas de saúde e o modelo de atenção. A Joint Commission on Accreditation of Health Care Organizations também incorpora uma subdimensão do acesso, que se refere à ideia de tempo oportuno que é o período no qual a prestação do cuidado se faz mais benéfica e necessária (VIACAVA et al., 2012).

Em estudos que mensuraram os incidentes de segurança do paciente na Atenção Primária, foram identificados problemas relacionados com a qualidade (acesso aos cuidados, gerenciamento do cuidado, recursos e sistema), erros de medicação, erros por desatenção e erros técnicos (MAKEHAM et al., 2008).

Altas taxas de internações por condições sensíveis à Atenção Primária em uma população, ou subgrupo(s) desta, podem indicar sérios problemas de acesso ao sistema de saúde ou desempenho da Atenção Primária (ALFRADIQUE, 2009). Muitas vezes, a baixa capacidade de resolução de problemas de saúde, a falta de vínculo com o usuário, a 
incapacidade da Atenção Primária em atender a demanda espontânea e a cultura dos usuários em procurar o hospital para resolver seus problemas de saúde dificultam a concretização da Atenção Primária como porta de entrada para os serviços de saúde. Para que ocorram avanços em relação a essa questão, é necessária, não somente, a mudança na cultura da equipe e do paciente, mas também, apoio político e dos gestores, proporcionando estrutura e financiamento para o fortalecimento da Atenção Primária como legítima ordenadora do sistema de saúde.

Uma forma de reorganização do processo de trabalho nesse sentido, já foi proposta pelo Ministério da Saúde, no Caderno de Atenção Básica 28, que trata do acolhimento da demanda espontânea, e tem como objetivo ampliar a resolutividade das equipes de atenção básica frente à demanda espontânea.

“A potência e o valor de uso desse caderno serão maiores se ele estiver vinculado a
experimentações concretas e à problematização dos efeitos, desafios e práticas reais
pelas próprias equipes, com apoio intensivo da gestão, nos próprios serviços,
tomando o processo de trabalho real como objeto de análise e de intervenão.
Espera-se o fortalecimento da atenção básica no seu papel protagonista de produção
e de gestão do cuidado integral em rede, impactando positivamente na vida das
pessoas e coletivos" (BRASIL, 2013).

O princípio da equidade também é contemplado na classificação de risco da livre demanda da atenção básica, avaliando a prioridade do atendimento baseado em critérios clínicos e de vulnerabilidade do usuário. Uma das formas de efetivação e implantação desse processo refere-se à instituição do acesso avançado, com a formulação de uma agenda com vagas reservadas para atendimento da demanda espontânea e parte com agenda programada. A classificação de risco deve ser feita por profissional qualificado, com a capacidade de discernimento entre casos mais urgentes ou eletivos, para ampliar o acesso e para que o atendimento ocorra no tempo oportuno e com redução dos riscos.

\subsubsection{Dimensão eficiência}

A eficiência é definida como a otimização dos recursos disponíveis para produzir o máximo de benefícios e resultados (VIACAVA et al., 2012). De acordo o PROADESS/MS (2011), eficiência é a relação entre o produto da intervenção de saúde e os recursos utilizados.

O indicador utilizado para dimensionar a eficiência dos serviços de saúde no Brasil foi a proporção de cirurgias realizadas em regime ambulatorial e hospitalar, com menos de um dia de permanência (VIACAVA et al., 2012). Nesse caso evitar a permanência desnecessária no hospital, utilizar as estruturas das unidades básicas, quando possível, para realização de pequenos procedimentos cirúrgicos. 
Há diversos fatores identificados que contribuem para a ocorrência de incidentes, como a pressão assistencial que ocasiona a diminuição do tempo de atendimento; a falta de insumos, inclusive de medicamentos; a comunicação incorreta dos resultados dos exames; o atraso dos resultados de exames; os problemas com medicamentos, principalmente erros de prescrição; erro na identificação do paciente; e mau funcionamento do equipamento (MARCHON; MENDES JÚNIOR, 2014).

Investimentos em tecnologia, recursos humanos, com capacitação adequada, podem melhorar a eficiência do serviço, evitando desperdícios de tempo e material, um exemplo disso é a disponibilização de coberturas para curativos de alta tecnologia, mas, se não houver preparo dos profissionais para indicar e utilizar de forma correta, o tratamento poderá não ser eficiente, desperdiçando material de alto custo.

Outros fatores que contribuem para os incidentes são enfermeiro cansado, estressado e doente; problemas de comunicação; sistemas de informação inadequados; decisões administrativas tomadas sem a participação dos profissionais de saúde; registros clínicos inadequados (MARCHON; MENDES JÚNIOR, 2014). A implantação de sistemas mais seguros não gerará cuidados mais seguros se o profissional estiver sobrecarregado, pouco treinado ou sem supervisão (WACHTER, 2010).

Os erros devido a um trabalho em equipe deficiente são reconhecidos nos serviços de saúde como causas de dano e óbito. Por isso, recomenda-se estabelecer enfoque proativo, sistemático e organizacional de formação em trabalho em equipe, com construção de habilidades e melhoria dos desempenhos das equipes para diminuir os danos preveníveis (GAMA; SATURNO, 2013).

\subsubsection{Dimensão respeito aos direitos das pessoas - centrado no paciente}

Essa dimensão, para o PROADESS/MS (2011), consiste na capacidade do Sistema de Saúde de assegurar que os serviços respeitem o indivíduo e a comunidade, e estejam orientados às pessoas.

No Plano de Segurança do Paciente, instituído pela Agência Nacional de Vigilancia Sanitária, a participação do paciente é premissa da segurança do paciente, assim como o retorno dos resultados das ações estabelecidas para esse público (BRASIL, 2014).

A atenção centrada no paciente consite em uma dimensão muito associada à segurança, pois demonstra respeito às preferências e valores do paciente, além de estimular sua participação nas tomadas de decisão que o envolvam, favorecendo a segurança (GAMA; 
SATURNO, 2013). Múltiplas barreiras e desafios precisam ser enfrentados na concepção de delineamentos de estudos e na utilização de novas técnicas, que envolvam o paciente na identificação do risco e na resolução dos problemas (REIS et al., 2013).

$\mathrm{Na}$ avaliação centrada na pessoa o profissional analisa a lista de problemas levantados, explica ao paciente sobre os possíveis planos de tratamento, considerando todos os diferentes problemas ao mesmo tempo. O paciente ajuda a priorizar, o que é mais importante para ele naquele momento. Dependendo do plano terapêutico eles vão concordar em fazer uma prescrição de medicamento naquele momento ou podem optar por mudança de estilo de vida, antes do medicamento (AHRQ, 2013).

Trabalhar em segurança constituirá uma mudança radical em relação aos pacientes, a proposta de um novo modelo, no qual se considere as preferências dos pacientes e melhor conhecimento e reconhecimento daqueles que são os responsáveis pela segurança do paciente (QUES et al., 2010). O cuidado sensível às preferências dos pacientes refere-se àquelas situações em que existem mais de uma opção de cuidado e que os resultados variam segundo a opção adotada (TRAVASSOS; CALDAS, 2013). Para tanto é necessária uma mudança da cultura médica atual, para ações centradas no paciente, que respeitem a individualidade e orientadas em evidências científicas.

Indicadores de boas práticas (estrutura e processo) e os de resultado podem estar baseados em relatos do próprio paciente ou dos familiares sobre aspectos relacionados à segurança, com o objetivo de detectar situações potencialmente perigosas ou arriscadas para eventos adversos (GAMA; SATURNO, 2013).

Segundo Esmail (2013) os pacientes são, ainda, um recurso largamente inexplorado para a segurança do paciente, eles podem observar erros nos seus cuidados de diagnóstico e tratamento no ambulatório. O cuidado centrado no paciente é uma característica fundamental da Atenção Primária, mas isso não se traduziu em um envolvimento explícito nos programas de segurança do paciente. Embora os pacientes não possam ser responsabilizados pela sua segurança, podem fazer relatos válidos sobre eventos adversos, e desempenhar um papel em alguns aspectos do planejamento e execução de seus cuidados de saúde.

Assim, dada à diversidade dos pacientes e locais de cuidados de saúde na Atenção Primária pode-se supor que isso cria limitações e oportunidades para o envolvimento do paciente na segurança. Pode ser proveitoso considerar as possibilidades de uma abordagem mais individualizada para a concretização de estratégias de envolvimento. Por outro lado, tanto o paciente quanto o médico generalista podem sentir-se incertos sobre o que exatamente é esperado e exigido deles, quando pacientes devem desempenhar papel mais ativo no 
processo de consulta. Esta é certamente uma questão a se levar em consideração na aplicação de métodos de envolvimento do paciente (MARTIM; LARSEN, 2012).

A qualidade da interação e relacionamento paciente-profissionais parece ser a chave para envolver os pacientes no processo. Futuras pesquisas são particularmente necessárias e tem de se concentrar em como promover esse envolvimento em programas de segurança do paciente (ESMAIL, 2013).

\subsubsection{Dimensão continuidade}

A dimensão continuidade, de acordo com o PROADESS/MS (2011) é a capacidade do Sistema de Saúde de prestar serviços de forma ininterrupta e coordenada entre diferentes níveis de atenção. A Atenção Primária trabalha em equipe, tem conhecimento prévio da população, possui, na maior parte das vezes, registro em prontuário anterior à queixa aguda, possibilita o retorno com a mesma equipe de saúde, o acompanhamento do quadro e o estabelecimento de vínculo, o que caracteriza a continuidade do cuidado, e não somente um atendimento pontual (BRASIL/MS, 2013).

Com os critérios de vinculação e regionalização da assistência, a Atenção Primária deveria ser o serviço coordenador da continuidade da assistência, agindo preventivamente nas causas dos problemas de saúde, utilizando a lógica da referência e contra referência como uma ferramenta nesse processo. Para que haja essa continuidade, são necessárias redes de atenção à saúde com conectores integrados em suas múltiplas dimensões. O prontuário eletrônico interligado em rede pode ser uma ferramenta útil na continuidade do tratamento e na segurança do paciente, desde que seja utilizado de forma adequada com registros precisos e completos.

De acordo com Hartz e Contandriopoulos (2004),

"A integração dos serviços de saúde aparece como atributo inerente às reformas das
políticas públicas fundamentadas na Atenção Primária à Saúde. [...] a integração
consiste em uma coordenação durável das práticas clinicas destinada a alguém que
sofre com problemas de saúde, visando a assegurar a continuidade e a globalidade
dos serviços requeridos de diferentes profissionais e organizações, articuladas no
tempo e no espaço, conforme os conhecimentos disponíveis."

No contexto da polifarmácia relacionada a vários problemas de saúde, é necessário um processo reflexivo de conciliação terapêutica, esta se constitui em uma estratégia da política de segurança do paciente inserida nos sistemas de saúde (LLAMAS et al., 2012). A relação da continuidade com a segurança do paciente está principalmente evidenciada no tratamento das doenças crônicas, em que a descontinuidade pode acarretar prejuízos e riscos ao paciente, por exemplo, o tratamento com anticonvulsivante, tratamentos para diabetes e hipertensão. Outro 
aspecto importante é a conciliação de medicamentos para prevenir interação medicamentosa, obter adequadamente o histórico do paciente, principalmente em pacientes com mais de um problema de saúde que fazem acompanhamento com mais de uma especialidade.

\subsubsection{Dimensão adequação}

A adequação, de acordo com o PROADESS/MS (2011), é o grau com que os cuidados prestados às pessoas estão baseados no conhecimento técnico-científico existente.

Uma vez identificados problemas reais de segurança do paciente, torna-se essencial tomar medidas de correção. Pode ser usado o ciclo PDCA (Plan-Do-Check-Act), que consiste em uma avaliação baseada em critérios ou requisitos de qualidade, intervenção para resolução dos critérios problemáticos e reavaliação para detectar e documentar a melhoria conseguida (GAMA; SATURNO, 2013). Todos os profissionais de saúde que prestam cuidados ao paciente, incluindo os enfermeiros, são elementos-chave no processo de interceptar erros, impedir decisões ruins, referente aos cuidados e também de assumir um papel de liderança no avanço e no uso de estratégias para promover a segurança e qualidade do cuidado (HARADA; PEDREIRA, 2013).

Em estudo qualitativo que avaliou a percepção dos enfermeiros sobre a segurança do paciente, identificou-se a preocupação com a adequada comunicação do evento entre os membros da equipe, atitude também considerada princípio básico da prática de enfermagem (OLIVEIRA et al., 2014). A enfermagem está consciente de que, da complexidade do desafio, se extrai sua disposição para assumir a liderança em segurança, tendo como elementos imprescindíveis a formação, a pesquisa, a prática baseada em evidências e a ideia de que a segurança do paciente é a segurança de todos nós (QUES, et al, 2010).

Uma ferramenta para segurança do paciente é a uniformização do processo por meio da elaboração de protocolos, apesar das críticas do engessamento que esse tipo de gerenciamento pode ocasionar, os protocolos podem servir como barreira preventiva ao erro, se forem verdadeiramente fáceis de aplicar e haja aderência por parte da equipe multidisciplinar, caso contrário pode não ser adequado. Estudos relacionados à segurança do paciente e à participação do enfermeiro na implantação de estratégias para a melhoria da qualidade e da segurança da assistência de enfermagem são necessários e, ao mesmo tempo, recentes e inovadores, podendo ajudar os profissionais da área a conhecer as causas e os efeitos à saúde do paciente, além de possibilitar treinamentos adequados à prevenção de novas 
ocorrências e implementação da cultura da segurança nos serviços de saúde em geral (OLIVEIRA et al., 2014).

De acordo com Gama e Saturno (2013), é importante que o desenho dos processos seja regulamentado internamente mediante normas ou protocolos adaptados pelos atores envolvidos na assistência e aprovados pelos gestores dos serviços. Os protocolos devem ter boa qualidade formal (facilidade de leitura, flexibilidade, confiabilidade), conteúdo baseado em evidências científicas, ser corretamente utilizado e comprovadamente efetivo.

Wachter (2010) enfatiza a necessidade de padronização e simplificação dos processos. Por outro lado, se respeitarmos demais as normas, os valores e os comportamentos existentes, existe o risco de perder-se a capacidade de questionar as práticas de má qualidade. (PROQUALIS/MS, 2012).

$\mathrm{Na}$ área da enfermagem, o desenvolvimento do cuidado tem sido baseado mais na tradição do que em evidências. É necessário capacitar e apoiar enfermeiros para identificar e utilizar práticas baseadas em evidências (HARADA; PEDREIRA, 2013). A interconexão existente entre a segurança do paciente e a prática, baseada em evidências, promove e facilita a incorporação de práticas seguras nos serviços de saúde (QUES et al, 2010).

É de considerável relevância promover a participação dos enfermeiros assistenciais nos processos de análise permanente das condições do serviço para contribuírem na identificação dos riscos, incorporando práticas seguras e baseadas em evidência na instituição. (OLIVEIRA et al., 2014). Nesse sentido é necessário mudança no processo de trabalho, priorizando o conhecimento na execução do cuidado, desenvolvendo o senso crítico sobre a prática na enfermagem. Erros de medicação podem ocorrer em qualquer etapa do sistema, como: erros de prescrição, erros de dispensação, erros de administração e erros de monitoramento das reações adversas (CARVALHO; CASSIANI, 2012).

O papel da tecnologia na prevenção de erros se dá no sentido de desenvolver sistemas com mecanismos de segurança com "funções forçadas", por exemplo, conectores de gases anestésicos que não conectam no sistema errado. Ou o uso da tecnologia da informação como ferramenta útil na redução de erros de medicação (WACHTER, 2010).

Outro fator observado é que a falta de padronização da nomenclatura dos medicamentos nas prescrições pode gerar confusão nos profissionais, uma vez que, atualmente, milhares de medicamentos estão disponíveis no mercado e muitos deles apresentam nomes parecidos na ortografia e/ou som potencializando o risco de erros (CARVALHO; CASSIANI, 2012). 
Algumas estratégias para prevenir erro de medicação são: elaboração de prescrições legíveis; elaborar prescrições completas; prescrever medicamentos pela denominação genérica; evitar uso de abreviaturas e símbolos nas prescrições, como por exemplo, a não utilizar a letra "U" para unidade; evitar uso de decimais na prescrição das doses (exemplo: prescrever $500 \mathrm{mg}$ em vez de 0,5 g); avaliar os benefícios da implantação da prescrição médica eletrônica; proporcionar informações ao paciente sobre o propósito de cada medicamento, nome, dose, frequência e o uso adequado, dentre outras (CARVALHO; CASSIANI, 2012). Outra ferramenta que pode ser utilizada consiste na implantação de sistemas com treinamentos para médicos para evitar erros diagnósticos comuns. (WACHTER, 2010).

\subsubsection{Dimensão segurança}

A dimensão segurança diz respeito à capacidade do Sistema de Saúde de identificar, evitar ou minimizar os riscos potenciais das intervenções em saúde ou ambientais (PROADESS/MS, 2011).

Erros estarão sempre presentes em qualquer ação realizada em qualquer setor de atividade, pois esta é uma característica imutável do processo de cognição da nossa espécie. Ademais, quanto mais complexo é um sistema, ou mais complexa a ação, maior o risco de erros e eventos (HARADA; PEDREIRA, 2013).

Para assegurarmos o envolvimento dos diversos grupos de interesse na melhoria da qualidade, precisamos utilizar muitas abordagens (PROQUALIS/MS, 2012). Os profissionais podem utilizar vários métodos e ferramentas validadas para a realização de uma abordagem proativa de gestão de riscos e efeitos adversos (LLAMAS et al., 2012). Não se deve estimular apenas a notificação do evento adverso grave, mas também dos riscos, de suas causas e das estratégias implementadas para seu tratamento (OLIVEIRA et al., 2014).

Para SOUSA et al. (2010) o conhecimento e compreensão dos eventos adversos, a frequência, as causas e determinantes, bem como o seu impacto nos doentes, e o desenvolvimento de formas inovadoras que contribuam para diminuir e/ou prevenir os mesmos, constituem, uma parte fundamental do processo, mais amplo, de avaliação e melhoria contínua da segurança do doente e da qualidade em saúde.

Os elementos centrais que traduzem o processo de melhoria contínua de qualidade e segurança do paciente nos planos estratégicos são: a existência de um programa de qualidade e segurança do paciente com ações monitoradas por indicadores, o qual deve ser gerido por 
uma instância responsável e de uma política de estímulo à utilização rotineira de protocolos e diretrizes clínicas (MENDES; MOURA, 2013). Identificar as áreas prioritárias para a investigação em segurança do doente e, preferencialmente, fazer convergir essas áreas com a agenda política da saúde em geral, e com a estratégia para a qualidade e segurança do paciente (SOUSA et al., 2010).

Em revisão realizada para localizar ferramentas e indicadores para medir e melhorar a segurança do paciente na Atenção Primária identificou-se que há escassez de estudos sobre como melhorar a segurança neste cenário. O uso de ferramentas de avaliação da cultura é indispensável para compreender as atitudes e comportamentos dos profissionais sobre a segurança do paciente (CAMARGO TOBIAS et al., 2014). O desafio é transformar instrumentos em ferramentas de melhoria de qualidade (SPENCER; CAMPBELL, 2014). A segurança do paciente é por isso, em si mesma, uma área de intervenção inovadora que, ao colocar no centro o paciente e a sua família, obriga a reinventar o sistema de saúde (e a própria lógica de investigação) numa perspectiva cada vez mais baseada em aspectos de cidadania e de ganhos em saúde (SOUSA et al., 2010).

Essa coincidência de dimensões reforça o argumento de que a segurança realmente é uma dimensão da qualidade, além da necessidade de integrar a sua gestão e melhoria com as atividades de gestão e melhoria da qualidade (GAMA; SATURNO, 2013). Embora a segurança seja um subconjunto do campo mais amplo da qualidade da assistência à saúde, é importante observar que muitas vezes há dificuldade em se perceber diferença entre as duas áreas, principalmente no que ser refere às medidas de desempenho e nas mudanças de práticas e sistemas (WACHTER, 2010). É apropriado e oportuno conhecer e refletir sobre a segurança do paciente relacionado com a gestão da segurança e a cultura organizacional, pois isso afeta diretamente a prática (CAMARGO TOBIAS et al., 2014).

Ao propor mudança no processo de trabalho centrado na segurança do paciente como dimensão ordenadora, é essencial incluir os aspectos da cultura da segurança, que são descritos a partir de cinco características operacionalizadas pela gestão de segurança da organização, de acordo com a Portaria $n^{\circ} 529$, de $1^{\circ}$ de abril de 2013, que Institui o Programa Nacional de Segurança do Paciente (PNSP):

\footnotetext{
“a) cultura na qual todos os trabalhadores, incluindo profissionais envolvidos no cuidado e gestores, assumem responsabilidade pela sua própria segurança, pela segurança de seus colegas, pacientes e familiares; b) cultura que prioriza a segurança acima de metas financeiras e operacionais; c) cultura que encoraja e recompensa a identificação, a notificação e a resolução dos problemas relacionados à segurança; d) cultura que a partir da ocorrência de incidentes, promove o aprendizado
} 
organizacional; e, e) cultura que proporciona recursos, estrutura e responsabilização para a manutenção efetiva da segurança (BRASIL, 2013).”

Evidências sugerem que é necessário compreender a cultura da segurança para fazer melhorias para a segurança do paciente (ALLEN et al., 2010). Essas referências demonstram como a segurança do paciente tem interseções com a qualidade e como se constitui uma dimensão ordenadora da reorganização do processo de trabalho na Atenção Primária, sendo abordados alguns aspectos com potencial de intervenção mais simples e outros que dependem de mais investimentos e recursos para serem implementados.

Na Atenção Primária, iniciou-se um movimento que vai ao encontro da segurança do paciente, que é a prevenção quaternária, proposto pelo médico de família e comunidade belga Jamoulle, em 1999 durante o encontro anual Wonca International Classification Committee. O conceito surgiu a partir da preocupação com o excesso de intervenção e medicalização, tanto diagnóstica quanto terapêutica. Jamoule propôs a prevenção quaternária como um quarto e último tipo de prevenção, não relacionada ao risco de doenças e sim ao risco de adoecimento iatrogênico, ao excessivo intervencionismo diagnóstico e terapêutico e a medicalização desnecessária (NORMAN; TESSER, 2009).

A medicina pode ser perigosa para a saúde, desde a relação médico-paciente individual até às campanhas de massa destinadas a milhões de indivíduos. Entre a prescrição de um benzodiazepínico a um paciente em luto e a compra de milhões de doses de vacinas inúteis, apenas varia a escala na dimensão de erro (JAMOULLE; GOMES, 2014).

O Plano de Segurança do Paciente deve ser focado na melhoria contínua dos processos de cuidado e do uso de tecnologias da saúde, na disseminação sistemática da cultura de segurança, na articulação e integração dos processos de gestão de risco e na garantia das boas práticas de funcionamento do serviço de saúde (BRASIL, 2014).

\subsection{ESTRATÉGIAS PARA TORNAR OS CUIDADOS MAIS SEGUROS}

O desenvolvimento de ações que visam à otimização da assistência ao paciente com a finalidade de diminuir os erros decorrentes de falhas no sistema são urgentes, e nesse aspecto os programas de qualidade podem ser ferramentas que auxiliam as instituições de saúde a conhecer melhor seus serviços, identificando suas fragilidades e implementando ações mais consistentes, seguras e ágeis, além de propiciar melhor utilização dos recursos disponíveis, evitando desperdícios e permitindo uma melhor aplicação dos mesmos (FRANÇOLIN et al., 2015). 
Nas instituições de saúde, o enfermeiro pode ser considerado facilitador no processo de identificação de riscos de eventos adversos, o que se configura em elemento chave nesse processo, dado o seu protagonismo na assistência (FRANÇOLIN et al., 2015). Identificação dos riscos, a incorporação de boas práticas na assistência direta e/ou indireta e a identificação das barreiras e oportunidades encontradas para promover a segurança na instituição, são algumas estratégias elencadas por enfermeiros assistenciais em estudo qualitativo (OLIVEIRA et al., 2014).

Estratégias simples e efetivas podem prevenir e reduzir riscos e danos nestes serviços, por meio do seguimento de protocolos específicos, associadas às barreiras de segurança nos sistemas e à educação permanente (OLIVEIRA et al., 2014). Dessa forma, sistematizar um processo educativo permanente, para todas as equipes multidisciplinares, focado em riscos (clínicos e não clínicos) à saúde advindos de erros/eventos adversos/sentinela, segundo legislações e padrões de qualidade poderá ser a melhor estratégia para se conseguir a qualidade institucional (HINRICHSEN et al., 2011).

O primeiro passo para implantar ações de segurança do pacientes no serviço é a elaboração do Plano de Segurança do Paciente, que segundo a RDC no 36/2013, é obrigatória, para todos os serviços de saúde (BRASIL, 2013).

O módulo de Implantação do Núcleo de Segurança do Paciente em Serviços de Saúde, elaborado pela ANVISA, tem como finalidade servir de roteiro para os profissionais estabelecerem ações que promovam a segurança e a qualidade dos processos de trabalho, nos serviços de saúde. Este módulo apresenta um capítulo específico sobre cultura de segurança e abordam aspectos para a melhoria e manutenção da cultura nos serviços de saúde, quais sejam:

- Desenvolvimento de sistemas de liderança, sendo que os líderes devem estar envolvidos no processo de criar e transformar a cultura de segurança do paciente. As estruturas de liderança devem ser estabelecidas com a intenção de sensibilizar, responsabilizar, habilitar e agir em favor da segurança de cada um dos pacientes atendidos.

- Realização periódica de avaliação da cultura de segurança, utilizando-se questionários validados que abrangem as várias dimensões que compõem o construto da cultura de segurança. Os resultados devem ser informados aos profissionais e gestores para a implementação local de medidas de melhoria necessárias.

- Promoção de trabalho em equipe, com um enfoque proativo, sistemático e organizacional de trabalho, contribuindo para a construção de habilidades profissionais e melhoria dos desempenhos das equipes para a redução de danos preveníveis.

- Identificação e mitigação de riscos e perigos, identificando e reduzindo os riscos e perigos relacionados com a segurança do paciente, por meio de um enfoque contínuo de redução dos danos preveníveis. Ainda, o serviço de saúde deve contar com um bom sistema de vigilância e monitoramento que revele os prováveis 
problemas de segurança do paciente, reforçando a importância do acompanhamento de bons indicadores (BRASIL, 2014).

O aprimoramento das habilidades e do conhecimento por parte dos enfermeiros se constitui em fator primordial para a melhoria da qualidade assistencial e, consequentemente, da segurança do paciente. Nesse contexto, é preciso investir na qualificação profissional e na prestação de assistência segura aos usuários dos serviços de saúde que buscam atendimento (FRANÇOLIN, et al, 2015). A incorporação da segurança do paciente como área em que a enfermagem pode crescer e se desenvolver profissionalmente, no momento atual, se constituirá em melhoria das competências adquiridas e expansão da participação da enfermagem (QUES et al, 2010).

Os erros no preparo e administração de medicamentos envolvem o enfermeiro como o principal profissional nesta área de trabalho, enfatizando a importância de uma equipe qualificada e a abordagem de práticas seguras na administração de medicamentos (CAMARGO TOBIAS et al., 2014). O desenvolvimento e a implementação de ferramentas de tecnologia da informação eficazes é essencial para o melhoramento da segurança ambulatorial, particularmente na área de gestão de medicamentos e resultado de exames (WACHTER, 2013).

Criar um diagrama que identifique os riscos poderá ser uma ferramenta de controle da qualidade institucional (HINRICHSEN et al., 2011). A redução dos riscos e dos danos e a incorporação de boas práticas favorecem a efetividade dos cuidados de enfermagem e o seu gerenciamento de modo seguro (OLIVEIRA et al., 2014). Os pacientes identificam os profissionais de enfermagem como seus melhores defensores, ante os riscos do sistema sanitário, e existe reconhecimento da participação chave da enfermagem na segurança do paciente (QUES et al, 2010). Ter um conjunto abrangente de ferramentas para monitoramento e prevenção de eventos de segurança é o primeiro passo na fixação de metas (SPENCER; CAMPBELL, 2014).

Wachter (2013) enfatiza a estratégia de utilizar uma liderança forte. Afirma que mudar uma cultura é difícil, na medida em que ocorre o empoderamento de outra pessoa, pode significar perda de poder e status para o outro. É importante que haja o apoio e envolvimento dos médicos, enfermeiros e gestores que estão no topo da cadeia de autoridade.

$\mathrm{Na}$ Atenção Primária, a troca de informação entre o médico de família e os especialistas, o reforço do trabalho em equipe, as reuniões regulares para discutir casos clínicos, e a divulgação das práticas seguras foram apontadas como as soluções para a melhoria da comunicação interprofissional (MARCHON; MENDES JÚNIOR, 2014). 
Destaca-se a importância de estabelecer comunicação eficaz desde a identificação do risco ou incidente crítico, do menos grave ao mais grave, evitando, assim, a ocorrência do evento adverso e dos danos por ele gerados (OLIVEIRA et al., 2014).

\subsection{AVALIAÇÃO DA CULTURA DE SEGURANÇA, ADAPTAÇÃO CULTURAL E VALIDAÇÃO DE INSTRUMENTOS DE MENSURAÇÃO}

Avaliar a cultura da segurança do paciente por meio de questionário é uma das formas de conhecer qual o nível de envolvimento e preocupação dos profissionais de saúde com essa questão. Considerando as características do objeto de pesquisa que não é embasado em senso comum e ideologia, mas é verificável porque segue um método, busca a validade, tem significado e relevância social, porque objetiva, de certa forma, influenciar na qualidade da assistência, prevenir danos à saúde e promover o debate sobre a segurança do paciente.

Uma avaliação, seja por questionário, seja por entrevista, só pode informar sobre a cultura de segurança naquele momento específico (VINCENT, 2009).

Em 2012 foram publicados dois estudos de adaptação transcultural de instrumentos para utilização em hospitais, o Safety Attitudes Questionnaire - Short Form 2006 para o Brasil (CARVALHO; CASSIANI, 2012), e o Hospital Survey on Patient Safety Culture (HSOPSC) para a língua portuguesa e contexto brasileiro (REIS et al., 2012).

Segundo Reis (2014):

"Esses questionários foram delineados com o objetivo de mensurar múltiplas
dimensões da cultura de segurança do paciente; eles questionam a opinião de seus
respondentes sobre pontos-chave relacionados à segurança - valores, crenças e
normas da organização, notificação de eventos adversos, comunicação, liderança e
gestão."

O objetivo do processo de tradução e adaptação de instrumento é de alcançar diferentes versões linguísticas que são conceitualmente equivalentes em cada um dos paísesalvo/culturas. Isto é, o instrumento deve ser igualmente natural e aceitável e deve ser aplicado praticamente da mesma forma. O foco está na equivalência transcultural e conceitual, em vez de equivalência linguística/literal (WHO, 2011).

Nesse estudo foram seguidas as etapas de validação de instrumento com base em referências nacionais e internacionais, com o método rigorosamente acompanhado para garantir a confiabilidade do estudo.

Em revisão realizada sobre o gerenciamento de segurança do paciente e cultura organizacional, observou-se que a produção científica aumentou a partir de 2010 e continua crescendo, sendo a predominância de autoria americana e publicada em periódicos científicos 
dos Estados Unidos da América, o que indicou a necessidade de desenvolver pesquisas sobre o assunto no Brasil (CAMARGO TOBIAS et al., 2014).

Reichenhei e Moraes (2007) defendem a necessidade do uso de instrumentos de aferição robustos, a importância de instrumentos "universais" que permitam sintonias transculturais, e a necessidade de partir para adaptação em contraposição ao desenvolvimento de um instrumento novo. É necessário que haja investimento em adaptações formais de instrumentos elaborados em outros contextos, sobretudo se há interesse em comparar os resultados de pesquisas epidemiológicas realizadas em diferentes localidades e culturas. Dessa forma, optou-se por realizar estudo Metodológico, que envolve investigações dos métodos de obtenção e organização de dados e condução de pesquisas rigorosas. Os estudos metodológicos tratam do desenvolvimento, da validação e da avaliação de ferramentas e métodos de pesquisa (LIMA, 2011).

O instrumento escolhido para ser validado foi o questionário de coleta de dados Medical Office Survey on Patient Safety Culture (MOSPSC) aplicado em mais de 200 serviços de saúde nos Estados Unidos da América. O MOSPSC enfatiza questões relacionadas à segurança do paciente e a qualidade do cuidado de saúde (SORRA et al., 2008).

Para análise do questionário, consideram-se como elementos as instruções, o formato das respostas e os itens de forma individual (ALEXANDRE; COLUCI, 2011). A validação apresenta dificuldades importantes e situa-se em três níveis: ao nível da teoria, da coleta empírica e da análise estatística (PASQUALI, 2009). Apesar do desafio de validação de um questionário produzido em outra cultura e das possíveis limitações da avaliação de um tema subjetivo, que é a cultura, com um questionário de questões objetivas, este instrumento tem se demonstrado útil como forma de investigação científica, sendo a adaptação transcultural e validação já realizada para outro idioma, como o espanhol, com resultados positivos.

A validação de conteúdo tem como propósito determinar se o conteúdo de um instrumento de medida explora, de maneira efetiva, os quesitos para mensuração de um determinado fenômeno a ser investigado (BELLUCCI; MATSUDA, 2012). Na análise de conteúdo, uma concordância de, pelo menos, $80 \%$ dos especialistas pode servir de critério quanto à pertinência do item (PASQUALI, 1998).

A validação de aparência é a avaliação da apresentação e clareza das afirmações, facilidade de leitura, interpretação e representatividade dos itens nas dimensões (BELLUCCI; MATSUDA, 2012). 


\section{O Índice de fidedignidade ou concordância interavaliadores (interrater} agrément) avalia a concordância dos especialistas quanto à representatividade e clareza dos itens em relação ao conteúdo estudado (VITURI; MATSUDA, 2009).

O quadro 1 apresenta os aspectos a serem avaliados em um instrumento e as estratégias de avaliação apresentados por Reichenhei e Moraes (2007).

\begin{tabular}{|c|c|}
\hline Aspecto avaliado & Estratégia para avaliação \\
\hline \multirow[t]{3}{*}{ Equivalência conceitual } & $\begin{array}{l}\text { - Revisão bibliográfica envolvendo publicações da cultura do } \\
\text { instrumento original e da população-alvo }\end{array}$ \\
\hline & • Discussão com especialistas \\
\hline & - Discussão com população-alvo \\
\hline \multirow[t]{2}{*}{ Equivalência de itens } & • Discussão com especialistas \\
\hline & - Discussão com população-alvo \\
\hline \multirow[t]{6}{*}{ Equivalência semântica } & - Traduções \\
\hline & - Retraduções \\
\hline & $\begin{array}{l}\text { - Avaliação da equivalência semântica entre as retraduções e o } \\
\text { original }\end{array}$ \\
\hline & • Discussão com população-alvo \\
\hline & - Discussão com especialistas para ajustes finais \\
\hline & - Pré-teste da versão \\
\hline \multirow[t]{5}{*}{$\begin{array}{l}\text { Equivalência } \\
\text { operacional }\end{array}$} & $\begin{array}{l}\text { - Avaliação pelo grupo de pesquisa quanto à pertinência e } \\
\text { adequação do: }\end{array}$ \\
\hline & - Veículo e formato das questões/instruções. \\
\hline & - Cenário de administração. \\
\hline & - Modo de aplicação. \\
\hline & - Modo de categorização. \\
\hline \multirow{4}{*}{$\begin{array}{l}\text { Equivalência } \\
\text { mensuração }\end{array}$} & - Estudos psicométricos \\
\hline & $\begin{array}{l}\text { - Enfoque 1: Avaliação de validade dimensional e adequação de } \\
\text { itens componentes. }\end{array}$ \\
\hline & - Enfoque 2: Avaliação de confiabilidade. \\
\hline & $\begin{array}{l}\text { - Enfoque 3: Avaliação de validade de construto de validade de } \\
\text { critério }\end{array}$ \\
\hline Equivalência funcional & $\begin{array}{l}\text { - Dada pelas equivalências identificadas nas demais etapas de } \\
\text { avaliação }\end{array}$ \\
\hline
\end{tabular}

Fonte: Reichenhei e Moraes (2007).

Quadro 1. Estratégia de avaliação por Reichenhei e Moraes. 


\section{MATERIAIS E MÉTODOS}

\subsection{DESENHO DO ESTUDO}

Estudo metodológico de tradução, adaptação transcultural e validação de um instrumento para avaliar cultura de segurança do paciente para o português do Brasil.

Inicialmente, realizou-se o levantamento das referências, com a estratégia de busca sobre cultura de segurança na Atenção Primária a Saúde, do período de 2011 a 2015, na base de dados na Biblioteca Virtual em Saúde (BVS) utilizando-se os descritores em portugues: segurança do paciente AND cultura AND cuidado primário OR Atenção Primária, não foi localizada pesquisa relacionada ao tema nessa base de dados em português, com os descritores segurança do paciente AND cuidado primário OR Atenção Primária, obteve-se um total de 21 estudos. Utilizando-se os descritores em inglês patient safety culture AND primary care encontrou-se 103 estudos.

A busca na Scientific Electronic Library Online (SciELO) foi realizada utilizando-se os descritores: segurança do paciente AND cultura, sendo encontrados 18 resultados. Na biblioteca Pubmed utilizando-se os descritores "Patient Safety culture" AND "Primary Health Care", surgiram 11 resultados, os mesmos descritores sem aspas apontaram 203 pesquisas.

Na base ScienceDirect, utilizaram-se os descritores "patient safety culture" AND "primary care", e jornais apareceram 14,954 artigos, sem realização de refinamento dos dados.

Constatou-se escassez de publicações em português, sendo localizado um estudo sobre questionários de cultura da segurança a serem utilizados em hospitais (REIS et al., 2012) e outros dois sobre clima de segurança (RIGOBELLO et al., 2012; CARVALHO; CASSIANI, 2012). Não foi localizado, até o momento, nenhum artigo brasileiro, publicado, de validação de instrumento sobre a cultura da segurança do paciente para ser utilizado em pesquisas direcionadas para Atenção Primária à Saúde.

Optou-se pelo estudo de tradução e adaptação cultural do instrumento de avaliação Medical Office Survey on Patient Safety Culture (MOSPSC), desenvolvido em 2007 pela Agency for Health Care Research and Quality (AHRQ) nos Estados Unidos da América. Este instrumento tem se demonstrado útil como forma de investigação científica, sendo a adaptação transcultural e validação já realizada para outro idioma, o espanhol (TORIJANOCASALENGUA et a.1., 2013). A opção do instrumento de avaliação baseou-se na livre disponibilidade sem ônus, no sítio eletrônico da AHRQ (http://www.ahrq.gov/professionals/quality-patient-safety/patientsafetyculture/medical- 
office/index.html), pelo fato de ter sido desenvolvido para aplicação ambulatorial e avaliar diversas dimensões da cultura de segurança.

O instrumento original é constituído de 51 perguntas, que medem 12 dimensões do construto da Segurança do Paciente que incluem: 1) comunicação aberta; 2) comunicação sobre o erro; 3) troca de informações com outros setores; 4) processo de trabalho e padronização; 5) aprendizagem organizacional; 6) percepção geral da segurança do paciente e qualidade; 7) apoio dos gestores na segurança do paciente; 8) seguimento da assistência ao paciente; 9) questões relacionadas à segurança do paciente e qualidade; 10) treinamento da equipe; 11) trabalho em equipe; 12) pressão no trabalho e ritmo.

Para tradução e validação do instrumento inicialmente foi solicitada autorização para a autora, ou seja, a AHRQ e obteve-se resposta positiva (Anexo A).

Para alcançar o objetivo do estudo seguiram-se inicialmente seis etapas (Figura 3), de acordo com guias para estudos de validação na área da saúde de Pasquali (1998) e de Sousa e Rojjanasrirat (2011), sendo cada etapa documentada em relatório.

\subsubsection{Etapas da tradução do instrumento}

O período das etapas de tradução, síntese I, retrotradução e síntese II decorreram nos meses de julho à outubro de 2014. Foi realizada uma criteriosa seleção dos tradutores de acordo com os critérios recomendados pelas referências do método. 


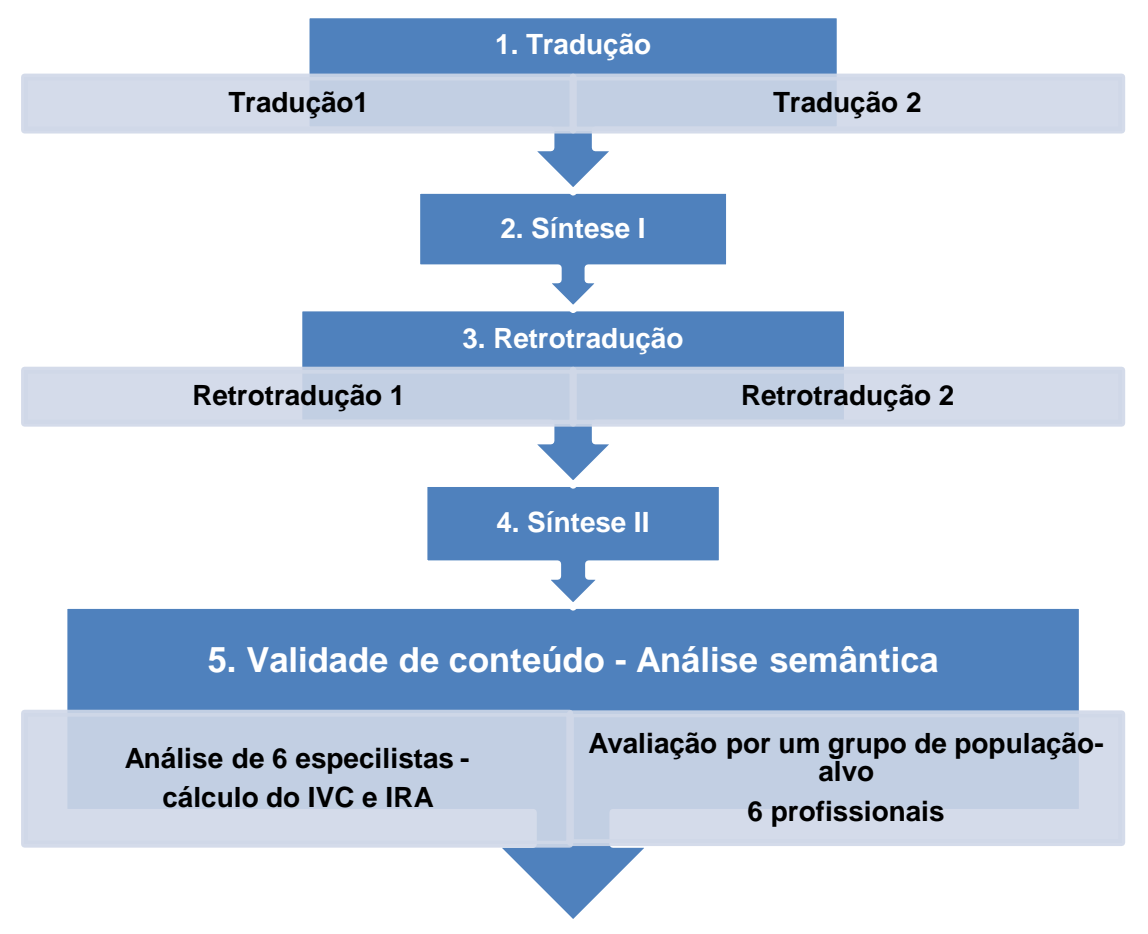

Adaptações para o contexto brasileiro

\section{Aplicação do pré-teste - 37 profissionais da Atenção Primária}

Fonte: originária da pesquisa.

Nota: IVC= índice de validade de conteúdo; IRA = concordância interavaliadores.

Figura 2. Etapas do método utilizado para validação do instrumento para o português do Brasil, Brasília - DF, 2015

4.1.1.1 Tradução do Instrumento Original para o Idioma de Destino: foi realizada por dois tradutores independentes, portanto duas versões (T1 e T2). Observou-se as qualificações e características dos tradutores, de acordo com os seguintes critérios: nativos brasileiros e bilíngues inglês/português, experiência prévia neste tipo de estudo, um com experiência na terminologia científica de saúde e o outro nas nuances culturais e linguísticas do português. Nesta etapa os tradutores tiveram conhecimento dos objetivos da tradução.

4.1.1.2 Comparação das duas versões traduzidas do instrumento (T1 e T2): síntese I. As versões T1 e T2 foram comparadas com a versão original do instrumento e sintetizadas. As ambiguidades e discrepâncias de palavras, frases e significados foram discutidas e resolvidas pela pesquisadora, orientadora e por um terceiro tradutor bilíngue. Esse processo gerou a versão traduzida preliminar do instrumento T1-2. 
4.1.1.3 Retrotradução cega da versão preliminar traduzida do instrumento T1-2: a retrotradução foi realizada por dois tradutores independentes, nativos norte-americanos bilíngues, que não conheciam a versão original do instrumento de avaliação e os objetivos do estudo, o que gerou mais duas versões (R-T1 e R-T2).

\subsubsection{Comparação das duas versões retraduzidas do instrumento (R-T1 e R-T2):} síntese II. As versões foram comparadas pela pesquisadora, orientadora e uma terceira tradutora bilíngue. Nessa etapa foram realizadas as adaptações transculturais, quanto aos termos utilizados no Brasil.

\subsubsection{Validação do instrumento}

\subsubsection{Validade de Conteúdo}

Para assegurar a validade de conteúdo foram seguidas outras duas fases:

4.1.2.1.1 Avaliação por Especialistas: o instrumento foi submetido à análise de seis especialistas, os quais foram selecionados pelos seguintes critérios: possuir produção científica na temática segurança do paciente, ou conhecimento metodológico na elaboração e/ou adaptação de instrumentos e, por fim, análise dos currículos obtidos via Plataforma Lattes do Conselho Nacional de Desenvolvimento Científico e Tecnológico (CNPq), sendo pesquisadores com formação de mestrado ou doutorado.

O convite foi enviado via endereço eletrônico para cada pesquisador que atendeu aos critérios estabelecidos. Após o aceite, o instrumento de avaliação foi enviado por meio eletrônico, com instruções para análise, utilizando-se o programa de pesquisa SurveyMonkey ${ }^{\circledR}$. O instrumento traduzido foi inserido no programa e cada item foi avaliado por meio de escala Likert, composta das seguintes pontuações: 1 para não claro, 2 para pouco claro, 3 para claro, e 4 para bastante claro. Ao final de cada item, havia um espaço para sugestões e observações.

Os especialistas foram orientados a analisar os itens do instrumento individualmente, desde as instruções de preenchimento do instrumento, as questões e as opções de respostas, verificando-se a clareza, pertinência e a forma do conteúdo, e ao final de cada item constava um espaço para sugestões e observações.

O período de análise dos especialistas ocorreu nos meses de novembro e dezembro de 2014. 
4.1.2.1.2 Análise Semântica: realizada para verificar se todos os itens são compreensíveis para a população a qual o instrumento se destina (PASQUALI, 1998).

A técnica utilizada para esta etapa foi realizar um grupo de população-alvo com seis profissionais. A escolha dos participantes foi realizada por conveniência e foi selecionado um representante de cada categoria profissional, desde o estrato de escolaridade mais baixo encontrado no serviço, ou seja, ensino médio até o mais alto, pós-gradução. Os participantes assinaram o Termo de Consentimento Livre e Esclarecido (TCLE) (APÊNDICE 1) e preencheram um questionário para identificação das características (APÊNDICE 2).

Esta etapa foi realizada no mês de fevereiro de 2014. Inicialmente, o projeto e o método de avaliação foram apresentados ao grupo. Cada item foi avaliado interativamente e analisado quanto a sua compreensão numa situação de Brainstorming (PASQUALI, 1998). Para as questões que suscitaram dúvidas na interpretação, foi solicitado sugestões de modificação, as quais foram registradas em relatório e analisadas posteriormente.

\subsubsection{Aplicação do pré-teste para a população-alvo}

O objetivo dessa etapa foi avaliar se o questionário é compreensível para a populaçãoalvo e realizar análise de confiabilidade do instrumento (PASQUALI, 1998, 2009; BELLUCCI; MATSUDA 2012).

\subsubsection{Período}

A coleta de dados do pré-teste foi realizada nos meses de março e abril de 2015.

\subsubsection{Casuística}

Os participantes foram escolhidos de forma intencional e abordados em seu ambiente de trabalho conforme a disponibilidade e o aceite em participar da pesquisa. Como critério de inclusão foi considerado o tempo de atuação superior a 30 dias no serviço; trabalhar no mínimo 20 horas semanais no serviço; aceitar ao convite para participar do estudo e assinar o TCLE. Foram excluídos os profissionais que participaram do grupo de população-alvo, os que realizam trabalho esporádico no serviço e aqueles que estavam de férias ou licença no período da realização da pesquisa.

Os participantes foram instruídos quanto aos objetivos do estudo e como proceder para preencher a escala. 
A caracterização da amostra do estudo foi realizada por meio da idade, sexo, grau de instrução, cargo no serviço, quanto ao contato direto com o paciente, tempo de serviço e tempo de profissão (APÊNDICE 2).

\subsubsection{Local}

A coleta dos dados foi realizada em três centros de saúde e uma clínica da família de uma regional de saúde da Secretaria de Estado de Saúde do Distrito Federal.

\subsubsection{Tamanho da Amostra}

Em três dos quatro serviços a coleta foi realizada exclusivamente pela pesquisadora e no quarto serviço com o auxílio da gerente que recebeu instruções de como proceder a coleta. No total foram entregues 52 instrumentos para profissionais da equipe multidisciplinar e profissionais das áreas de apoio, foram recebidos 37 instrumentos preenchidos. De acordo com Pasquali (1998), no pré-teste, pode-se aplicar o instrumento a uma amostra de aproximadamente 30 pessoas da população-alvo.

\subsubsection{Tratamento e Análise dos dados}

A avaliação da compreensão do instrumento traduzido foi realizada por meio de escala Likert para analisar cada item do questionário individualmente, sendo cinco graduações, com as seguintes opções de resposta: 1 para não entendi; 2 para entendi pouco; 3 para entendi mais ou menos; 4 para entendi; e 5 para entendi plenamente.

Os dados dos instrumentos aplicados no pré-teste foram transcritos para o programa Excel $^{\circledR}$ para análise por meio de cálculo do coeficiente de alfa de Cronbach, com elaboração dos gráficos e tabelas. Para transcrição os instrumentos receberam um código alfa numérico, com a letra $\mathrm{P}$ (participante) e numerados em ordem crescente.

O coeficiente alfa de Cronbach foi apresentado por Lee J. Cronbach, em 1951, como uma forma de estimar a confiabilidade de um questionário aplicado em uma pesquisa. $\mathrm{O}$ alfa mede a correlação entre respostas em um questionário através da análise do perfil das respostas dadas pelos respondentes. Trata-se de uma correlação média entre perguntas. Dado que todos os itens de um questionário utilizam a mesma escala de medição, o coeficiente $\alpha$ é calculado a partir da variância dos itens individuais e da variância da soma dos itens de cada avaliador (HAIR et al., 2005; TABACHNICK; FIDELL, 2007). 
Confiabilidade do questionário segundo o valor de alfa de Cronbach:

\begin{tabular}{l|l}
\hline Valor de alfa & Confiabilidade \\
\hline Maior do que 0,9 & Excelente \\
\hline $0,8-\mid 0,9$ & Bom \\
\hline $0,7-\mid 0,8$ & Aceitável \\
\hline $0,6-\mid 0,7$ & Questionável \\
\hline \multicolumn{2}{|c}{ Fonte: GEORGE; MALLERY, 2003 }
\end{tabular}

"A análise da precisão de um instrumento quer mostrar precisamente o quanto ele se afasta do ideal da correlação 1, determinando um coeficiente que, quanto mais próximo de 1 , menos erro o teste comete ao ser utilizado (PASQUALI, 2009).”

\subsection{CONSIDERAÇÕES ÉTICAS}

O projeto seguiu os preceitos éticos e legais conforme Resolução $\mathrm{n}^{\circ} 466$, de 12 de dezembro de 2012 e foi aprovado pelo Comitê de Ética em Pesquisa da Secretaria de Estado de Saúde do Distrito Federal/FEPECS/SES/DF (Anexo B). Os participantes da fase de grupo de público alvo e do pré-teste assinaram o TCLE (APÊNDICE 1), preservando-se a identidade dos mesmos. 


\section{RESULTADOS}

\subsection{ADAPTAÇÕES REALIZADAS}

Algumas adaptações em relação à forma e aplicabilidade do instrumento para o Brasil foram realizadas antes da análise dos especialistas, pela pesquisadora, orientadora e uma terceira tradutora bilíngue que coordenou a equipe de tradutores, e possuía experiência nesse tipo de estudo.

As adaptações do instrumento de avaliação iniciaram-se pelo título, "Medical Office Survey on Patient Safety", sendo a tradução original "Pesquisa de Consultório Médico sobre Segurança do Paciente". Como no contexto brasileiro, a Atenção Primária faz parte do Sistema Único de Saúde (SUS), a finalidade foi adaptar um instrumento que pudesse ser utilizado nas diversas configurações que englobam a Atenção Primária. Assim, o título foi modificado para "Pesquisa sobre Cultura de Segurança do Paciente para Atenção Primária". Além disso, o termo "consultório médico" foi alterado para "serviço de saúde", e o termo "provedor", para "médico". Também foi realizada a adaptação das profissões que compõem a equipe de saúde, pelo fato de algumas categorias profissionais não possuírem o equivalente no Brasil. A versão original do instrumento consta no Anexo C, as comparações entre a primeira síntese T1 - 2 e após a avaliação dos especialistas consta no Apêndice 3.

\subsection{ANÁLISE DOS DADOS}

\subsection{1 Índice de Validade de Conteúdo e Concordância Interavaliadores}

Os itens do instrumento de avaliação que apresentaram pontuação 1 (não claro) ou 2 (pouco claro) em mais de $20 \%$ foram considerados insatisfatórios. Eles foram, desta forma, modificados com base nas sugestões, mantendo o conceito geral. Assim, o acordo mínimo entre avaliadores foi de $80 \%$ para que o item não necessitasse de adaptações.

Para medir a proporção ou porcentagem de concordância entre os especialistas, os dados obtidos foram analisados quanto ao Índice de Validade de Conteúdo (IVC) (ALEXANDRE; COLUCI, 2011), seguindo a seguinte fórmula:

Número de respostas “3” e "4" dividido pelo número total de respostas

Também se calculou a concordância interavaliadores de cada seção com a seguinte fórmula:

Número de itens com Índice de Validade de Conteúdo $\geq 80 \%$ dividido pelo número total de itens de cada seção 
A concordância interavaliadores é destinada a avaliar a extensão em que os especialistas são confiáveis nas avaliações dos itens frente ao contexto estudado (BELLUCCI; MATSUDA 2012). Por fim, foi calculado o Índice de Validade de Conteúdo do instrumento realizado, mediante a soma total dos Índices de Validade de Conteúdo, dividida pelo número total de itens.

Para o cálculo do IVC total do instrumento considerou-se 56 itens, pois cinco subitens da seção $\mathrm{G}$ foram desmembrados para análise individual; a seção $\mathrm{H}$ refere-se ao perfil sócio demográfico e também foi considerada nessa avaliação. O cálculo do IVC do instrumento como um todo, foi realizado por meio da soma total dos IVC dividido pelo número total de itens $(47,76 / 56$ itens $=0,85)$. O IVC das seções A e B não foram satisfatórios, sendo alvo de maior número de adaptações, mas quando calculado o IVC do instrumento geral observa-se que o mesmo atingiu o IVC satisfatório de 0,85 (Tabela 1). De acordo com a literatura, para verificar a validade de novos instrumentos de uma forma geral, autores sugerem uma concordância mínima de 0,80 (ALEXANDRE; COLUCI, 2011). 
Tabela 1 - Resultado dos cálculos de índice de validade de conteúdo e concordância Inter avaliadores na fase de análise dos especialistas, Brasília - DF, 2015.

\begin{tabular}{|c|c|c|c|c|c|c|c|c|}
\hline Seção & Questão & IVC & IRA & & Seção & Questão & IVC & IRA \\
\hline \multirow{10}{*}{ Seção A } & A1 & 0,83 & $\overline{0,3}$ & Continuação: & Seção E & E1 & 0,83 & $\overline{c 1,0}$ \\
\hline & A2 & 0,54 & & & & E2 & 0,83 & \\
\hline & A3 & 0,83 & & & & E3 & 1,0 & \\
\hline & A4 & 0,66 & & & & E4 & 1,0 & \\
\hline & A5 & 0,66 & & & & & & \\
\hline & A6 & 0,66 & & & & $\mathrm{~F} 1$ & 0,83 & \\
\hline & A7 & 0,33 & & & & F2 & 0,83 & \\
\hline & A8 & 0,83 & & & & F3 & 1,0 & \\
\hline & A9 & 0,33 & & & Seção F & F4 & 0,83 & 1,0 \\
\hline & & & & & & F5 & 0,83 & \\
\hline \multirow[t]{8}{*}{ Seção B } & B1 & 0,33 & 0,0 & & & F6 & 0,83 & \\
\hline & & & & & & F7 & 1,0 & \\
\hline & $\mathrm{C} 1$ & 1,0 & & & & & & \\
\hline & $\mathrm{C} 2$ & 1,0 & & & & G1a & 1,0 & \\
\hline & $\mathrm{C} 3$ & 0,66 & & & & G1b & 0,83 & \\
\hline & $\mathrm{C} 4$ & 1,0 & & & Seção G & G1c & 0,83 & 1,0 \\
\hline & $\mathrm{C} 5$ & 1,0 & & & & G1d & 1,0 & \\
\hline & C6 & 1,0 & & & & G1e & 1,0 & \\
\hline \multirow{5}{*}{ Seção C } & $\mathrm{C} 7$ & 0,83 & & & & & & \\
\hline & $\mathrm{C} 8$ & 1,0 & 0,8 & & & $\mathrm{H} 1$ & 1,0 & \\
\hline & $\mathrm{C} 9$ & 0,83 & & & & $\mathrm{H} 2$ & 1,0 & \\
\hline & $\mathrm{C} 10$ & 0,83 & & & Seção H & $\mathrm{H} 3$ & 1,0 & 1,0 \\
\hline & $\mathrm{C} 11$ & 0,83 & & & & & & \\
\hline
\end{tabular}

$\begin{array}{clll} & \text { D1 } & 0,83 & \\ & \text { D2 } & 1,0 & \\ & \text { D3 } & 1,0 & \\ & \text { D4 } & 1,0 & \\ \text { Seção D } & \text { D5 } & 0,83 & \\ & \text { D6 } & 0,41 & 0,9 \\ & \text { D7 } & 1,0 & \\ & \text { D8 } & 1,0 & \\ & \text { D9 } & 1,0 & \\ & \text { D10 } & 1,0 \\ \text { D11 } & 1,0 \\ \text { D12 } & 1,0\end{array}$

Continua

$\mathrm{C} 12 \quad 0,54$

C13 1,0

C14 0,7

C15 1,0

Fonte: Originada da pesquisa.

Notas: IVC - Índice de Validade de Conteúdo; IRA - Concordância Inter Avaliadores (interrater agrément).

Resultado do IVC total do instrumento: 47,76 / 56 itens $=0,85$

Na seção A, apenas três itens (questões 1, 3 e 8) atingiram IVC 0,83; as questões 4, 5 e 6 atingiram índice de 0,66 e as demais foram abaixo de 0,5. Na seção B, o IVC não foi satisfatório, devido à manutenção das alternativas das respostas em uma única questão. $\mathrm{Na}$ Seção C, a maioria dos itens atingiu índice entre 0,83 e 1,0; em somente três itens (questões 3 , 12 e 14) foi abaixo de 0,66, necessitando de adequações. Na seção D, somente um item 
(questão 6) não atingiu IVC satisfatório; os demais ficaram entre 0,83 e 1,0. Nas seções E, F, $\mathrm{G}$ e $\mathrm{H}$, todas as questões obtiveram índice acima de 0,83 .

Quanto à concordância interavaliadores, os valores obtidos nas seções A $(0,3)$ e B $(0,0)$ não foram satisfatórios, necessitando de mais adaptações. Na seção $\mathrm{C}$, a concordância interavaliadores foi de 0,8; na D, 0,9 e as demais seções alcançaram pontuação igual a 1,0.

Embora algumas seções necessitassem de mais adaptações, o cálculo do IVC do instrumento geral foi satisfatório, com pontuação de 0,85 .

\subsubsection{Adaptações do instrumento sugeridas pelos especialistas}

$\mathrm{Na}$ seção A foi sugerido por uma especialista para modificar as respostas de frequência de "2. semanalmente" e "3. mensalmente" para "2. pelo menos uma vez na semana" e "3. pelo menos uma vez ao mês", em todos os itens. Por esse motivo houve redução no IVC de todos os itens da seção A, porque a mesma atribuiu pontuação "2. Pouco claro" para todos os itens desta seção, mesmo nos casos que considerou a pergunta clara.

Ainda, na seção A foram alterados os itens 2, 3 e 4 em que na tradução inicial constava prontuário/registro "médico" foi subtraído médico, mantendo somente prontuário/registro, por considerar que o prontuário ou registro são do paciente e contém informações que toda a equipe registra e não somente o médico.

\subsubsection{Adaptações sugeridas pelo grupo de população-alvo}

Na fase seguinte de análise semântica, realizada pelo grupo de população-alvo, participaram um enfermeiro, um médico, um odontólogo, um técnico de enfermagem, um agente comunitário de saúde e uma técnica em saúde bucal.

Caracterização dos participantes do grupo multidisciplinar: $67 \%(n=4)$ são do sexo feminino, idade média de 36 anos, a maioria trabalha de 33 a 40 horas semanais, somente um trabalha $24 \mathrm{~h}$ semanais no serviço.

Quanto ao tempo de profissão 50\% $(\mathrm{n}=3)$ trabalha de 6 a 10 anos na profissão, 33\% $(\mathrm{n}=2)$ trabalha de 11 a 15 anos e $16 \%(\mathrm{n}=1)$ de 16 a 20 anos.

Em relação ao nível de escolaridade, esta variável foi bastante diversificada, com representantes do estrato mais baixo até o mais alto, sendo um com ensino médio, um com ensino superior em andamento e um com ensino superior completo, dois com especialização e um com nível de mestrado. 
As sugestões do grupo foram analisadas pela pesquisadora e orientadora, e os itens considerados relevantes foram modificados após consenso. Na Seção A - Diagnósticos e testes, foi incluída uma questão compreendendo um total de 10 questões para esta seção. A questão foi sugerida pelo grupo, porque reflete de forma mais fidedigna a realidade brasileira observada na prática clínica, muitas vezes os exames necessários não estão disponíveis, seja devido à demanda reprimida como pela falta de materiais ou indisponibilidade de exames especializados no sistema público de saúde.

Após a análise das sugestões, na segunda fase de validade de conteúdo, que foi a avaliação pelo grupo de população-alvo, as sugestões consideradas relevantes foram adaptadas após consenso entre a pesquisadora e orientadora, considerando-se a evolução quanto à clareza e aparência dos itens.

\subsubsection{Pré-teste}

Quanto às características descritivas das unidades nas quais foram aplicados o préteste, participaram oito profissionais de um centro de saúde em processo de transformação do modelo tradicional de atenção para estratégia de saúde da família, dois centros de saúde com modelo tradicional de atenção, sendo oito profissionais de um e sete profissionais de outro e uma Clínica da Família composta por oito equipes de saúde da família, com a participação de 14 profissionais, esta última se constitui um centro de formação de estudantes de medicina e residência médica, assim como campo de estágio para o curso de enfermagem de uma Instuição de Ensino Superior.

\subsubsection{Características dos participantes}

A caracterização da amostra do pré-teste os dados coletados incluiram: 1) idade; 2) sexo; 3) grau de instrução; 4) função/cargo; 5) número de horas trabalhadas por semana; 6) interação com paciente; 7) tempo de trabalho na profissão; 8) tempo de trabalho no serviço atual.

Foi entregue um total de 52 questionários e destes foram devolvidos 37 (71\%). Na distribuição por categoria profissional, a coleta foi realizada de forma que incluísse a maior diversidade possível de forma proporcional ao número de profissionais das unidades, sendo composta por: técnicos de enfermagem $(n=11 ; 29,7 \%)$, enfermeiros $(n=7 ; 19,0 \%)$, médicos $(n=4 ; 10,8 \%)$, odontólogos $(n=3 ; 8,1 \%)$, equipe administrativa $(n=3 ; 8,1 \%)$, técnicos de laboratório $(n=2 ; 5,4 \%)$, nutricionista $(n=1 ; 2,7 \%)$, técnico de saúde bucal $(n=1 ; 2,7 \%)$, 
administrador $(n=1 ; 2,7 \%)$, gerente $(n=1 ; 2,7 \%)$, chefia de enfermagem $(n=1 ; 2,7 \%)$, chefe do setor de registro $(n=1 ; 2,7 \%)$, agente comunitário de saúde $(n=1 ; 2,7 \%)$. A maioria $(n=31$; $84 \%$ ) dos profissionais trabalha no serviço de 33 a 40 horas semanais.

Quanto ao grau de instrução 18 (49\%) possuíam especialização concluída, nove (24\%) concluíram o nível médio, quatro (11\%) concluíram o nível superior, três (8\%) possuem superior em andamento, dois (5\%) especialização em andamento e por fim um (3\%) possui mestrado.

Na distribuição por faixa etária observa-se certa equivalência entre as idades acima de 30 anos, no entanto, a maioria $(n=8 ; 21,6 \%)$ se encontra na faixa etária de 50 anos ou mais (Gráfico 1).

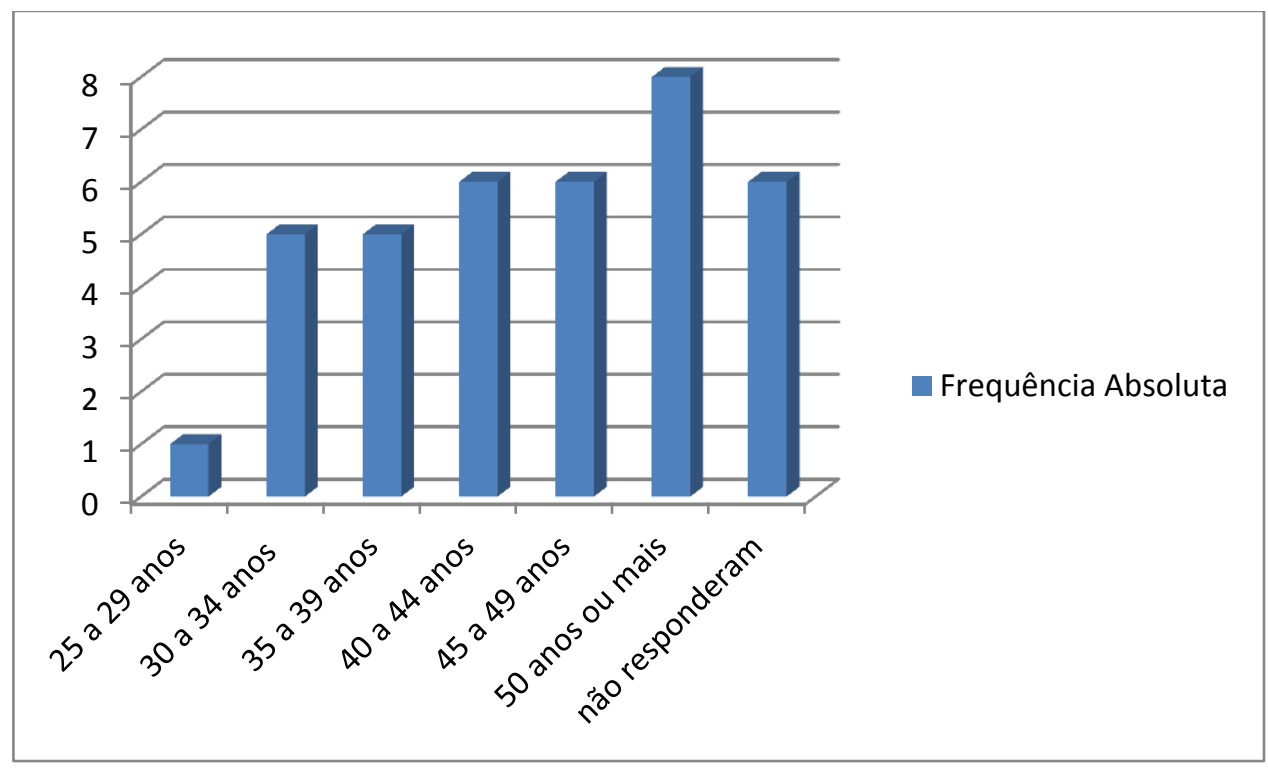

Fonte: Originária da pesquisa.

Gráfico 1. Distribuição dos participantes da pesquisa na etapa de pré-teste, por faixa etária. Brasília - DF, 2015.

Todos os participantes tinham contato direto com o paciente, mesmo nas áreas administrativas, por exemplo, na realização de registros e identificação.

Com relação ao tempo de profissão, seis (16,2\%) trabalhavam de 1 a 5 anos, cinco $(13,5 \%)$ de 6 a 10 anos, seis $(16,2 \%)$ de 11 a 15 anos, quatro (10,8\%) de 16 a 20 anos e a maioria $14(37,8 \%)$ trabalha de 21 anos ou mais, dois $(5,4 \%)$ não responderam ao item.

Outra variável mensurada foi o tempo de trabalho no serviço, de dois meses a menos de um ano foram cinco profissionais $(13,5 \%)$, de um ano a menos de três anos foram 11 profissionais $(29,7 \%)$, de três anos a menos de seis anos foram cinco profissionais $(13,5 \%)$, de 
seis anos a menos de 11 anos foi somente um profissional (2,7\%), 13 profissionais $(35,1 \%)$ trabalham há 11 anos ou mais, constituindo a maioria.

$\mathrm{Na}$ análise dados do pré-teste observa-se que a maioria dos participantes exerce a profissão há 21 anos ou mais $(37,8 \% ; n=14)$, quanto ao tempo no serviço atual $35 \%(n=13)$ trabalhavam há mais de 11 anos. Relativo ao grau de instrução, 48,6\% (n=18) possuiam especialização concluída, 48,6\% (n=18) exerciam cargo de nível médio, sendo que 24\% (n=9) possuiam grau de instrução até nível médio, 19\% tinham nível superior em andamento ou concluído e a maioria $57 \%(n=21)$ possuiam pós-graduação em andamento ou concluída (incluindo mestrado), portanto, pode-se observar que a maioria dos profissionais procurou avançar nos estudos, ao nível de pós-graduação.

Os itens do instrumento foram de fácil compreensão para a população-alvo, demonstradas nas tabelas que apresentaram média de compreensão, sendo o valor mínimo igual a 1 e máximo igual a 5, ou seja, quanto mais próximo de cinco estiver a média melhor a compreensão dos itens. As tabelas referentes à média estão subdivididas nas seções do instrumento.

Observa-se na tabela 2 que a seção A possui 10 questões e apresentou média de compreensão geral de 4,62, o que representa uma boa compreensão.

Tabela 2 - Médias e medianas relativas à compreensão dos itens do questionário, segundo população-alvo, aplicados no pré-teste - Seção A. Brasília - DF, 2015

\begin{tabular}{lllllc}
\hline Seção - A & Mínimo & Máximo & Média & DP & Mediana \\
\hline A1 & 3 & 5 & 4,62 & 0,55 & 5 \\
A2 & 1 & 5 & 4,57 & 0,80 & 5 \\
A3 & 4 & 5 & 4,78 & 0,42 & 5 \\
A4 & 1 & 5 & 4,58 & 0,77 & 5 \\
A5 & 3 & 5 & 4,62 & 0,55 & 5 \\
A6 & 1 & 5 & 4,57 & 0,77 & 5 \\
A7 & 3 & 5 & 4,35 & 0,68 & 4 \\
A8 & 4 & 5 & 4,70 & 0,46 & 5 \\
A9 & 4 & 5 & 4,73 & 0,45 & 5 \\
A10 & 4 & 5 & 4,68 & 0,47 & 5 \\
\hline \multicolumn{5}{l}{ Média da Seção } & 4,62 \\
\hline \multicolumn{5}{r}{ Fonte: originada da pesquisa. Nota: DP (Desvio Padrão) }
\end{tabular}

A seção B possui somente uma questão e apresentou média de compreensão de 4,22, com desvio padrão de 0,96 (Tabela 3). 
Tabela 3 - Média e mediana de compreensão dos itens do questionário aplicados no pré-teste, com cálculo de desvio padrão - Seção B. Brasília - DF, 2015.

\begin{tabular}{lccccc}
\hline Seção B & Mínimo & Máximo & Média & DP & Mediana \\
\hline B1 & 1 & 5 & 4,22 & 0,96 & 4 \\
\hline \multicolumn{5}{l}{ Fonte: originada da pesquisa. DP (Desvio Padrão) }
\end{tabular}

A Seção C, apresentada na tabela 4, possui 15 itens e a média geral de compreensão foi 4,66 .

Tabela 4 - Médias e medianas de compreensão dos itens do questionário aplicados no préteste, com cálculo de desvio padrão - Seção C. Brasília - DF, 2015.

\begin{tabular}{lccccc}
\hline Seção C & Mínimo & Máximo & Média & DP & Mediana \\
\hline C1 & 2 & 5 & 4,70 & 0,62 & 5 \\
C2 & 4 & 5 & 4,73 & 0,45 & 5 \\
C3 & 3 & 5 & 4,57 & 0,60 & 5 \\
C4 & 3 & 5 & 4,68 & 0,53 & 5 \\
C5 & 4 & 5 & 4,76 & 0,43 & 5 \\
C6 & 4 & 5 & 4,75 & 0,44 & 5 \\
C7 & 4 & 5 & 4,62 & 0,49 & 5 \\
C8 & 4 & 5 & 4,68 & 0,47 & 5 \\
C9 & 3 & 5 & 4,57 & 0,69 & 5 \\
C10 & 1 & 5 & 4,57 & 0,87 & 5 \\
C11 & 3 & 5 & 4,62 & 0,59 & 5 \\
C12 & 3 & 5 & 4,64 & 0,59 & 5 \\
C13 & 3 & 5 & 4,73 & 0,51 & 5 \\
C14 & 3 & 5 & 4,68 & 0,53 & 5 \\
C15 & 3 & 5 & 4,68 & 0,53 & 5 \\
\hline Média da Seção & & & 4,66 & & \\
\hline
\end{tabular}

Fonte: originada da pesquisa. Nota: DP (Desvio Padrão)

A Seção D possui 12 questões no total e a média global de compreensão foi de 4,57 (Tabela 5). 
Tabela 5 - Médias e medianas de compreensão dos itens do questionário aplicados no préteste, com cálculo de desvio padrão - Seção D. Brasília - DF, 2015.

\begin{tabular}{lccccc}
\hline Seção D & Mínimo & Máximo & Média & DP & Mediana \\
\hline D1 & 3 & 5 & 4,65 & 0,54 & 5 \\
D2 & 4 & 5 & 4,70 & 0,46 & 5 \\
D3 & 3 & 5 & 4,65 & 0,59 & 5 \\
D4 & 3 & 5 & 4,68 & 0,53 & 5 \\
D5 & 3 & 5 & 4,53 & 0,56 & 5 \\
D6 & 1 & 5 & 4,16 & 0,99 & 4 \\
D7 & 1 & 5 & 4,43 & 0,99 & 5 \\
D8 & 3 & 5 & 4,57 & 0,60 & 5 \\
D9 & 2 & 5 & 4,59 & 0,69 & 5 \\
D10 & 3 & 5 & 4,61 & 0,60 & 5 \\
D11 & 3 & 5 & 4,65 & 0,54 & 5 \\
D12 & 3 & 5 & 4,68 & 0,53 & 5 \\
\hline \multicolumn{5}{l}{ Média da Seção } & Fonte: originada da pesquisa. Nota: DP (Desvio Padrão)
\end{tabular}

A Seção E possui quatro questões, a tabela 6 apresenta a média global de compreensão, que foi de 4,37.

Tabela 6 - Médias e medianas de compreensão dos itens do questionário aplicados no préteste, com cálculo de desvio padrão - Seção E. Brasília - DF, 2015.

\begin{tabular}{lccccc}
\hline Seção E & Mínimo & Máximo & Média & DP & Mediana \\
\hline E1 & 1 & 5 & 4,41 & 0,86 & 5 \\
E2 & 1 & 5 & 4,38 & 0,89 & 5 \\
E3 & 1 & 5 & 4,30 & 0,94 & 5 \\
E4 & 1 & 5 & 4,41 & 0,90 & 5 \\
\hline \multicolumn{5}{l}{ Média da Seção } \\
\hline \multicolumn{7}{c}{ Fonte: originada da pesquisa. Nota: DP (Desvio Padrão) }
\end{tabular}

A Seção F possui sete questões com média global de compreensão de 4,55 (Tabela 7).

Tabela 7 - Médias e medianas de compreensão dos itens do questionário aplicados no préteste, com cálculo de desvio padrão - Seção F. Brasília - DF, 2015

\begin{tabular}{lccccc}
\hline Seção F & Mínimo & Máximo & Média & DP & Mediana \\
\hline F1 & 4 & 5 & 4,73 & 0,45 & 5 \\
F2 & 4 & 5 & 4,68 & 0,47 & 5 \\
F3 & 2 & 5 & 4,58 & 0,66 & 5 \\
F4 & 2 & 5 & 4,24 & 0,82 & 4 \\
F5 & 3 & 5 & 4,56 & 0,61 & 5 \\
F6 & 1 & 5 & 4,47 & 0,90 & 5 \\
F7 & 4 & 5 & 4,62 & 0,49 & 5 \\
\hline \multicolumn{5}{l}{ Média da Seção } \\
\hline \multicolumn{7}{c}{ Fonte: originada da pesquisa. Nota: DP (Desvio Padrão) } \\
\multicolumn{7}{l}{}
\end{tabular}


A Seção $G$ possui cinco itens e a média total de compreensão foi de 4,46 (Tabela 8).

Tabela 8 - Médias e medianas de compreensão dos itens do questionário aplicados no préteste, com cálculo de desvio padrão - Seção G. Brasília - DF, 2015.

\begin{tabular}{lccccc}
\hline Seção G & Mínimo & Máximo & Média & DP & Mediana \\
\hline G. a & 1 & 5 & 4,32 & 0,91 & 5 \\
G. b & 3 & 5 & 4,46 & 0,65 & 5 \\
G. c & 3 & 5 & 4,50 & 0,61 & 5 \\
G. d & 4 & 5 & 4,46 & 0,51 & 4 \\
G. e & 4 & 5 & 4,59 & 0,50 & 5 \\
\hline Média da Seção & \multicolumn{5}{c}{4,46} \\
\hline \multicolumn{7}{c}{ Fonte: originada da pesquisa. DP (Desvio Padrão) }
\end{tabular}

A última Seção H, com uma questão, apresentou média de 4,36 e DP: 0,93 (Tabela 9).

Tabela 9 - Média e mediana de compreensão dos itens do questionário aplicados no pré-teste, com cálculo de desvio padrão - Avaliação Global. Brasília - DF, 2015.

\begin{tabular}{lccccc}
\hline Seção H & Mínimo & Máximo & Média & DP & Mediana \\
\hline H1 & 1 & 5 & 4,36 & 0,93 & 5 \\
\hline \multicolumn{5}{c}{ Fonte: originada da pesquisa. Nota: DP (Desvio Padrão) }
\end{tabular}

A versão do MOSPSC em português apresentou o alfa de Cronbach total de 0,95, indicando uma confiabilidade alta de acordo com a análise estatística.

A seguir são apresentadas as tabelas de frequência da compreensão dos itens, distribuídos por seção e separado por itens.

A tabela 10 demonstra que o item foi compreensível em 97,3 \% na aplicação do préteste. Portanto, neste item foi mantida a forma da tradução inicial sem necessidade de ajustes.

Tabela 10 - Frequência das opções de respostas da amostra do pré-teste, seção A, item 1. Brasília - DF, 2015.

\begin{tabular}{lcc}
\hline \multicolumn{2}{l}{ Um paciente não conseguiu uma consulta em até $\mathbf{4 8}$ horas para um problema sério/agudo. } \\
\hline Opções de resposta & $\mathrm{N}$ & $\%$ \\
\hline Não Entendi & - & - \\
Entendi pouco & - & - \\
Entendi mais ou menos & 1 & 2,7 \\
Entendi & 12 & 32,4 \\
Entendi plenamente & 24 & 64,9 \\
\hline Total & 37 & 100,0
\end{tabular}

Fonte: originada da pesquisa.

A tabela 11 apresenta o item 2 da seção A, sendo o item que gerou mais dúvidas. Na avaliação pelos especialistas não atingiu IVC satisfatório, assim foi sugerido revisar a redação 
de forma que ficasse mais clara, a tradução original foi: Um prontuário/registro médico errado foi utilizado para um paciente. Portanto, na etapa de grupo de população-alvo foi realizada a reformulação da questão para melhor compreensão e expressar o que se pretendia medir. Desta forma, o item apresentou uma compreensão satisfatória em 94,6\% na aplicação do préteste.

Tabela 11 - Frequência das opções de respostas da amostra do pré-teste, seção A, item 2. Brasília - DF, 2015.

No atendimento de um paciente foi utilizado um prontuário/registro de outro paciente.

\begin{tabular}{lcc}
\hline Opções de resposta & $\mathrm{N}$ & $\%$ \\
\hline Não entendi & 1 & 2,7 \\
Entendi pouco & - & - \\
Entendi mais ou menos & 1 & 2,7 \\
Entendi & 10 & 27,0 \\
Entendi plenamente & 25 & 67,6 \\
\hline Total & 37 & 100,0 \\
\hline
\end{tabular}

Fonte: originada da pesquisa.

Na tabela 12 observa-se que o item não apresentou dúvidas e foi compreensível para $100 \%$ da amostra no pré-teste.

Tabela 12 - Frequência das opções de respostas da amostra do pré-teste, seção A, item 3. Brasília - DF, 2015.

O prontuário/registro de um paciente não estava disponível quando necessário.

\begin{tabular}{lcc}
\hline Opções de resposta & $\mathrm{N}$ & $\%$ \\
\hline Não entendi & - & - \\
Entendi pouco & - & - \\
Entendi mais ou menos & - & - \\
Entendi & 8 & 21,6 \\
Entendi plenamente & 29 & 78,4 \\
\hline Total & 37 & 100,0 \\
\hline Fonte: originada da pesquisa. & &
\end{tabular}

A tabela 13 demonstra que a questão foi compreensível para a maioria da populaçãoalvo (94,6\%), na avaliação pelos especialistas foi sugerido substituir informações médicas, por informações clínicas, já o grupo de população-alvo sugeriu modificar a expressão paciente errado para outro paciente. 
Tabela 13 - Frequência das opções de respostas da amostra do pré-teste, seção A, item 4. Brasília - DF, 2015.

\section{Informações clínicas de um paciente foram arquivadas, digitalizadas ou inseridas} no prontuário/registro de outro paciente.

\begin{tabular}{lcc}
\hline Opções de resposta & $\mathrm{N}$ & $\%$ \\
\hline Não entendi & 1 & 2,7 \\
Entendi pouco & - & - \\
Entendi mais ou menos & - & - \\
Entendi & 11 & 29,7 \\
Entendi plenamente & 24 & 64,9 \\
Sem resposta & 1 & 2,7 \\
\hline Total & 37 & 100,0 \\
\hline
\end{tabular}

Fonte: originada da pesquisa.

A tabela 14 demonstra que a questão foi compreensível para a maioria da populaçãoalvo no pré-teste $(97,3 \%)$. Na fase de avaliação pelos especialistas, foi sugerido alterar o gerúndio da frase "estava funcionando", um especialista sugeriu aprimorar a frase porque não ficou claro se o equipamento não funcionou durante o atendimento e outro sugeriu alterar a frequência das respostas. Da mesma forma, na avaliação pelo grupo de população-alvo sugeriram acrescentar um equipamento necessário ao atendimento, para ressaltar que isso interferiu no atendimento ao paciente.

Tabela 14 - Frequência das opções de respostas da amostra do pré-teste, seção A, item 5. Brasília - DF, 2015.

Um equipamento necessário ao atendimento não funcionou adequadamente ou necessitava reparo ou substituição.

\begin{tabular}{lcc}
\hline Opções de resposta & $\mathrm{N}$ & $\%$ \\
\hline Não entendi & - & - \\
Entendi pouco & - & - \\
Entendi mais ou menos & 1 & 2,7 \\
Entendi & 12 & 32,4 \\
Entendi plenamente & 24 & 64,9 \\
\hline Total & 37 & 100,0 \\
\hline Fonte: originada da pesquisa. & &
\end{tabular}

No item 6 da seção A (Tabela 15) foi necessária adaptação significativa para que pudesse medir o que se pretendia. Na tradução original era da seguinte forma: uma farmácia entrou em contato com o nosso consultório para esclarecer ou corrigir uma prescrição. Foi sugerido adaptar a questão porque na realidade brasileira não é comum uma farmácia ou farmacêutico entrar em contato com a unidade de saúde para corrigir uma prescrição, mas sim o próprio paciente é orientado a retornar ou entrar em contato com a equipe para corrigir a 
prescrição. Portanto, após as adaptações a questão foi compreensível para 97,3\% da amostra no pré-teste.

Tabela 15 - Frequência das opções de respostas da amostra do pré-teste, seção A, item 6. Brasília - DF, 2015.

\begin{tabular}{lccc}
\hline $\begin{array}{l}\text { O paciente retornou à unidade de saúde para esclarecer ou corrigir uma } \\
\text { prescrição. }\end{array}$ & N & $\%$ \\
\hline Opções de resposta & 1 & 2,7 \\
\hline Não entendi & - & - \\
Entendi pouco & - & - \\
Entendi mais ou menos & 12 & 32,4 \\
Entendi & 24 & 64,9 \\
Entendi plenamente & 37 & 100,0 \\
\hline Total & &
\end{tabular}

O item 7 originalmente foi traduzido da seguinte forma: A lista de medicamentos de um paciente não foi atualizada durante a sua consulta, este item foi adaptado para realidade brasileira. No pré-teste apresentou compreensão satisfatória de $89,1 \%$, demonstrado na tabela 16.

Tabela 16 - Frequência das opções de respostas da amostra do pré-teste, seção A, item 7. Brasília - DF, 2015.

Os medicamentos utilizados de um paciente não foram revisados pelo profissional de saúde durante sua consulta.

\begin{tabular}{lcc}
\hline Opções de resposta & $\mathrm{N}$ & $\%$ \\
\hline Não entendi & - & - \\
Entendi pouco & - & - \\
Entendi mais ou menos & 4 & 10,8 \\
Entendi & 16 & 43,2 \\
Entendi plenamente & 17 & 46,0 \\
\hline Total & 37 & 100,0 \\
\hline Fonte: originada da pesquisa. & &
\end{tabular}

O grupo de população-alvo sugeriu acrescentar o item 8 na seção A, o qual se refere ao acesso à realização dos exames, porque na realidade brasileira nem sempre os exames necessários estão disponíveis aos pacientes gratuitamente pelo SUS. Portanto, foi considerado pertinente pela pesquisadora e orientadora. Desta forma, a seção A finalizou com o total de 10 itens. Na avaliação do pré-teste atingiu compreensão de 100\% (Tabela 17). 
Tabela 17 - Frequência das opções de respostas da amostra do pré-teste, seção A, item 8 . Brasília - DF, 2015.

Os exames laboratoriais ou de imagem não foram realizados quando necessário.

\begin{tabular}{lcc}
\hline Opções de resposta & $\mathrm{N}$ & $\%$ \\
\hline Não entendi & - & - \\
Entendi pouco & - & - \\
Entendi mais ou menos & - & - \\
Entendi & 11 & 29,7 \\
Entendi plenamente & 26 & 70,3 \\
\hline Total & 37 & 100,0 \\
\hline Fonte: originada da pesquisa. & &
\end{tabular}

O Item 9 na tabela 18 apresentou clareza na sua tradução inicial, somente uma especialista sugeriu alteração na frequência de respostas para todos os itens da seção A. No pré-teste a compreensão do item foi de $100 \%$.

Tabela 18 - Frequência das opções de respostas da amostra do pré-teste, seção A, item 9. Brasília - DF, 2015.

Os resultados de exames laboratoriais ou de imagem não estavam disponíveis quando necessário.

\begin{tabular}{lcc}
\hline Opções de resposta & $\mathrm{N}$ & $\%$ \\
\hline Não entendi & - & - \\
Entendi pouco & - & - \\
Entendi mais ou menos & - & - \\
Entendi & 10 & 27,0 \\
Entendi plenamente & 27 & 73,0 \\
\hline Total & 37 & 100,0 \\
\hline
\end{tabular}

Fonte: originada da pesquisa.

No item 10, seção A, na avaliação dos especialistas, foi sugerido remover a palavra "crítico" da tradução inicial, mantido somente anormal, por considerar redundante "crítico anormal". Também foi alterado "acompanhado dentro de um dia útil” para “acompanhado/avaliado em tempo hábil". Na tabela 19 observa-se que a compreensão foi de $100 \%$ no pré-teste. 
Tabela 19 - Frequência das opções de respostas da amostra do pré-teste, seção A, item 10. Brasília - DF, 2015.

\begin{tabular}{lccc}
\hline $\begin{array}{l}\text { Um resultado anormal de um exame laboratorial ou de imagem } \\
\text { acompanhado/avaliado em tempo hábil. }\end{array}$ & foi \\
\hline Opções de resposta & $\mathrm{N}$ & $\%$ \\
\hline Não entendi & - & - \\
Entendi pouco & - & - \\
Entendi mais ou menos & 12 & 32,4 \\
Entendi & 25 & 67,6 \\
Entendi plenamente & 37 & 100,0 \\
\hline Total & &
\end{tabular}

A Seção B possui um item que apresentou compreensão de $89,1 \%$, no pré-teste (Tabela 20).

Tabela 20 - Frequência das opções de respostas da amostra do pré-teste, seção B, item 1. Brasília - DF, 2015.

Troca de informações com outras instituições.

\begin{tabular}{lcc}
\hline Opções de resposta & $\mathrm{N}$ & $\%$ \\
\hline Não entendi & 2 & 5,4 \\
Entendi pouco & - & - \\
Entendi mais ou menos & 1 & 2,7 \\
Entendi & 18 & 48,6 \\
Entendi plenamente & 15 & 40,5 \\
Sem resposta & 1 & 2,7 \\
\hline Total & 37 & 100,0 \\
\hline
\end{tabular}

Fonte: originada da pesquisa.

$\mathrm{Na}$ fase de análise dos especialistas a seção B apresentou dificuldade técnica no momento de transcrição do instrumento para o programa SurveyMonkey®, o qual não permitiu a edição da numeração da pergunta. Assim, se optou por manter as alternativas das respostas em uma única questão, porque se referiam a mesma pergunta. Para não gerar cinco questões separadamente, o item foi apresentado da seguinte forma no programa para os especialistas: 


\section{SEÇÃO B: Troca de informações com outras instituições}

Nos últimos 12 meses, com que frequência o seu serviço de saúde apresentou problemas relacionados à troca de informações completas, precisas e pontuais com:

1. Centros de imagem/laboratórios externos?

2. Outros serviços de saúde/médicos externos?

3. Farmácias?

4. Hospitais?

5. Outro? (Especificar):

$\square$ 1. Problemas diariamente

$\square$ 2. Problemas semanalmente

$\square$ 3. Problemas mensalmente

$\square$ 4. Vários problemas nos últimos 12 meses

$\square$ 5. Um ou dois problemas nos últimos 12 meses

$\square$ 6. Nenhum problema nos últimos 12 meses

$\square$ 9. Não se aplica ou não sei

Assim, a maioria dos especialistas sugeriu que para cada serviço deveria constar as alternativas de resposta separadamente, como no formato original do instrumento, portanto, considerou-se que este fato interferiu na análise do item. Da mesma forma, na seção B foram alteradas as opções de respostas de frequência de número "2. Problemas semanalmente" e “3. Problemas mensalmente”, para “2. Problemas pelo menos uma vez na semana" e "3. Problemas pelo menos uma vez ao mês".

Na seção C foram alteradas as opções de resposta " 1 . Discordo fortemente" para "1. discordo totalmente" e "5. Concordo fortemente" para "5. Concordo totalmente", de acordo com sugestão dos especialistas. Também foi alterado de "neste consultório" para "neste serviço" em todos os itens foi realizada essa adaptação. 
Tabela 21 - Frequência das opções de respostas da amostra do pré-teste, seção C, item 1. Brasília - DF, 2015.

Quando alguém neste serviço está muito ocupado, outros colegas ajudam.

\begin{tabular}{lcc}
\hline Opções de resposta & $\mathrm{N}$ & $\%$ \\
\hline Não entendi & - & - \\
Entendi pouco & 1 & 2,7 \\
Entendi mais ou menos & - & - \\
Entendi & 8 & 21,6 \\
Entendi plenamente & 28 & 75,7 \\
\hline Total & 37 & 100,0 \\
\hline
\end{tabular}

Fonte: originada da pesquisa.

Na tabela 22 seção C, questão 2, observa-se que o item obteve $100 \%$ de compreensão no pré-teste.

Tabela 22 - Frequência das opções de respostas da amostra do pré-teste, seção C, item 2. Brasília - DF, 2015.

No seu serviço há uma boa relação de trabalho entre os médicos e demais profissionais.

\begin{tabular}{lcc}
\hline Opções de resposta & $\mathrm{N}$ & $\%$ \\
\hline Não entendi & - & - \\
Entendi pouco & - & - \\
Entendi mais ou menos & - & - \\
Entendi & 10 & 27,0 \\
Entendi plenamente & 27 & 73,0 \\
\hline Total & 37 & 100,0 \\
\hline
\end{tabular}

Fonte: originada da pesquisa.

Observa-se na tabela 23, item C3, a compreensão satisfatória em 94,6\%.

Tabela 23 - Frequência das opções de respostas da amostra do pré-teste, seção C, item 3. Brasília - DF, 2015.

Neste serviço frequentemente nos sentimos apressados ao atender o paciente.

\begin{tabular}{lcc}
\hline Opções de resposta & $\mathrm{N}$ & $\%$ \\
\hline Não entendi & - & - \\
Entendi pouco & - & - \\
Entendi mais ou menos & 2 & 5,4 \\
Entendi & 12 & 32,4 \\
Entendi plenamente & 23 & 62,2 \\
\hline Total & 37 & 100,0 \\
\hline Fonte: originada da pesquisa. & &
\end{tabular}

A tabela 24 item C4 demonstra que a questão obteve 97,3\% de compreensão. Na avaliação dos especialistas foi sugerida a mudança da palavra "quando" para "sempre que". 
Tabela 24 - Frequência das opções de respostas da amostra do pré-teste, seção C, item 4. Brasília - DF, 2015.

Seu serviço treina a equipe sempre que novos processos são implantados.

\begin{tabular}{lcc}
\hline Opções de resposta & $\mathrm{N}$ & $\%$ \\
\hline Não entendi & - & - \\
Entendi pouco & - & - \\
Entendi mais ou menos & 1 & 2,7 \\
Entendi & 10 & 27,0 \\
Entendi plenamente & 26 & 70,3 \\
\hline Total & 37 & 100,0 \\
\hline
\end{tabular}

Fonte: originada da pesquisa.

A tabela 25, seção C, item 5 demonstra que o item obteve $100 \%$ de compreensão no pré-teste.

Tabela 25 - Frequência das opções de respostas da amostra do pré-teste, seção C, item 5. Brasília - DF, 2015.

Neste serviço tratamos uns aos outros com respeito.

\begin{tabular}{lcc}
\hline Opções de resposta & $\mathrm{N}$ & $\%$ \\
\hline Não entendi & - & - \\
Entendi pouco & - & - \\
Entendi mais ou menos & - & - \\
Entendi & 9 & 24,3 \\
Entendi plenamente & 28 & 75,7 \\
\hline Total & 37 & 100,0 \\
\hline
\end{tabular}

Fonte: originada da pesquisa.

Observa-se na tabela 26 item C6 demonstrou 97,3\% de compreensão no pré-teste. No entanto, foi realizada adaptação em relação à versão inicialmente traduzida: "Temos pacientes demais para o número de provedores neste consultório". 
Tabela 26 - Frequência das opções de respostas da amostra do pré-teste, seção C, item 6. Brasília - DF, 2015.

\begin{tabular}{lcc}
\hline $\begin{array}{l}\text { Neste serviço a quantidade de pacientes é muito alta em relação ao número de } \\
\text { médicos disponíveis. }\end{array}$ & $\mathrm{N}$ & $\%$ \\
\hline Opções de resposta & - & - \\
\hline Não entendi & - & - \\
Entendi pouco & - & - \\
Entendi mais ou menos & 9 & 24,3 \\
Entendi & 27 & 73,0 \\
Entendi plenamente & 1 & 2,7 \\
Sem resposta & 37 & 100,0 \\
\hline Total & &
\end{tabular}

Fonte: originada da pesquisa.

A Tabela 27, referente ao item C7 apresentou 100\% de compreensão no pré-teste. A tradução inicial foi: "Este consultório se certifica de que sua equipe recebe a capacitação prática que precisa". A sugestão dos especialistas foi trocar a palavra "capacitação" por "atualização", porque quando se contrata alguém para determinada função pressupõe-se que já é capacitado, o que o serviço oferece, normalmente, é atualização do conhecimento dos colaboradores.

Tabela 27 - Frequência das opções de respostas da amostra do pré-teste, seção C, item 7. Brasília - DF, 2015.

Este serviço garante que sua equipe receba atualizações necessárias ao atendimento.

\begin{tabular}{lcc}
\hline Opções de resposta & $\mathrm{N}$ & $\%$ \\
\hline Não entendi & - & - \\
Entendi pouco & - & - \\
Entendi mais ou menos & - & - \\
Entendi & 14 & 37,8 \\
Entendi plenamente & 23 & 62,2 \\
\hline Total & 37 & 100,0 \\
\hline Fonte: originada da pesquisa. & &
\end{tabular}

A compreensão no pré-teste para o item C8 (Tabela 28) foi de 100\%. A primeira tradução foi: Este consultório é mais desorganizado que deveria ser. Assim, foi realizada adaptação antes da avaliação dos especialistas para a forma apresentada na tabela 28 , visto que não é aceitável que um serviço seja desorganizado. 
Tabela 28 - Frequência das opções de respostas da amostra do pré-teste, seção C, item 8. Brasília - DF, 2015.

Neste serviço a desorganização é maior que o aceitável.

\begin{tabular}{lcc}
\hline Opções de resposta & $\mathrm{N}$ & $\%$ \\
\hline Não entendi & - & - \\
Entendi pouco & - & - \\
Entendi mais ou menos & - & - \\
Entendi & 12 & 32,4 \\
Entendi plenamente & 25 & 67,6 \\
\hline Total & 37 & 100,0 \\
\hline Fonte: originada da pesquisa. & &
\end{tabular}

A tabela 29 demonstra 89,2\% de compreensão do item C9. Na avaliação dos especialistas, foi sugerido retirar a palavra "bons" e manter somente "procedimentos", devido à dificuldade de caracterizar o que é um bom procedimento.

Tabela 29 - Frequência das opções de respostas da amostra do pré-teste, seção C, item 9. Brasília - DF, 2015.

Neste serviço temos procedimentos para verificar se o trabalho foi realizado corretamente.

\begin{tabular}{lcc}
\hline Opções de resposta & $\mathrm{N}$ & $\%$ \\
\hline Não entendi & - & - \\
Entendi pouco & - & - \\
Entendi mais ou menos & 4 & 10,8 \\
Entendi & 8 & 21,6 \\
Entendi plenamente & 25 & 67,6 \\
\hline Total & 37 & 100,0 \\
\hline Fonte: originada da pesquisa. & &
\end{tabular}

A tabela 30 apresenta o item C10 com nível de 94,6\% de compreensão. Foi sugerido substituir a frase: "funcionários da equipe deste consultório" para "profissionais que trabalham neste serviço".

Tabela 30 - Frequência das opções de respostas da amostra do pré-teste, seção C, item 10. Brasília - DF, 2015.

Os profissionais que trabalham neste serviço são solicitados a realizar tarefas para as quais não foram treinados.

\begin{tabular}{lcc}
\hline Opções de resposta & $\mathrm{N}$ & $\%$ \\
\hline Não entendi & 1 & 2,7 \\
Entendi pouco & 1 & 2,7 \\
Entendi mais ou menos & - & - \\
Entendi & 9 & 24,3 \\
Entendi plenamente & 26 & 70,3 \\
\hline Total & 37 & 100,0 \\
\hline
\end{tabular}

Fonte: originada da pesquisa. 
O item 11 da Seção C obteve 94,6\% de compreensão no pré-teste, conforme as opções de respostas pelos especialistas (Tabela 31).

Tabela 31 - Frequência das opções de respostas da amostra do pré-teste, seção C, item 11. Brasília - DF, 2015.

Neste serviço a quantidade de profissionais da equipe é suficiente para atender o número de pacientes.

\begin{tabular}{lcc}
\hline Opções de resposta & $\mathrm{N}$ & $\%$ \\
\hline Não entendi & - & - \\
Entendi pouco & - & - \\
Entendi mais ou menos & 2 & 5,4 \\
Entendi & 10 & 27,0 \\
Entendi plenamente & 25 & 67,6 \\
\hline Total & 37 & 100,0 \\
\hline
\end{tabular}

Fonte: originada da pesquisa.

De acordo com as opções de resposta, obteve-se total de 91,9\% de compreensão do item C12, seção C (Tabela 32).

Tabela 32 - Frequência das opções de respostas da amostra do pré-teste, seção C, item 12. Brasília - DF, 2015.

Neste serviço temos problemas com o fluxo de trabalho.

\begin{tabular}{lcc}
\hline Opções de resposta & $\mathrm{N}$ & $\%$ \\
\hline Não entendi & - & - \\
Entendi pouco & - & - \\
Entendi mais ou menos & 2 & 5,4 \\
Entendi & 9 & 24,3 \\
Entendi plenamente & 25 & 67,6 \\
Sem resposta & 1 & 2,7 \\
\hline Total & 37 & 100,0 \\
\hline
\end{tabular}

Fonte: originada da pesquisa.

Um total de 97,3\% de compreensão do item 13 da seção $C$ foi obtido, de acordo com as opções de respostas. Foi sugerido pelos especialistas e modificada a palavra "enfatiza" para "valoriza", assim reformulado este item. 
Tabela 33 - Frequência das opções de respostas da amostra do pré-teste, seção C, item 13. Brasília - DF, 2015.

Este serviço valoriza o trabalho em equipe no cuidado aos pacientes.

\begin{tabular}{lcc}
\hline Opções de resposta & $\mathrm{N}$ & $\%$ \\
\hline Não entendi & - & - \\
Entendi pouco & - & - \\
Entendi mais ou menos & 1 & 2,7 \\
Entendi & 8 & 21,6 \\
Entendi plenamente & 28 & 75,7 \\
\hline Total & 37 & 100,0 \\
\hline Fonte: originada da pesquisa.
\end{tabular}

Fonte: originada da pesquisa.

Na tabela 34 a compreensão foi 97,3 no pré-teste. A tradução inicial foi: "este consultório tem pacientes demais para ser capaz de cuidar de tudo eficazmente". Portanto, foi realizada adaptação para melhorar a clareza do item.

Tabela 34 - Frequência das opções de respostas da amostra do pré-teste, seção C, item 14. Brasília - DF, 2015.

Neste serviço há número maior de pacientes que a capacidade para atendê-los de maneira eficiente.

\begin{tabular}{lcc}
\hline Opções de resposta & $\mathrm{N}$ & $\%$ \\
\hline Não entendi & - & - \\
Entendi pouco & - & - \\
Entendi mais ou menos & 1 & 2,7 \\
Entendi & 10 & 27,0 \\
Entendi plenamente & 26 & 70,3 \\
\hline Total & 37 & 100,0 \\
\hline
\end{tabular}

Fonte: originada da pesquisa.

A tradução inicial foi: "A equipe deste consultório segue processos padronizados para cumprir tarefas". Com a sugestão dos especialistas e do grupo de população-alvo, o item 15 da seção C foi adaptado e apresentou compreensão de 97,3\% (Tabela 35). 
Tabela 35 - Frequência das opções de respostas da amostra do pré-teste, seção C, item 15. Brasília - DF, 2015.

\begin{tabular}{lccc}
\hline $\begin{array}{l}\text { A equipe deste serviço segue processos padronizados } \\
\text { atividades. }\end{array}$ & para & realizar suas \\
\hline Opções de resposta & $\mathrm{N}$ & $\%$ \\
\hline Não entendi & - & - \\
Entendi pouco & - & - \\
Entendi mais ou menos & 1 & 2,7 \\
Entendi & 10 & 27,0 \\
Entendi plenamente & 26 & 70,3 \\
\hline Total & 37 & 100,0 \\
\hline Fonte: originada da pesquisa & & &
\end{tabular}

Fonte: originada da pesquisa.

O item 1 da seção $D$ passou por adaptações significativas em relação a sua apresentação inicial: "Os provedores deste consultório são abertos para as ideias da equipe sobre como melhorar os processos do consultório." Assim, a compreensão apresentada foi de 97,3\% (Tabela 36).

Tabela 36 - Frequência das opções de respostas da amostra do pré-teste, seção D, item 1. Brasília - DF, 2015.

Os médicos deste serviço estão abertos para as ideias dos demais integrantes da equipe sobre como melhorar os processos de trabalho.

\begin{tabular}{lcc}
\hline Opções de resposta & $\mathrm{N}$ & $\%$ \\
\hline Não entendi & - & - \\
Entendi pouco & - & - \\
Entendi mais ou menos & 1 & 2,7 \\
Entendi & 11 & 29,7 \\
Entendi plenamente & 25 & 67,6 \\
\hline Total & 37 & 100,0 \\
\hline
\end{tabular}

Fonte: originada da pesquisa.

A tradução inicial do item 2 seção D foi: "A equipe é incentivada a expressar pontos de vista alternativos neste consultório.” Assim, como no item anterior, foi modificada a palavra "consultório" para "serviço" por considerar mais abrangente. Após as adaptações o item atingiu $100 \%$ de compreensão no pré-teste (Tabela 37). 
Tabela 37 - Frequência das opções de respostas da amostra do pré-teste, seção D, item 2. Brasília - DF, 2015.

Neste serviço a equipe é incentivada a expressar outros pontos de vista.

\begin{tabular}{lcc}
\hline Opções de resposta & $\mathrm{N}$ & $\%$ \\
\hline Não entendi & - & - \\
Entendi pouco & - & - \\
Entendi mais ou menos & - & - \\
Entendi & 11 & 29,7 \\
Entendi plenamente & 26 & 70,3 \\
\hline Total & 37 & 100,0 \\
\hline Fonte: originada da pesquisa. & &
\end{tabular}

Obteve-se um total de $94,6 \%$ na compreensão do item 3 , seção D, de acordo com as opções assinaladas no pré-teste (Tabela 38).

Tabela 38 - Frequência das opções de respostas da amostra do pré-teste, seção D, item 3. Brasília - DF, 2015.

Neste serviço os pacientes são avisados quando precisam agendar uma consulta para cuidados preventivos ou de rotina.

\begin{tabular}{lcc}
\hline Opções de resposta & $\mathrm{N}$ & $\%$ \\
\hline Não entendi & - & - \\
Entendi pouco & - & - \\
Entendi mais ou menos & 2 & 5,4 \\
Entendi & 9 & 24,3 \\
Entendi plenamente & 26 & 70,3 \\
\hline Total & 37 & 100,0 \\
\hline
\end{tabular}

Fonte: originada da pesquisa.

A tabela 39 apresenta as opções de respostas no pré-teste, com compreensão de 97,3\%. Neste item somente foi substituída a palavra "medo" por "receio".

Tabela 39 - Frequência das opções de respostas da amostra do pré-teste, seção D, item 4. Brasília - DF, 2015.

Neste serviço a equipe tem receio de fazer perguntas quando algo não parece correto.

\begin{tabular}{lcc}
\hline Opções de resposta & $\mathrm{N}$ & $\%$ \\
\hline Não entendi & - & - \\
Entendi pouco & - & - \\
Entendi mais ou menos & 1 & 2,7 \\
Entendi & 10 & 27,0 \\
Entendi plenamente & 26 & 70,3 \\
\hline Total & 37 & 100,0 \\
\hline
\end{tabular}

Fonte: originada da pesquisa. 
A compreensão no item 5, seção $\mathrm{D}$, foi de 94,6\% (Tabela 40), sendo somente substituída a palavra "forma" por "maneira" (Tabela 40).

Tabela 40 - Frequência das opções de respostas da amostra do pré-teste, seção D, Item 5. Brasília - DF, 2015.

\begin{tabular}{lcc}
\hline $\begin{array}{l}\text { Este serviço registra a maneira como pacientes crônicos seguem o plano de } \\
\text { tratamento. }\end{array}$ & $\mathrm{N}$ & $\%$ \\
\hline Opções de resposta & - & - \\
\hline Não entendi & - & - \\
Entendi pouco & 1 & 2,7 \\
Entendi mais ou menos & 15 & 40,5 \\
Entendi & 20 & 54,1 \\
Entendi plenamente & 1 & 2,7 \\
Sem resposta & 37 & 100,0 \\
\hline Total &
\end{tabular}

Fonte: originada da pesquisa.

O item $\mathrm{D}$, seção 6, gerou dúvidas na fase de análise dos especialistas, em relação à expressão "faz acompanhamento" os questionamentos foram relacionados à forma de acompanhamento "solicita" ou "cobra". No pré-teste, a compreensão foi 83,5\% (Tabela 41), ou seja, menor em relação aos demais itens, mesmo assim manteve-se acima de $80 \%$.

Tabela 41 - Frequência das opções de respostas da amostra do pré-teste, seção D, item 6. Brasília - DF, 2015.

Nosso serviço faz acompanhamento quando não recebemos um relatório esperado de outro serviço.

\begin{tabular}{lcc}
\hline Opções de resposta & $\mathrm{N}$ & $\%$ \\
\hline Não entendi & 1 & 2,7 \\
Entendi pouco & 2 & 5,4 \\
Entendi mais ou menos & 3 & 8,1 \\
Entendi & 15 & 40,5 \\
Entendi plenamente & 16 & 43,3 \\
\hline Total & 37 & 100,0 \\
\hline
\end{tabular}

Fonte: originada da pesquisa.

A tradução inicial do item 7 , seção $D$, foi: “A equipe sente que seus erros são usados contra ela". Foi realizada adaptação para melhorar a clareza, portanto, a compreensão no préteste foi de $89,2 \%$ (Tabela 42 ). 
Tabela 42 - Frequência das opções de respostas da amostra do pré-teste, seção D, item 7. Brasília - DF, 2015.

A equipe deste serviço acredita que seus erros possam ser usados contra si.

\begin{tabular}{lcc}
\hline Opções de resposta & $\mathrm{N}$ & $\%$ \\
\hline Não entendi & 1 & 2,7 \\
Entendi pouco & 2 & 5,4 \\
Entendi mais ou menos & 1 & 2,7 \\
Entendi & 9 & 24,3 \\
Entendi plenamente & 24 & 64,9 \\
\hline Total & 37 & 100,0 \\
\hline Fonte:
\end{tabular}

Fonte: originada da pesquisa.

O item D8 apresentou compreensão de 94,6\% (Tabela 43), sendo somente realizado adaptações em relação à versão inicial, conforme comparação apresentada no apêndice 3.

Tabela 43 - Frequência das opções de respostas da amostra do pré-teste, seção D, item 8. Brasília - DF, 2015.

A equipe fala abertamente sobre os problemas neste serviço.

\begin{tabular}{lcc}
\hline Opções de resposta & $\mathrm{N}$ & $\%$ \\
\hline Não entendi & - & - \\
Entendi pouco & - & - \\
Entendi mais ou menos & 2 & 5,4 \\
Entendi & 12 & 32,4 \\
Entendi plenamente & 23 & 62,2 \\
\hline Total & 37 & 100,0 \\
\hline Fonte: originada da pesquisa. & &
\end{tabular}

A compreensão do item 9 da seção D foi 94,6\% no pré-teste (Tabela 44).

Tabela 44 - Frequência das opções de respostas da amostra do pré-teste, seção D, item 9. Brasília - DF, 2015.

Este serviço acompanha os pacientes que precisam de monitoramento.

\begin{tabular}{lcc}
\hline Opções de resposta & $\mathrm{N}$ & $\%$ \\
\hline Não entendi & - & - \\
Entendi pouco & 1 & 2,7 \\
Entendi mais ou menos & 1 & 2,7 \\
Entendi & 10 & 27,0 \\
Entendi plenamente & 25 & 67,6 \\
\hline Total & 37 & 100,0 \\
\hline Fonte: originada da pesquisa. & & \\
O Item 10 da seção D apresentou compreensão de 91,9\% (Tabela 45), portanto sem
\end{tabular}
necessidade de adaptações. 
Tabela 45 - Frequência das opções de respostas da amostra do pré-teste, seção D, item 10. Brasília - DF, 2015.

\section{Neste serviço é difícil expressar opiniões diferentes.}

\begin{tabular}{lcc}
\hline Opções de resposta & $\mathrm{N}$ & $\%$ \\
\hline Não entendi & - & - \\
Entendi pouco & - & - \\
Entendi mais ou menos & 2 & 5,4 \\
Entendi & 10 & 27,0 \\
Entendi plenamente & 24 & 64,9 \\
Sem resposta & 1 & 2,7 \\
\hline Total & 37 & 100,0 \\
\hline Fonte: originada da pesquisa. & \multicolumn{3}{c}{}
\end{tabular}

Na tabela 46 item 11 da seção $\mathrm{D}$, apresentou compreensão de 97,3\%. O item foi adaptado somente alterando a palavra "forma" para "maneira".

Tabela 46 - Frequência das opções de respostas da amostra do pré-teste, seção D, item 11. Brasília - DF, 2015.

Neste serviço discutimos maneiras de evitar que erros aconteçam novamente.

\begin{tabular}{lcc}
\hline Opções de resposta & $\mathrm{N}$ & $\%$ \\
\hline Não entendi & - & - \\
Entendi pouco & - & - \\
Entendi mais ou menos & 1 & 2,7 \\
Entendi & 11 & 29,7 \\
Entendi plenamente & 25 & 67,6 \\
\hline Total & 37 & 100,0 \\
\hline Fonte: originada da pesquisa. & &
\end{tabular}

O Item D da seção 12 obteve compreensão de 97,3\% no pré-teste (Tabela 47), não necessitando de adaptações, mas somente foi substituído o termo "reportar" por "relatar".

Tabela 47 - Frequência das opções de respostas da amostra do pré-teste, seção D, item 12. Brasília - DF, 2015.

Os funcionários estão dispostos a relatar erros que observam neste serviço.

\begin{tabular}{lcc}
\hline Opções de resposta & $\mathrm{N}$ & $\%$ \\
\hline Não entendi & - & - \\
Entendi pouco & - & - \\
Entendi mais ou menos & 1 & 2,7 \\
Entendi & 10 & 27,0 \\
Entendi plenamente & 26 & 70,3 \\
\hline Total & 37 & 100,0 \\
\hline
\end{tabular}

Fonte: originada da pesquisa. 
A tabela 48 apresenta o item 1 da Seção E, com 89,2 \% de compreensão. A adaptação realizada, conforme sugestões foi alterar o enunciado da questão de: "proprietários/sócios diretores/líderes do seu consultório médico" para "gestores/administradores/líderes".

Tabela 48 - Frequência das opções de respostas da amostra do pré-teste, seção E, item 1. Brasília - DF, 2015.

Eles não estão investindo recursos suficientes para melhorar a qualidade do cuidado neste serviço.

\begin{tabular}{lcc}
\hline Opções de resposta & $\mathrm{N}$ & $\%$ \\
\hline Não entendi & 1 & 2,7 \\
Entendi pouco & - & - \\
Entendi mais ou menos & 3 & 8,1 \\
Entendi & 12 & 32,4 \\
Entendi plenamente & 21 & 56,8 \\
\hline Total & 37 & 100,0 \\
\hline
\end{tabular}

Fonte: originada da pesquisa.

Na tabela 49, seção E, item 2, observa-se a compreensão de 91,9\%. Não foi necessário realizar adaptações no item.

Tabela 49 - Frequência das opções de respostas da amostra do pré-teste, seção E, item 2. Brasília - DF, 2015.

Eles ignoram erros que se repetem no cuidado aos pacientes.

\begin{tabular}{lcc}
\hline Opções de resposta & $\mathrm{N}$ & $\%$ \\
\hline Não entendi & 1 & 2,7 \\
Entendi pouco & 1 & 2,7 \\
Entendi mais ou menos & 1 & 2,7 \\
Entendi & 14 & 37,8 \\
Entendi plenamente & 20 & 54,1 \\
\hline Total & 37 & 100,0 \\
\hline Fonte: originada da pesquisa.
\end{tabular}

A compreensão do item 3, seção E, demonstrada na tabela 50 foi de 86,5 \%. Antes do pré-teste foram realizadas adaptações para melhorar a redação do item, sendo inicialmente traduzido da seguinte forma: "Eles dão alta prioridade ao aprimoramento dos processos de cuidado aos pacientes". A sugestão dos especialistas foi retirar a palavra alta por considerar redundante. Outra alteração foi a troca da palavra "cuidado" para "atendimento", porque reflete de maneira mais ampla, desde o acolhimento do paciente na unidade até o atendimento com os profissionais de saúde, bem como nos setores que compõem o serviço, como farmácia e laboratório, ou seja, em todos os ambientes de atendimento que compõem o serviço. 
Tabela 50 - Frequência das opções de respostas da amostra do pré-teste, seção E, item 3. Brasília - DF, 2015.

Eles dão prioridade à melhoria dos processos de atendimento aos pacientes.

\begin{tabular}{lcc}
\hline Opções de resposta & $\mathrm{N}$ & $\%$ \\
\hline Não entendi & 1 & 2,7 \\
Entendi pouco & 1 & 2,7 \\
Entendi mais ou menos & 3 & 8,1 \\
Entendi & 13 & 35,1 \\
Entendi plenamente & 19 & 51,4 \\
\hline Total & 37 & 100,0 \\
\hline Fonte: originada da pesquisa. & \multicolumn{3}{l}{}
\end{tabular}

A tabela 51 apresenta o item 4 da seção E com nível de compreensão de 91,9\%, não sendo necessário adaptações para este item.

Tabela 51 - Frequência das opções de respostas da amostra do pré-teste, seção E, item 4. Brasília - DF, 2015.

\begin{tabular}{lcc}
\hline $\begin{array}{l}\text { Eles frequentemente tomam decisões baseadas no que é melhor para o serviço e não } \\
\text { no que é melhor para os pacientes. }\end{array}$ \\
\hline Opções de resposta & $\mathrm{N}$ & $\%$ \\
\hline Não entendi & 1 & 2,7 \\
Entendi pouco & 1 & 2,7 \\
Entendi mais ou menos & 1 & 2,7 \\
Entendi & 13 & 35,1 \\
Entendi plenamente & 21 & 56,8 \\
\hline Total & 37 & 100,0 \\
\hline Fonte: originada da pesquisa. & \multicolumn{3}{c}{}
\end{tabular}

A compreensão apresentada na tabela 52, do item 1, seção F, foi de 89,2\%. Somente foi realizada uma adaptação, sendo substituído "existe" por "há um problema".

Tabela 52 - Frequência das opções de respostas da amostra do pré-teste, seção F, item 1. Brasília - DF, 2015.

Quando há um problema em nosso serviço avaliamos se é necessário mudar a maneira como fazemos as coisas.

\begin{tabular}{lcc}
\hline Opções de resposta & $\mathrm{N}$ & $\%$ \\
\hline Não entendi & - & - \\
Entendi pouco & - & - \\
Entendi mais ou menos & - & - \\
Entendi & 9 & 24,3 \\
Entendi plenamente & 24 & 64,9 \\
Sem resposta & 4 & 10,8 \\
\hline Total & 37 & 100,0 \\
\hline Fonte: originada da pesquisa. & &
\end{tabular}

Fonte: originada da pesquisa. 
Na tabela 53, o item 2 da seção F, obteve 91,9\% de compreensão. O item sofreu adaptação para melhorar a redação, que anteriormente estava da seguinte forma: "Nossos processos são bons em prevenir erros que poderiam afetar os pacientes”.

Tabela 53 - Frequência das opções de respostas da amostra do pré-teste, seção F, item 2. Brasília - DF, 2015.

\begin{tabular}{lcc}
\hline $\begin{array}{l}\text { Nossos processos de trabalho são adequados para prevenir erros que poderiam } \\
\text { afetar os pacientes. }\end{array}$ & $\mathrm{N}$ & $\%$ \\
\hline Opções de resposta & - & - \\
\hline Não entendi & - & - \\
Entendi pouco & - & - \\
Entendi mais ou menos & 11 & 29,7 \\
Entendi & 23 & 62,2 \\
Entendi plenamente & 3 & 8,1 \\
Sem resposta & 37 & 100,0 \\
\hline Total & &
\end{tabular}

Na tabela 54, o item 3 da seção $F$, apresentou 86,5 \% de compreensão. Não foram necessárias adaptações no item.

Tabela 54 - Frequência das opções de respostas da amostra do pré-teste, seção F, item 3. Brasília - DF, 2015.

Neste serviço acontecem erros com mais frequência do que deveriam.

\begin{tabular}{lcc}
\hline Opções de resposta & $\mathrm{N}$ & $\%$ \\
\hline Não entendi & - & - \\
Entendi pouco & 1 & 2,7 \\
Entendi mais ou menos & - & - \\
Entendi & 11 & 29,7 \\
Entendi plenamente & 21 & 56,8 \\
Sem resposta & 4 & 10,8 \\
\hline Total & 37 & 100,0 \\
\hline
\end{tabular}

Fonte: originada da pesquisa.

O item 4 da seção $F$ apresentou compreensão de 75,6\% (Tabela 55). Esse item apresentou avaliação inferior em relação aos demais itens. A percepção é que este item é impactante, porque requer autoavaliação e inclui a pessoa para a qual está sendo perguntado, fato que pode ter contribuído para o resultado e também porque quatro participantes não responderam o item. 
Tabela 55 - Frequência das opções de respostas da amostra do pré-teste, seção F, item 4. Brasília - DF, 2015.

É apenas por acaso que não cometemos mais erros que afetam nossos pacientes.

\begin{tabular}{lcc}
\hline Opções de resposta & $\mathrm{N}$ & $\%$ \\
\hline Não entendi & - & - \\
Entendi pouco & 1 & 2,7 \\
Entendi mais ou menos & 5 & 13,5 \\
Entendi & 13 & 35,2 \\
Entendi plenamente & 15 & 40,5 \\
Sem resposta & 3 & 8,1 \\
\hline Total & 37 & 100,0 \\
\hline
\end{tabular}

Fonte: originada da pesquisa.

Na tabela 56 observa-se que o item 5, seção F, obteve $86,5 \%$ de compreensão. Foram realizadas algumas adaptações na redação do item, para melhorar a redação e clareza, a tradução inicial era "Este consultório é bom em mudar processos para garantir que os mesmos problemas não voltem a ocorrer".

Tabela 56 - Frequência das opções de respostas da amostra do pré-teste, seção F, item 5. Brasília - DF, 2015.

Este serviço é eficiente em modificar processos de trabalho para prevenir que problemas se repitam.

\begin{tabular}{ccc}
\hline Opções de resposta & $\mathrm{N}$ & $\%$ \\
\hline Não entendi & - & - \\
Entendi pouco & - & - \\
Entendi mais ou menos & 2 & 5,4 \\
Entendi & 11 & 29,7 \\
Entendi plenamente & 21 & 56,8 \\
Sem resposta & 3 & 8,1 \\
\hline Total & 37 & 100,0 \\
\hline
\end{tabular}

Fonte: originada da pesquisa.

A tabela 57 demonstra que o item 6, seção $\mathrm{F}$ obteve 86,5\% de compreensão, foram necessárias pequenas adaptações em relação à versão inicial. 
Tabela 57 - Frequência das opções de respostas da amostra do pré-teste, seção F, item 6. Brasília - DF, 2015.

\begin{tabular}{lcc}
\hline $\begin{array}{l}\text { Neste serviço a quantidade de atividades realizadas é mais importante que a } \\
\text { qualidade do cuidado prestado. }\end{array}$ & $\mathrm{N}$ & $\%$ \\
\hline Opções de resposta & 1 & 2,7 \\
\hline Não entendi & 1 & 2,7 \\
Entendi pouco & - & - \\
Entendi mais ou menos & 11 & 29,7 \\
Entendi & 21 & 56,8 \\
Entendi plenamente & 3 & 8,1 \\
Sem resposta & 37 & 100,0 \\
\hline Total
\end{tabular}

Fonte: originada da pesquisa.

A tabela 58 demonstra que o item 7, seção F obteve compreensão 91,9\% no pré-teste. Foram realizadas pequenas adaptações em relação à versão inicial, com a seguinte redação: “Após mudanças realizadas neste consultório para melhorar o processo de atendimento ao paciente, verificamos se as mudanças funcionaram".

Tabela 58 - Frequência das opções de respostas da amostra do pré-teste, seção F, item 7. Brasília - DF, 2015.

Neste serviço, após realizarmos mudanças para melhorar o processo de atendimento ao paciente, avaliamos se elas funcionaram.

\begin{tabular}{lcc}
\hline Opções de resposta & $\mathrm{N}$ & $\%$ \\
\hline Não entendi & - & - \\
Entendi pouco & - & - \\
Entendi mais ou menos & - & - \\
Entendi & 13 & 35,1 \\
Entendi plenamente & 21 & 56,8 \\
Sem resposta & 3 & 8,1 \\
\hline Total & 37 & 100,0 \\
\hline
\end{tabular}

Fonte: originada da pesquisa.

A tabela 59, seção $G$, item 1a demonstra que a compreensão foi de 89,2\% para esta questão, sendo realizadas apenas adaptações nas opções de frequência das respostas, ao invés de "fraco" foi alterado para "ruim" em todos os itens da seção. 
Tabela 59 - Frequência das opções de respostas da amostra do pré-teste, seção G, item 1a. Brasília - DF, 2015.

\begin{tabular}{lcc}
\hline $\begin{array}{l}\text { Centrado no paciente: } \mathbf{E} \\
\text { valores dos pacientes. }\end{array}$ & \multicolumn{1}{c}{ sensível às preferências individuais, necessidades e } \\
\hline Opções de resposta & 1 & $\%$ \\
\hline Não entendi & 1 & 2,7 \\
Entendi pouco & 2 & 5,4 \\
Entendi mais ou menos & 14 & 37,8 \\
Entendi & 19 & 51,4 \\
Entendi plenamente & 37 & 100,0 \\
\hline Total &
\end{tabular}

Fonte: originada da pesquisa.

O item 2 da seção $\mathrm{G}$ apresentou compreensão de $91,9 \%$, e não houve necessidade de adaptações (Tabela 60).

Tabela 60 - Frequência das opções de respostas da amostra do pré-teste, seção G, item b. Brasília - DF, 2015.

Efetivo: É baseado no conhecimento científico.

\begin{tabular}{lcc}
\hline Opções de resposta & $\mathrm{N}$ & $\%$ \\
\hline Não entendi & - & - \\
Entendi pouco & - & - \\
Entendi mais ou menos & 3 & 8,1 \\
Entendi & 14 & 37,8 \\
Entendi plenamente & 20 & 54,1 \\
\hline Total & 37 & 100,0 \\
\hline
\end{tabular}

Fonte: originada da pesquisa.

A tabela 61 apresenta compreensão 91,9\%, do item c, seção G, sem necessidade de adaptações.

Tabela 61 - Frequência das opções de respostas da amostra do pré-teste, seção G, item c. Brasília - DF, 2015.

\section{Pontual: Minimiza esperas e atrasos potencialmente prejudiciais.}

\begin{tabular}{lcc}
\hline Opções de resposta & $\mathrm{N}$ & $\%$ \\
\hline Não entendi & - & - \\
Entendi pouco & - & - \\
Entendi mais ou menos & 2 & 5,4 \\
Entendi & 14 & 37,8 \\
Entendi plenamente & 20 & 54,1 \\
Sem resposta & 1 & 2,7 \\
\hline Total & 37 & 100,0
\end{tabular}

Fonte: originada da pesquisa. 
A tabela 62 demonstrou compreensão em $100 \%$ do item d, seção $G$, não sendo necessárias adaptações para o item.

Tabela 62 - Frequência das opções de respostas da amostra do pré-teste, seção G, item d. Brasília - DF, 2015.

Eficiente: Garante um cuidado de bom custo-benefício (evita o desperdício, uso excessivo e incorreto de serviços).

\begin{tabular}{lcc}
\hline Opções de resposta & $\mathrm{N}$ & $\%$ \\
\hline Não entendi & - & - \\
Entendi pouco & - & - \\
Entendi mais ou menos & - & - \\
Entendi & 20 & 54,1 \\
Entendi plenamente & 17 & 45,9 \\
\hline Total & 37 & 100,0 \\
\hline
\end{tabular}

Fonte: originada da pesquisa.

O item "e" seção G apresentou compreensão de 100\% (Tabela 63), sem necessidade de adaptações. Foi somente modificada a palavra "equitativa" que havia sido alterada após a avaliação dos especialistas, no entanto, optou-se pela palavra "imparcial", por acreditar que apresenta melhor compreensão.

Tabela 63 - Frequência das opções de respostas da amostra do pré-teste, seção G, item e. Brasília - DF, 2015.

Imparcial: Fornece a mesma qualidade de cuidados a todos os indivíduos, independentemente de gênero, etnia, status socioeconômico, idioma, etc...

\begin{tabular}{lcc}
\hline Opções de resposta & $\mathrm{N}$ & $\%$ \\
\hline Não entendi & - & - \\
Entendi pouco & - & - \\
Entendi mais ou menos & - & - \\
Entendi & 15 & 40,5 \\
Entendi plenamente & 22 & 59,5 \\
\hline Total & 37 & 100,0 \\
\hline
\end{tabular}

Fonte: originada da pesquisa.

O último item, do instrumento, apresentou 86,5\% de compreensão, sem necessidade de adaptações. Foi somente alterado as opções de frequência de respostas de "pobre" para "ruim" (Tabela 64). 
Tabela 64 - Frequência das opções de respostas da amostra do pré-teste, seção G, item 2. Brasília - DF, 2015.

No geral, como você classificaria os sistemas e processos clínicos que o seu serviço utiliza para prevenir, identificar e corrigir problemas que tenham o potencial de afetar pacientes?

\begin{tabular}{lcc}
\hline Opções de resposta & $\mathrm{N}$ & $\%$ \\
\hline Não entendi & 1 & 2,7 \\
Entendi pouco & 1 & 2,7 \\
Entendi mais ou menos & 2 & 5,4 \\
Entendi & 12 & 32,4 \\
Entendi plenamente & 20 & 54,1 \\
Sem resposta & 1 & 2,7 \\
\hline Total & 37 & 100,0 \\
\hline
\end{tabular}

Fonte: originada da pesquisa. 


\section{DISCUSSÃO}

A utilização de um método consistente para o processo de tradução, adaptação transcultural e validação de instrumento de pesquisa é essencial (SOUSA; ROJJANASRIRAT, 2011). Neste estudo, as etapas foram cuidadosamente acompanhadas, analisadas e documentadas, para atingir um melhor nível de consistência.

Um instrumento robusto, bem desenvolvido, com validade e confiabilidade dos dados na versão de origem, rigorosamente adaptado e traduzido em diversas línguas, permite comparar os resultados internacionalmente, em diversas culturas (TUTHILL et al., 2014). A mensuração confiável dos serviços de saúde para identificar os resultados de segurança do paciente é o primeiro desafio para a análise comparativa (HARADA; PEDREIRA, 2013). A validade está relacionada à verificação se um instrumento realmente mede aquilo que se propõe a medir. Já a confiabilidade está relacionada com a isenção de erros aleatórios, ou seja, os resultados são os mesmos ao repetir o estudo (HORA et al., 2010).

As etapas da pesquisa foram utilizadas para apoiar a equivalência conceitual, semântica e de conteúdo do instrumento a ser traduzido. A etapa de análise de conteúdo foi realizada por especialistas. De acordo com a referência metodológica utilizada, um número de seis especialistas é suficiente para obtenção da validade de conteúdo (PASQUALI, 1998; SOUSA; ROJJANASRIRAT, 2011; ALEXANDRE; COLUCI, 2011). Para tanto, seguiu-se criteriosa seleção dos mesmos, para assegurar a qualidade da avaliação realizada.

Os procedimentos experimentais consistem em coletar informação empírica válida e submetê-la às análises estatísticas pertinentes em Psicometria (PASQUALI,1998). A análise semântica foi realizada por meio do grupo de população-alvo, com avaliação da compreensão e validade aparente. Os itens foram revisados e modificados, para aprimorar a compreensão e clareza, conforme as sugestões.

O processo de realização da pesquisa envolveu algumas questões complexas, como observado na seção A, que se referiu a questões gerais relacionadas à segurança e à qualidade, a qual foi alvo de maior número de sugestões de adaptações, tanto na fase de análise dos especialistas quanto na avaliação pelo grupo de população-alvo. Um fator que contribuiu para redução do Índice de Validade de Conteúdo nessa seção foi a avaliação de um dos especialistas, que graduou todos os itens como "pouco claro", não em relação à pergunta, mas sim na frequência de resposta. Sugeriu-se substituir as opções de resposta "semanalmente" ou "mensalmente" por "pelo menos uma vez na semana" e "pelo menos uma vez ao mês", respectivamente. 
$\mathrm{Na}$ seção $\mathrm{H}$, realizaram-se adaptações das categorias profissionais que compõem os serviços da Atenção Primária no Brasil, considerando que o tema engloba a estrutura organizacional e a equipe multiprofissional. Da mesma forma, outro estudo de tradução e validação de instrumento para uso em hospitais realizou essa adaptação (REIS et al, 2012).

Não foi excluído nenhum item do instrumento de avaliação, pelo contrário, foi acrescentado o item 8 na seção A, sugerido pelo grupo de população-alvo. $\mathrm{O}$ item refere-se ao acesso à realização dos exames, em tempo hábil. Esse fato interfere diretamente na segurança, porque dificulta diagnóstico e tratamento adequados. No entanto, acredita-se que o elevado número de questões do instrumento pode interferir na aderência à pesquisa. Cabe destacar que, em outro estudo, foi igualmente sugerido que seria mais apropriado menor número de itens (TORIJANO-CASALENGUA et al, 2013).

A análise da consistência interna foi realizada por meio da aplicação do pré-teste que avaliou a compreensão e a confiabilidade do instrumento, utilizando-se o coeficiente alfa de Cronbach, com resultado de 0,95 , valor semelhante de 0,96 foi encontrado na validação do instrumento para o espanhol (TORIJANO-CASALENGUA et al., 2013). Em outro estudo de validação de questionário de atitude de segurança para o Brasil o alfa de Cronbach foi de 0,89 (CARVALHO; CASSIANI, 2012).

A expressão "lista de medicamentos", da Seção A item 7, foi questionada pelos juízes, justificado pelo fato que no Brasil os pacientes recebem receita médica, não é comum a utilização da lista de medicamentos como instrumento de conciliação dos medicamentos que um paciente faz uso.

A reconciliação de medicação é utilizada por profissionais de saúde para levantar uma lista completa e precisa dos medicamentos prescritos para um paciente, para identificar discrepâncias nos regimes de drogas em diferentes níveis de atenção, ambientes de cuidados, ou pontos no tempo. Essa informação é usada para informar decisões de prescrição, identificar e prevenir erros (BOOCKVAR, 2006). A lista de medicamentos para conciliação deve incluir todos os possíveis tipos de drogas em uso pelo paciente, como: medicamentos com prescrição médica, medicamentos sem prescrição médica, ervas, suplementos, cogumelos, entre outros. Deve constrar dose, frequência, via e horário da última administração de cada medicamento (COSTA, 2014).

No Brasil essa metodologia de utilizar a lista de medicamentos para conciliação não é uma prática difundida, fato que pode explicar o questionamento, mesmo entre especialistas. Assim, a questão foi modificada para: "Os medicamentos utilizados de um paciente não foram atualizados durante a consulta”. Já o grupo de população-alvo sugeriu substituir 
"atualizados" para "revisados", pelo fato de que no acompanhamento de pacientes com doenças crônicas nem sempre é necessário atualizar a medicação, mas sim revisar. Essa revisão pode ser realizada por outro profissional da equipe, como enfermeiro, farmacêutico ou odontólogo, para avaliar risco de interação medicamentosa ou possíveis eventos adversos.

Desta forma, demonstrou-se na tabela 1 que alguns itens das seções A e B não apresentaram o Índice de Validade de Conteúdo e a Concordância Interavaliadores satisfatórios, ou seja, acima de 0.8 , portanto estes itens foram revisados e modificados, para melhorar a compreensão e clareza, conforme as sugestões dos especialistas e também pelo grupo de população-alvo.

Outro aspecto pouco praticado no Brasil é a troca de informações com outros serviços, referente ao item B do instrumento. Rodríguez-Cogollo et al. (2014), discutem que a necessidade de reforçar a interação entre os vários serviços de assistência da Atenção Primária à Saúde, pode ser corrigida a partir da percepção deficiente da dimensão "troca de informações com outras instituições de assistência".

Esta etapa foi utilizada para apoiar a equivalência conceitual, semântica e de conteúdo do instrumento traduzido (SOUSA; ROJJANASRIRAT, 2011). Embora o processo de validação de conteúdo envolva aspetos relacionados ao desenvolvimento do instrumento, análise e julgamento dos especialistas, é importante a associação com outros processos de validação para que o instrumento produza o efeito esperado, ou seja, ser capaz de mensurar o que se propõe (TUTHILL et al., 2014).

Tanto na fase de avaliação pelos especialistas quanto na avaliação pelo grupo população-alvo, a Seção A foi alvo de maior número de sugestões de adaptações, no restante do instrumento foram necessárias poucas adaptações. Também, na última seção $H$, realizaram-se alterações e adaptações para incluir a maioria das categorias profissionais que compõem os serviços da Atenção Primária à Saúde no Brasil, considerando um tema que abrange a estrutura organizacional e a equipe multiprofissional.

Observa-se na seção "F" que houve um número de três pessoas que não responderam a seção toda, porque provavelmente compreenderam de forma equivocada a orientação em relação à seção "E" que indicava aos gestores/administradores/líderes "Vá para a seção F", possivelmente essas pessoas entenderam que a seção "F" seria exclusiva para os gestores.

Uma vez que a aplicação do pré-teste tem o propósito de testar se os sujeitos compreenderam as instruções e a entrevista consiste em solicitar às pessoas representantes da população-alvo, para opinarem em que tipo de comportamento tal construto se manifesta (MEDEIROS et al, 2015). 
Todas as etapas foram rigorosamente acompanhadas e pautadas em referências consistentes para assegurar a validade do estudo. Um projeto para traduzir, adaptar e validar um instrumento de pesquisa transcultural pode levar vários anos, e é normalmente realizado com base metodológica em mais de um estudo. Pode-se definir como meta inicial traduzir, adaptar e validar um instrumento, posteriormente, realizar o teste psicotécnico completo da versão pré-final do instrumento traduzido em uma amostra do público-alvo (SOUSA e ROJJANASRIRAT, 2011).

A pretensão de um questionário multidisciplinar para a Atenção Primária foi propagada porque cada vez mais aumenta a colaboração e o trabalho em equipe nos serviços de saúde, um questionário genérico estaria em consonância com esta evolução, e reforça o intercâmbio de lições aprendidas (VERBAKEL et al, 2014). Em pesquisa realizada por Sánchez et al. (2013) melhores níveis de segurança foram detectados nos centros de ensino, esses centros são sujeitos a um processo de recredenciamento bianual, fato que pode justificar um melhor comprometimento com a segurança e qualidade. Outro aspecto é que a presença de estudantes no serviço requer atualização constante da equipe.

Todo processo de identificação do problema, elaboração e publicação da política pública de segurança do paciente já foi percorrido no Brasil e algumas ações isoladas de implementação estão sendo efetivadas, no entanto se avançou muito pouco em relação à segurança do paciente nos serviços de saúde no país, sobretudo na Atenção Primária, existe um longo caminho a percorrer até que essa política seja efetivamente implementada, monitorada e avaliada. Espera-se que alcance todos os níveis de atenção e que seja incorporada em todos os serviços como parte essencial do processo de trabalho. Para tanto é necessário o envolvimento da equipe multidisciplinar e a mudança na cultura, considerada base fundamental para percepção do problema e identificação da necessidade dessa mudança objetivando uma assistência mais segura.

O Plano Nacional de Segurança do Paciente institui a implantação do Núcleo de Segurança do Paciente nos serviços ambulatoriais, que dispensam a internação para tratamento ou diagnóstico. No âmbito do Sistema Único de Saúde, podem ser, portanto, os serviços tanto de Atenção Primária quanto de Atenção Secundária. O Núcleo de Segurança do Paciente deve ser composto por uma equipe multidisciplinar, com representatividade dos dois níveis de atenção que compõem o atendimento ambulatorial. Esse plano tem como foco a melhoria do olhar sobre as atividades desenvolvidas cotidianamente e fazer diferente mediante um olhar mais focado nos processos, à luz da gestão de riscos e a definição de boas 
práticas que atendam a cada nível de atenção e complexidade dentro de suas peculiaridades (BRASIL, 2014).

Segundo Vincent (2009) a cultura de segurança dentro de uma organização pode variar acentuadamente em diferentes setores e em diferentes grupos. A enfermagem, por exemplo, tende a ter um código disciplinar mais rígido e atitudes mais duras em relação a erros do que os médicos.

$\mathrm{Na}$ observação de diversas equipes de saúde da família instaladas em um único instrumento de saúde, como por exemplo, em uma clínica da família com oito equipes, observam-se diferentes formas de organização em pequenos núcleos, em que a maneira com que cada equipe desenvolve o seu trabalho é singular, mesmo nos casos em que as equipes tenham as mesmas oportunidades de atualizações e capacitações profissionais. Portanto, a forma com que as pessoas realizam as coisas é influenciada pelas crenças e valores que são construídos ao longo da vida, por isso, as mudanças também são graduais.

Enfim, o estudo não finaliza nas etapas ora desenvolvidas. Para que se possa disponibilizar o instrumento traduzido e adaptado faz-se necessário avaliar sua equivalência operacional e de mensuração, para comprovar suas propriedades psicométricas (REIS et al., 2012). Para isso, deve-se prosseguir em etapas seguintes, iniciando-se com procedimentos experimentais, os quais consistem em coletar informação empírica válida e submetê-la às análises estatísticas pertinentes em Psicometria (PASQUALI, 1998). 


\section{CONCLUSÃO}

Constata-se a originalidade da pesquisa visto que, até o momento, não havia sido realizada a adaptação deste instrumento para o português do Brasil, para ser aplicado em pesquisa na Atenção Primária. A importância da opção de validação de um instrumento testado e amplamente utilizado em outros países já foi bem justificada, com a conclusão destas etapas da pesquisa, o instrumento pode ser utilizado na Atenção Primária em qualquer lugar do Brasil, possibilitando a comparação com estudos realizados em outros locais nacional e internacionalmente. Recomenda-se que seja realizada aplicação do instrumento em ampla escala na população-alvo para avaliação da validade de constructo e realização de Análise Psicométrica.

Buscou-se neste estudo a utilização de um método de adaptação transcultural e validação, aceitos nacional e internacionalmente, mantendo-se o mais alto rigor metodológico. $\mathrm{Na}$ etapa de tradução e retrotradução do instrumento foram selecionandos profissionais com experiência e reconhecimento na realização de validação de instrumento e todas as fases foram acompanhadas pela pesquisadora, orientadora e por uma terceira tradutora bilíngue que coordenou o grupo de tradutores mantendo as recomendações do método.

Cumpriu-se a tradução, adaptação transcultural e validação do instrumento de pesquisa Medical Office Survey on Patient Safety Culture, com análise semântica e avaliação da clareza e compreensão dos itens. Cada etapa foi cuidadosamente acompanhada, registrada e discutida. Realizou-se a análise de validade do conteúdo, esta etapa contribuiu para aprimorar a clareza e forma dos itens do instrumento. Os resultados da pesquisa demonstraram validade de conteúdo satisfatória na análise dos especialistas. Da mesma forma, a etapa de análise do conteúdo semântico realizada pelo grupo multiprofissional de forma interativa, enriqueceu o conteúdo e contribuiu para que fosse compreensível para todos os estratos de escolaridade encotrados no serviço, melhorando a forma das sentenças que suscitaram dúvidas e expressando o que de fato cada item pretendia medir.

A aplicação do pré-teste foi realizada em serviços que representam o modelo de Estratégia de Saúde da Família e em Centros de Saúde que trabalham no modelo tradicional, buscando-se a maior diversidade possível dos representantes da população-alvo.

Apesar de o tema segurança do paciente ainda ser pouco conhecido por se tratar de um assunto novo para a maioria da população-alvo e que está em fase inicial de implantação nos serviços de saúde, sobretudo na Atenção Primária, o instrumento de pesquisa foi considerado 
de fácil compreensão pela população no pré-teste e apresentou alta confiabilidade na análise estatística.

A cultura de segurança do paciente é um tema bastante amplo, que tem seus aspectos relacionados a todos os níveis de atenção à saúde, e envolve todas as categorias de profissionais que compõem o serviço, desde a recepção até o especialista, sendo que, na Atenção Primária à Saúde, é pouco conhecida e apresenta grande potencialidade de investigação, monitoramento e intervenções que possam contribuir para melhorar a segurança e a qualidade da assistência.

Como limitações do estudo, observou-se que, para atingir um nível satisfatório com somente seis especialistas, na realização dos cálculos do Índice de Validade de Conteúdo, era necessário que cinco desses avaliassem o item com pontuação mínima de 3 (claro) ou 4 (bastante claro). Outro aspecto foi que houve dificuldade no momento de transcrição para o programa SurveyMonkey ${ }^{\circledR}$, que não permitiu a edição da numeração das questões, como na configuração original do instrumento. Por isso, na seção B os subitens foram mantidos em uma única questão. Desse modo, a maioria dos especialistas sugeriu que as respostas deveriam ser desmembradas, com a inclusão da escala Likert para cada uma das alternativas, fato que interferiu na avaliação do item. Ainda, a despeito das limitações, o Índice de Validade de Conteúdo do instrumento geral atingiu um nível de validade satisfatório de 0,85.

No sentido de justificar a utilidade e a aplicabilidade do presente estudo, tendo-se em vista que no Brasil a avaliação da cultura de segurança na Atenção Primária em saúde ainda é um campo a ser explorado, acredita-se que esta pesquisa é o primeiro passo para investigar esse cenário e espera-se que possa ser utilizada como fundamentação para estudos futuros.

Espera-se com este estudo a sensibilização para o tema da cultura de segurança na Atenção Primária e que possa contribuir para divulgação e implantação de ações preventivas na assistência e gestão de riscos, como a implantação do Núcleo de Segurança do Paciente, também nos serviços de Atenção Primária à Saúde. 


\section{REFERÊNCIAS}

AGENCY FOR HEALTHCARE RESEARCH AND QUALITY (AHRQ). Health

Assessments in Primary Care: A How-to Guide for Clinicians and Staff, set. 2013.

Disponível em: <www.ahrq.gov>. Acesso em: 04 jul. 2015.

AGENCY FOR HEALTHCARE RESEARCH AND QUALITY [homepage on the Internet]. Medical Office Survey on Patient Safety Culture. Rockville, MD. Revisado em: fev. 2015. Disponível em: <http://www.ahrq.gov/professionals/quality-patientsafety/patientsafetyculture/medical-office/index.html>. Acesso em: 26 abr. 2015.

ALEXANDRE, Neusa Maria Costa; COLUCI, Marina Zambon Orpinelli. Content validity in the development and adaptation processes of measurement instruments. Ciência \& Saúde Coletiva, v. 16, n. 7, p. 3061-3068, 2011. Disponível em: < http://www.scielo.br/pdf/csc/v16n7/06.pdf > Acesso em: 05 mar. 2015.

ALFRADIQUE, Maria Elmira et al. Internações por condições sensíveis à atenção primária: a construção da lista brasileira como ferramenta para medir o desempenho do sistema de saúde (Projeto ICSAP - Brasil). Cad. Saúde Pública, Rio de Janeiro, v. 25, n. 6, p. 1337-1349, Jun. 2009. Disponível em <http://www.scielo.br/scielo.php?script=sci_arttext\&pid=S0102311X2009000600016\&lng=en\&nrm=iso> Acesso em: 07 jun. 2013.

ALLEN, Suellen; CHIARELLA, Mary; HOMER, Caroline S. E. Lessons learned from measuring safety culture: An Australian case study. Midwifery, Australia, v. 26, p. 497-503, jul. 2010. Disponível em: 〈www.elsevier.com/midwfery>. Acesso em: 07 jun. 2013.

AMMOURI, Ali Ahmad; TAILAKH, Ayman K.; MULIIRA, Joshua Kanaabi; GEETHAKRISHNAN, Renu; AL KINDI, Sumaiya Nasser. Patient safety culture among nurses. International Nursing Review, n. 62, p. 102-110, 2015. Disponível em: <http://qap2.onlinelibrary.wiley.com/doi/10.1111/inr.12159/pdf>. Acesso em: 18 abr. 2015.

ANDERSON, Janet E; KODATE, Naonori; WALTERS, Rhiannon, DODDS, Anneliese. Can incident reporting improve safety? Healthcare practitioners' views of the effectiveness of incident reporting. International Journal for Quality in Health Care Advance. 2013. p. 110. Disponível em: 〈http://intqhc.oxfordjournals.org/〉. Acesso em: 07 jun 2013.

BELLUCCI JUNIOR, José Aparecido; MATSUDA, Laura Misue. Construção e validação de instrumento para avaliação do Acolhimento com Classificação de Risco. Revista Brasileira de Enfermagem, n. 65, n. 5, p. 751-757, out. 2012. Disponível em: $<$ http://www.scielo.br/scielo.php?script=sci_arttext\&pid=S0034-71672012000500006\&lng $=$ en\&nrm=iso $>$. Acesso em: 16 out. 2014.

BONDEVIK, Gunnar Tschudi; HOFOSS, Dag; HANSEN, Elisabeth Holm; DEILKÅS, Ellen Catharina Tveter The safety attitudes questionnaire - ambulatory version: psychometric properties of the Norwegian translated version for the primary care setting. BMC Health Services Research, n. 14, p. 139, 2014. Disponível em:

<http://www.biomedcentral.com/1472-6963/14/139>. Acesso em: 13 nov. 2014. 
BOOCKVAR, K. S. et al. Medication reconciliation for reducing drug-discrepancy adverse events. Am J Geriatr Pharmacother. v. 4, n. 3, p. 236-43, set 2006. Disponível em: http://www.ncbi.nlm.nih.gov/pubmed/17062324. Acesso em: 15 jun. 2015.

BRANCO FILHO, José Ribamar Carvalho. Segurança do Paciente no Cenário Mundial e no Brasil: uma Breve Revisão Histórica. In: FONSECA, Ariadne da Silva; PETERLINI, Fábio Luís; COSTA, Daniela Akemi (Coord). Segurança do Paciente. 1. ed. São Paulo: Martinari, 2014. p. 1-10.

BRASIL. Ministério da Saúde. Portaria n. 529, de $1^{\circ}$ de abril de 2013. Institui o Programa Nacional de Segurança do Paciente. Diário Oficial da União - Seção 1, No 62, terça-feira, 2 de abril de 2013.

BRASIL. Ministério da Saúde. Secretaria de Atenção à Saúde. Departamento de Atenção Básica. Acolhimento à demanda espontânea. 1. ed. 1. reimpr. Brasília: Ministério da Saúde, 2013. Disponível em:

http://bvsms.saude.gov.br/bvs/publicacoes/acolhimento_demanda_espontanea_cab28v1.pdf Acesso em: 03 ago. 2015.

BRASIL. Ministério da Saúde. Agência Nacional de Vigilância Sanitária. Documento de referência para o Programa Nacional de Segurança do Paciente/Ministério da Saúde. Brasília: Fundação Oswaldo Cruz; Agência Nacional de Vigilância Sanitária, 2014. Disponível em: <http://s.anvisa.gov.br/wps/s/r/bzu8>. Acesso em: 23 abr. 2015.

BRASIL. Agência Nacional de Vigilância Sanitária. Implantação do Núcleo de Segurança do Paciente em Serviços de Saúde - Série Segurança do Paciente e Qualidade em Serviços de Saúde/Agência Nacional de Vigilância Sanitária- Brasília: Anvisa, 2014. Disponível em: <file:///C:/Users/Marcia/Google\%20Drive/N\%C3\%BAcleo\%20de\%20seguran\%C3\%A7a\%2 0do\%20paciente/modulo6.pdf > Acesso em 15 jul 2015.

CAMARGO TOBIAS, Gabriela et al. Cultura de la seguridad del paciente en la atención sanitaria: un estudio bibliométrico. Enfermería Global, Murcia, v. 13, n. 33, ene. 2014. Disponível em: <http://scielo.isciii.es/scielo.php?script=sci_arttext\&pid=S169561412014000100017\&lng=es\&nrm=iso>. Acesso em: 30 mai. 2015.

CARVALHO, Rhanna Emanuela Fontenele Lima de; CASSIANI, Silvia Helena de Bortoli. Questionário Atitudes de Segurança: adaptação transcultural do Safety Attitudes Questionnaire - Short Form 2006 para o Brasil. Revista Latino-Americana de Enfermagem, Ribeirão Preto, v. 20, n. 3, p. 575-582, 2012. Disponível em: <http://www.scielo.br/pdf/rlae/v20n3/pt_a20v20n3.pdf>. Acesso em: 30 mai. 2013.

COLLA, J. B; BRACKEN, A. C. KINNEY, L.M.; WEEKS, W. B. Measuring patient safety climate: a review of surveys. Qual Saf Health Care, v.14, p. 364-366, 2005. Disponível em: <http://www.ncbi.nlm.nih.gov/pmc/articles/PMC1744072/pdf/v014p00364.pdf>. Acesso em: 19 jul. 2015

COSTA, Aléxia Regina Mandolesi. Segurança no uso de Medicações: Atuação da Farmácia. In: FONSECA, Ariadne da Silva; PETERLINI, Fábio Luís; COSTA, Daniela Akemi (Coord). Segurança do Paciente. 1. ed. São Paulo: Martinari, 2014. p. 177 - 190. 
CRESSWELL, K. M. et al. Global Research Priorities to Better Understand the Burden of Iatrogenic Harm in Primary Care: An International Delphi Exercise. PLoS Med. v. 10, n. 11, Nov. 2013. Disponível em: http://www.who.int/patientsafety/primary-care-prioirties.pdf

DIXON-WOODS, Mary; BOSK, Charles L.; AVELING, Louise; GOESCHEL, Christine A.; PRONOVOST, Peter J. Explaining Michigan: Developing an Ex Post Theory of a Quality Improvement Program. Milbank Quarterly, v. 89, n. 2, p. 167-205, 2011. Disponível em: <http://onlinelibrary.wiley.com/doi/10.1111/milq.2011.89.issue-2/issuetoc>. Acesso em: 12 mar. 2015.

EKLÖF, Mats; TÖRNER, Marianne; POUSETTE, Anders. Organizational and socialpsychological conditions in healthcare and their importance for patient and staff safety: a critical incident study among doctors and nurses. Safety Science, n. 70, p. 211-221, 2014. Disponível em: <http://dx.doi.org/10.1016/j.ssci.2014.06.007>. Acesso em: 11 set. 2014.

ESMAIL, Aneez. Measuring and monitoring safety: a primary care perspective. Health Foundation, 2013. Disponível em: <http://socialwelfare.bl.uk/subject-areas/servicesactivity/health-services/healthfoundation/1551872013_Measuring_and_ monitoring_safety_a\%20primary_care_perspective.pdf>. Acesso em 08 mar. 2014.

ESTUDO IBERO-AMERICANO DE EVENTOS ADVERSOS. Prevalencia de efectos adversos em hospitales de Latinoamérica. 2010. Espanha. Disponível em: <http://www.seguridaddelpaciente.es/resources/contenidos/castellano/2009/INFORME_IBEA S.pdf>. Acesso em: 23 jun. 2014.

FRANÇOLIN, Lucilena et al. Patient safety management from the perspective of nurses. Revista da Escola de Enfermagem da USP, São Paulo, v. 49, n. 2, p. 0277-0283, abr. 2015. Disponível em: <http://www.scielo.br/scielo.php?script=sci_arttext\&pid=S008062342015000200277\&lng=en\&nrm=iso>. Acesso em: 30 mai. 2015.

GAAL, Sander; VERSTAPPE, Wim; WENSING, Michel. What do primary care physicians and researchers consider the most important patient safety improvement strategies? BMC Health Services Research, n. 11, p. 102, 2011. Disponível em: <http://www.biomedcentral.com/1472-6963/11/102>. Acesso em: 11 set. 2014.

GAMA, Zenewton André da Silva; SATURNO, Pedro Jesus. A segurança do paciente inserida na gestão da qualidade dos serviços de saúde. In: ANVISA (Org.). Assistência segura: uma reflexão teórica aplicada à prática. Brasília: ANVISA, 2013. Cap. 3, p. 29-40.

GEORGE, D.; MALLERY, P. SPSS for Windows step by step: A simple guide and reference. 4th ed. Boston: Allyn \& Bacon. (2003). Apud: Gliem, JA e Gliem, RR Calculating, interpreting and reporting Cronback's alpha reliability coefficient for Likert-type scales.

HAIR, J. F.; ANDERSON, R. E.; TATHAM, R. L.; Black, W. C. Análise multivariada de dados. A. S. Sant'Anna \& A. C. Neto (Trad.). Porto Alegre: Bookman, 2005.

HALLIGAN, Michelle; ZECEVIC, Aleksandra. Safety culture in healthcare: a review of concepts, dimensions, measures and progress. BMJ Quality \& Safety, fev. 2011. Disponível em: <http://qualitysafety.bmj.com>. Acesso em: 20 fev. 2015. 
HARADA, Maria de Jesus Castro Sousa; PEDREIRA, Mavilde da Luz Gonçalves. O erro humano e sua prevenção. In: ANVISA (Org.). Assistência segura: uma reflexão teórica aplicada à prática. ANVISA: Brasília, 2013.

HARTZ, Zulmira M. de Araújo; CONTANDRIOPOULOS, André-Pierre. Integralidade da atenção e integração de serviços de saúde: desafios para avaliar a implantação de um "sistema sem muros". Cadernos de Saúde Pública, Rio de Janeiro, v. 20, supl. 2, p. S331- S336, 2004. Disponível em: <http://www.scielo.br/scielo.php?script=sci_arttext\&pid=S0102311X2004000800026\&lng=en\&nrm=iso >. Acesso em: 08 jun. 2015.

HINRICHSEN, Sylvia Lemos et al. Gestão da qualidade e dos riscos na segurança do paciente: estudo-piloto. RAHIS - Revista de Administração Hospitalar e Inovação em Saúde, v. 7, p. 10-17, jul.-dez. 2011.

HOFFMANN, Barbara; MIESSNER, Carolin; ALBAY, Zeyca et al. Impact of Individual and Team Features of Patient Safety Climate: A Survey in Family Practices. Annals of Family Medicine. v. 11, n. 4, Jul/Aug 2013. Disponível em: www.annfammed.org. Acesso em: jun. 2015.

HORA, Henrique Rego Monteiro; MONTEIRO, Gina Torres Rego; ARICA, Jose. Confiabilidade em Questionários para Qualidade: Um Estudo com o

Coeficiente Alfa de Cronbach. Produto \& Produção, vol. 11, n. 2, p. 85 - 103, jun. 2010.

JAMOULLE, M.; GOMES, L. F. Prevenção Quaternária e limites em medicina. Rev Bras Med Fam Comunidade. Rio de Janeiro, v. 9, n. 31, p. 186-191, Abr-Jun. 2014. Disponível em: 〈www.rbmfc.org.br $>$. Acesso em: 15 jul. 2015.

KIRWAN, Marcia; MATTHEWS, Anne; SCOTT, P. Anne. The impact of the work environment of nurses on patient safety outcomes: a multi-level modelling approach.

International Journal of Nursing Studies, v. 50, n. 2, p. 253-263, 2013. Disponível em: <http://www.ncbi.nlm.nih.gov/pubmed/23116681>. Acesso em: 12 dez. 2013.

KOHN, Linda T.; CORRIGAN, Janet M.; DONALDSON, Molla S. To err is human: building a safer health care system. Washington (DC): National Academy Press; Institute of Medicine, 2000. Disponível em: <http://neurosurgery.ucsf.edu/tl_files/NS_Main/QI/IOM_To\%20Err\%20is\%20Human.pdf> Acesso em: 18 abr. 2015. 
LIMA, D. V. M.; Desenhos de pesquisa: uma contribuição ao autor. Online braz. J. nurs, v. 10, n. 2, abr-ago. 2011. Disponível em:

$<$ http://www.uff.br/enfermagemdotrabalho/desenhos\%20de\%20pesquisa.pdf $>$. Acesso em: jun 2013.

LINNEAUS EURO-PC. A classification system for adverse events in healthcare. [Internet]. European Union. The University of Manchester School of Community-Based Medicine Faculty of Medical and Human Sciences, UK. Disponível em: 〈http://www.linneaus-pc.eu〉. Acesso em: 16 dez. 2014.

LLAMAS, José Saura; GÓMEZ, María José Lázaro; BALBUENA, Juan José Jurado. Seguridad del paciente en las consultas de Atención Primaria. Barcelona: Sociedad Española de Medicina de Familia y Comunitaria, 2012.

LUNNEY, Margaret et al. Pensamento crítico para o alcance de resultados positivos em saúde. Porto Alegre: Artmed, 2011.

MAKEHAM, Meredith; DOVEY, Susan; RUNCIMAN, William. Methods and Measures used in Primary Care Patient Safety Research: Results of a literature review. Switzerland: World Health Organization, 2008.

MARCHON, Simone Grativol; MENDES JÚNIOR, Walter Vieira. Segurança do paciente na atenção primária à saúde: revisão sistemática. Cadernos de Saúde Pública, Rio de Janeiro, v. 30, n. 9, p. 1-21, set. 2014. Disponível em: 〈http://dx.doi.org/10.1590/0102-311X00114113>. Acesso em: 24 jan. 2015.

Tradução e adaptação de um questionário elaborado para avaliar a segurança do paciente na atenção primária em saúde. Cad. Saúde Pública, Rio de Janeiro, v. 31, n. 7, p. 1395-1402, jul. 2015 . Disponível em:

<http://www.scielo.br/scielo.php?script=sci_arttext\&pid=S0102-

311X2015000701395\&lng=en\&nrm=iso>. Acesso em: 09 ago. 2015.

MARTIM, Helle Max; LARSEN, Jessica. Patient Involvement in Patient Safety: A Literature Review about European Primary Care. The Danish Institute for Health Services Research, jan. 2012. Disponível em: <http://patientsikkerhed.dk/media/563675/patient_ involvement_in_patient_safety_a_literature_review_about_european_primary_care.pdf $>$. Acesso em: 12 mar. 2015.

MEDEIROS, Rosana Kelly da Silva; FERREIRA JÚNIOR, Marcos Antonio; PINTO, Diana Paula de Souza Rêgo; VITOR, Allyne Fortes; SANTOS, Viviane Euzébia Pereira;

BARICHELLO, Elizabeth. Pasquali's model of content validation in nursing research.

Revista de Enfermagem Referência, v. 4, n. 4, 2015. Disponível em: <http://dx.doi.org/10.12707/RIV14009>. Acesso em: 15 abr. 2015.

MENDES, Carla Maria Ferreira Guerreiro da Silva; BARROSO, Fernando Fausto Margalho. Promover uma cultura de segurança em cuidados de saúde primários. Revista Portuguesa de Saúde Pública, v. 32, n. 2, p. 197-205, set. 2014. Disponível em: http://dx.doi.org/10.1016/j.rpsp.2014.06.003>. Acesso em: 04 jun. 2015. 
MENDES, Walter; MOURA, Maria de Lourdes Oliveira. Estratégias para segurança do paciente em serviços de saúde. In: ANVISA (Org.). Assistência segura: uma reflexão teórica aplicada à prática. ANVISA: Brasília, 2013.

MERHY, Emerson Elias; ONOCKO, Rosana (ORG). AGIR EM SAÚDE um desafio para o público. São Paulo: Hucitec, 1997.

MONTSERRAT-CAPELLA, Dolors; CHO, Malhi; LIMA, Rogério da Silva. A segurança do paciente e a qualidade em serviços de saúde no contexto da América Latina e Caribe. In: ANVISA (Org.). Assistência segura: uma reflexão teórica aplicada à prática. ANVISA: Brasília, 2013.

MOURA, M. L. $13^{\circ}$ Encontro da Rede Sentinela. Mesa redonda: Conversando sobre gestão de risco em serviços de saúde - conceitos e dimensões para o contexto da vigilância sanitária. Fundação Oswaldo Cruz, Ministério da Saúde.

NASCIMENTO, Nádia Bomfim. O erro e as violações no cuidado em saúde. In: SOUSA, Paulo; MENDES, Walter (Org). Segurança do Paciente - Conhecendo os riscos nas organizações de saúde. Fundação Oswaldo Cruz. Rio de Janeiro: Fiocruz, 2014. p. 74-92.

NIGHTINGALE, Florence. Notes on Hospitals. London: Harvard College Library, 1863. Disponível em: <http://books.google.com.br>. Acesso em: 28 abr. 2015.

NORMAN, Armando Henrique; TESSER, Charles Dalcanale. Prevenção quaternária na atenção primária à saúde: uma necessidade do Sistema Único de Saúde. Cad. Saúde Pública, Rio de Janeiro , v. 25, n. 9, p. 2012-2020, set. 2009 . Disponível em: $<$ http://www.scielosp.org/scielo.php?script=sci_arttext\&pid=S0102311X2009000900015\&lng=en\&nrm=iso>. Acesso em: 26 jul. 2015.

OLIVEIRA, Roberta Meneses et al. Estratégias para promover segurança do paciente: da identificação dos riscos às práticas baseadas em evidências. Escola de Enfermagem Anna Nery, Rio de Janeiro, v. 18, n. 1, p. 122-129, mar. 2014. Disponível em: $<$ http://www.scielo.br/scielo.php?script=sci_arttext\&pid=S1414-81452014000100122\&lng= en\&nrm=iso>. Acesso em: 30 mai. 2015.

PAESE, Fernanda; SASSO, Grace Teresinha Marcon Dal. Cultura da segurança do paciente na atenção primária à saúde. Texto contexto - enferm., Florianópolis , v. 22, n. 2, p. 302310,June 2013 . Disponível em: <http://www.scielo.br/scielo.php?script=sci_arttext\&pid=S010407072013000200005\&lng=en\&nrm=iso>. Acesso em: 03 ago 2015.

PASQUALI, Luiz. Principles of elaboration of psychological scales. Revista de Psiquiatria Clínica, v. 25, n. 5, p. 206-213, 1998. Disponível em: <http://www.hcnet.usp.bt/ipq/revista/vol26/vol25/n5/conc255a.htm>. Acesso em: 16 out. 2014.

PASQUALI, Luiz. Psicometria. Rev. esc. enferm. USP, São Paulo, v. 43, n. spe, p. $992-$ 999, Dec. 2009. Disponível em: http://www.scielo.br/pdf/reeusp/v43nspe/a02v43ns.pdf Acesso em: 03 jul. 2015. 
PROADESS/MINISTÉRIO DA SAÚDE; FUNDAÇÃO OSWALDO CRUZ. Programa de Avaliação de Desempenho do Sistema de Saúde. 2011. Disponível em:

<http://www.proadess.icict.fiocruz.br/index.php?pag=matp>. Acesso em: 21 jun. 2014.

PROQUALIS/MINISTÉRIO DA SAÚDE; FUNDAÇÃO OSWALDO CRUZ. Superando

desafios para melhorar a qualidade: lições extraídas das avaliações dos programas de melhoria da Health Foundation e de literatura relevante. Instituto de Comunicação Científica e Tecnológica em Saúde/Fiocruz. 2012. Disponível em: <http://FUNDAÇÃO OSWALDO CRUZ - PROQUALIS, 2012.net>. Acesso em: 24 jan. 2015.

PORTUGAL. MINISTÉRIO DA SAÚDE. Estrutura Conceitual da Classificação Internacional sobre Segurança do Doente. Relatório Técnico Final. Lisboa, Direção-Geral da Saúde, 2011.

QUES, Ángel Alfredo Martínez; MONTORO, César Hueso; GONZALEZ, María Gálvez. Fortalezas e ameaças em torno da segurança do paciente segundo a opinião dos profissionais de enfermagem. Revista Latino-Americana de Enfermagem, Ribeirão Preto, v. 18, n. 3, p. 339-345, jun. 2010. Disponível em: <http://www.scielo.br/scielo.php?script=sci_arttext\&pid $=$ S0104-11692010000300007\&lng=en\&nrm=iso $>$. Acesso em: 05 jul. 2015 .

REICHENHEIM, Michael Eduardo; MORAES, Cláudia Leite. Operacionalização de adaptação transcultural de instrumentos de aferição usados em epidemiologia. Revista de Saúde Pública, São Paulo, v. 41, n. 4, ago. 2007. Disponível em: <http://www.scielo.br/pdf/rsp/v41n4/6294.pdf>. Acesso em: 15 jul. 2013.

REIS, Claudia Tartaglia. Cultura de segurança. In: SOUSA, Paulo; MENDES, Walter (Org.). Segurança do Paciente: Criando Organizações de Saúde Seguras. Fundação Oswaldo Cruz. Rio de Janeiro: Fiocruz, 2014. p. 75-99.

REIS, Cláudia Tartaglia; MARTINS, Mônica; LAGUARDIA, Josué. Translation and crosscultural adaptation of the Brazilian version of the Hospital Survey on Patient Safety Culture: initial stage. Cadernos de Saúde Pública, v. 18, n. 7, 2012. Disponível em: <http://www.scielosp.org/pdf/csp/v28n11/19.pdf >. Acesso em: 28 abr. 2013.

Patient safety as a dimension of the quality of health care - a look at the literature.

Ciência \& Saúde Coletiva, v. 18, n. 7, p. 2029-2036, 2013. Disponível em:

<http://dx.doi.org/10.1590/S1413-81232013000700018>. Acesso em: 19 jun. 2014.

RIGOBELLO, Mayara Carvalho Godinho et al. Clima de segurança do paciente: percepção dos profissionais de enfermagem. Acta Paulista de Enfermagem, São Paulo, v. 25, n. 5, 2012. Disponível em: <http://www.scielo.br/scielo.php?script=sci_arttext\&pid= S0103$21002012000500013 \& \operatorname{lng}=$ en\&nrm=iso>. Acesso em: 15 jun 2013.

RODRÍGUEZ-COGOLLO, Ronald; PAREDES-ALVARADO, I. R.; GALICIA-FLORES, T.; BARRASA-VILLAR, José Ignacio Barrasa; RUIZ, Silvia Castán. Cultura de seguridad del paciente en residentes de medicina familiar y comunitaria de Aragón. Revista de Calidad Asistencial, v. 29, n. 3, 2014, p. 143-149, 2014. Disponível em:

<http://dx.doi.org/10.1016/j.cali.2014.01.00>. Acesso em: 11 jan. 2014. 
ROSENTHAL, Meredith B. Nonpayment for Performance? Medicare's New Reimbursement Rule. N Engl J Med., Massachusetts, v. 357, n. 16, p. 1573-1575, 2007. Disponível em: <http://www.nejm.org/doi/pdf/10.1056/NEJMp078184>. Acesso em: 3 ago. 2015.

SÁNCHEZ, Míriam Ruiz; BORRELL-CARRIÓ, Francisco; PARRA, Cristina Ortodó; DANÉS, Neus Fernández; GALLEGO, Anna Fité. Auditorías en seguridad clínica para centros de atención primaria. Estudio piloto. Atención Primaria, v. 45, n. 7, p. 341-348, 2013. Disponível em: 〈http://dx.doi.org/10.1016/j.aprim.2013.01.005>. Acesso em: 14 out. 2014.

SETZ, Vanessa Grespan; D'INNOCENZO, Maria. Avaliação da qualidade dos registros de enfermagem no prontuário por meio da auditoria. Acta paul. enferm., São Paulo , v. 22,n. 3,p. 313-317, jun. 2009. Disponível em: <http://www.scielo.br/scielo.php?script=sci_arttext\&pid=S0103-

$21002009000300012 \& \operatorname{lng}=$ en\&nrm=iso>. Acesso em: 19 jul. 2015.

SHEKElle, P. G.; WACHTER, R. M.; PRONOVOST, P. J. et al. Making Health Care Safer II: An Updated Critical Analysis of the Evidence FOR Patient Safety Practices. Comparative Effectiveness Review. AHRQ Publication No. 13-E001-EF. Rockville, MD: Agency for Healthcare Research and Quality. Mar 2013. Disponível em: www.ahrq.gov/research/findings/evidence-based-reports/ptsafetyuptp.html. Acesso em: 08 mar. 2014.

SORRA, Joann S.; DYER Naomi. Multilevel psychometric properties of the AHRQ hospital survey on patient safety culture. BMC Health Services Research, n. 10, p. 199, 2010. Disponível em:< http://www.biomedcentral.com/content/pdf/1472-6963-10-199.pdf>. Acesso em: 18 abr. 2015.

SORRA, Joann; FRANKLIN, Martha; STREAGLE, Suzanne (Eds.). Medical office survey on patient safety culture. Agency for Healthcare Research and Quality. AHRQ Publication, v. 8, n. 9, p. 0059. 2008. Disponível em: <http://www.ahrq.gov/professionals/quality-patientsafety/patientsafetyculture/medical-office/2008/mosurveyguide.pdf $>$. Acesso em $30 \mathrm{abr}$. 2013.

SOUSA, Valmi Delfino de; ROJJANASRIRAT, Wilaiporn, Translation, adaptation and validation of instruments or scales for use in cross-cultural health care research: a clear and user-friendly guideline. Journal of Evaluation in Clinical Practice, n. 17, p. 268-274, 2011. Disponível em: <doi:10.1111/j.1365-2753.2010.01434.x>. Acesso em: 16 abr. 2014.

SOUSA, P.; UVA, A. S.; SERRANHEIRA, F. Investigação e inovação em segurança do doente. Rev Port Saúde Pública, v. 10, p.89-95, 2010. Disponível em: $<$ http://www.ensp.unl.pt/dispositivos-de-apoio/cdi/cdi/sector-depublicacoes/revista/2010/pdf/volume-tematico-seguranca-do-doente/10Investigacao $\% 20 \mathrm{e} \% 20 \mathrm{inovacao} \% 20 \mathrm{em} \% 20$ seguranca $\% 20 \mathrm{do} \% 20 \mathrm{doente}$.pdf $>$. Acesso em: 23 jun. 2014.

SPENCER, Rachel; CAMPBELL Stephen M. Tools for primary care patient safety: a narrative review. BMC Family Practice, n. 15, p. 166, 2014. Disponível em: <http://www.biomedcentral.com/1471-2296/15/166>. Acesso em: 30 mai. 2015. 
STARFIELD, Barbara. Atenção Primária: equilíbrio entre necessidades de saúde, serviços e tecnologia. Brasília: UNESCO, Ministério da Saúde, 2002.

TABACHNICK, B. G.; FIDELL, L. S. Using Multivariate Statistics. 5. ed. Boston: Allyn and Bacon, 2007.

THOMAS, Lily; GALLA, Catherine. Building a culture of safety through team training and engagement. BMJ Quality \& Safety, 2013, v. 22, p. 425-434. Disponível em:

<http://10.1136/bmjqs-2012-001011>. Acesso em: 20 fev. 2014.

TORIJANO-CASALENGUA, María Luisa; OLIVERA-CAÑADAS, Guadalupe; ASTIERPEÑA, María Pilar; MADERUELO-FERNÁNDEZ, José Ángel; SILVESTRE-BUSTO, Carmen. Validation of a questionnaire to assess patient safety culture in Spanish Primary Health Care professional. Atención Primaria, v. 45, n. 1, p. 21-37, 2013. Disponível em: $<$ http://www.elsevier.es/es/revistas/atencion-primaria-27/validacion-un-cuestionario-evaluarcultura-seguridad-paciente-90185333-originales-2013>. Acesso em: 14 out. 2014.

TRAVASSOS, Cláudia Maria de Resende; CALDAS, Bárbara. A qualidade do cuidado e a segurança do paciente: histórico e conceitos. In: ANVISA (Org.). Assistência segura: uma reflexão teórica aplicada à prática. Brasília: ANVISA, 2013. Cap. 2, p. 19-27.

TSAI, Yafang. Relationship between Organizational Culture, Leadership Behavior and Job Satisfaction. BMC Health Services Research, n. 11, p. 98, 2011. Disponível em: <http://www.biomedcentral.com/1472-6963/11/98>. Acesso em: 13 dez. 2013.

TUTHILL, Emily L; BUTLER, Lisa M; MCGRATH, Jacqueline M; CUSSON, Regina M; MAKIWANE, Gracia Nokhaya; GABLE, Robert K; FISHER, Jeffrey D. Cross-cultural adaptation of instruments assessing breastfeeding determinants: a multi-step approach.

International Breastfeeding Journal, v. 9, n. 1, p. 16, 2014. Disponível em: $<$ http://www.internationalbreastfeedingjournal.com/content/9/1/16>. Acesso em: 30 mai. 2015.

VASCONCELLOS, Miguel Murat; GRIBEL, Else Bartholdy; MORAES, Ilara Hammerli Sozzi de. Registros em saúde: avaliação da qualidade do prontuário do paciente na atenção básica, Rio de Janeiro, Brasil. Cad. Saúde Pública, Rio de Janeiro , v. 24, supl. 1, p. s173s182, 2008 . Disponível em: <http://www.scielo.br/scielo.php?script=sci_arttext\&pid=S0102311X2008001300021\&lng=en\&nrm=iso>. Acesso em: 19 jul. 2015.

VERBAKEL, Natasha J.; VAN MELLE, Marije; LANGELAAN, Maaike; VERHEIJ, Theo J. M.; WAGNER, Cordula; ZWART, Dorien L. M. Exploring patient safety culture in primary care. International Journal for Quality in Health Care, 2014, p. 1-7. Disponível em: < http://intqhc.oxfordjournals.org/content/intqhc/early/2014/08/01/intqhc.mzu074.full.pdf > Acesso em: 19 jul. 2015

VIACAVA, Francisco et al. Avaliação de Desempenho de Sistemas de Saúde: um modelo de análise. Ciência \& Saúde Coletiva, v. 17, n. 4, p. 921-934, 2012. Disponível em: <http://www.scielo.br/pdf/csc/v17n4/v17n4a14.pdf>. Acesso em: 19 jun. 2014.

VINCENT, Charles. Segurança do Paciente: Orientações para Evitar Eventos Adversos. São Caetano do Sul: Yedis, 2009. 
VITURI, Dagmar Willamowius; MATSUDA, Laura Misue. Validação de conteúdo de indicadores de qualidade para avaliação do cuidado de enfermagem. Rev. esc. enferm. USP, São Paulo, v. 43,n. 2,p. 429-437, jun. 2009 . Disponível em:

<http://www.scielo.br/scielo.php?pid=S0080-62342009000200024\&script=sci_arttext > Acesso em: 23 jun. 2014.

WACHTER, Robert M. Compreendendo a segurança do paciente. Porto Alegre: Artmed, 2010.

Compreendendo a segurança do paciente. $2^{\mathrm{a}}$ ed. Porto Alegre: Artmed, 2013.

WATERSON, Patrick. Patient Safety Culture: Theory, Methods and Application. British Library, 2014.

WORLD HEALTH ORGANIZATION (WHO). Methods and Measures used in Primary Care Patient Safety Research Results of a literature review. Geneva, 2008. Disponível em: $\langle$ http://www.who.int/patientsafety/research/methods_measures/makeham_dovey_full.pdf $>$ Acesso em: 30 abr. 2013.

WORLD HEALTH ORGANIZATION (WHO). Management of substance abuse. Geneva, 2015. Disponível em: <http://www.who.int/substance_abuse/research_tools/translation/en/> . Acesso em: $30 \mathrm{jul}$. 2015 .

WORLD HEALTH ORGANIZATION (WHO). Patient Safety Curriculum Guide: Multiprofessional edition. Edited by Margaret Chan. Geneva, 2011. Disponível em:

http://whqlibdoc.who.int/publications/2011/9789241501958_eng.pdf> Acesso em: 12 dez. 2013.

YOSHIKAWA, Jamile Mika; SOUSA, Bruna Elisa Catin de; PETERLINI, Maria Angélica Sorgini; KUSAHARA, Denise Miyuki; PEDREIRA, Mavilde da Luz Gonçalves; AVELAR, Ariane Ferreira Machado. Comprehension of undergraduate students in nursing and medicine on patient safety. Acta Paulista de Enfermagem, São Paulo, v. 26, n. 1, p. 21-29, 2013. Disponível em: <http://dx.doi.org/10. 1590/S0103-21002013000100005> . Acesso em: 21 abr. 2015.

ZWART, Dorien L. M.; LANGELAAN, Maaike; VOOREN, Rosalinde Cvan; KUYVENHOVEN, Marijke M.; KALKMAN, Cor J.; VERHEIJ, Theo J. M.; CORDULA, Wagner. Patient safety culture measurement in general practice. Clinimetric properties of "SCOPE". BMC Family Practice, n. 12, p. 117, 2011. Disponível em:

<http://www.biomedcentral.com/content/pdf/1472-6963-10-199.pdf>. Acesso em: 18 abr. 2015. 
ANEXOS

ANEXO A - Autorização da Agency for Health Care Research and Quality (AHRQ) para utilização do instrumento

3010/2014 Gmall - Fwd. Request for authorization for translation and cross-culturaladaptation of the questlornalre Medcal Omce Survey on Patiert Safely Cu...

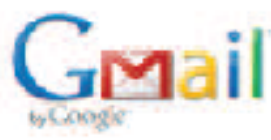

Marcia Timm <marcia.timm@gmail.com>

\section{Fwd: Request for authorization for translation and cross-culturaladaptation of the questionnaire Medical Office Survey on Patient Safety Culture: *ref\#24-24618 \\ 1 mensagem}

Maria Cristina Soares Rodrigues <sr.mariacristina@gmail.com> 30 de outubro de 2014 16:58 Para: Marcia Timm <marcia.timm@gmail.com>, Marcia Timm <timm.marcia74@gmail.com>

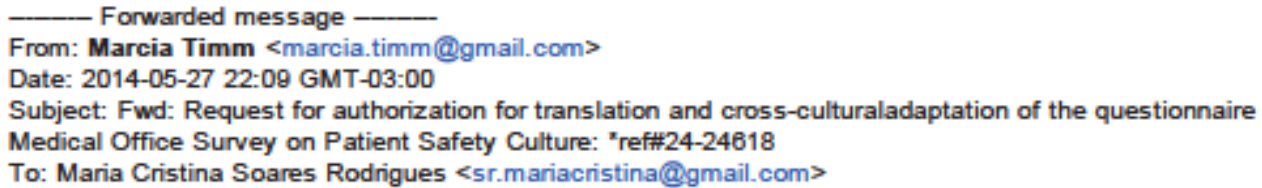

Recebemos a resposta da AHRQ autorizando o uso do questionário e algumas recomendações.

Abraços

Forwarded message

From: <SafetyCultureSurveys@westat.com>

Date: 2014-05-27 11:10 GMT-03:00

Subject: Re: Request for authorization for translation and cross-culturaladaptation of the questionnaire

Medical Office Survey on Patient Safety Culture: "ref\#24-24618

To: marcia.timm@gmail.com

Dear Marcia,

Thank you for your interest in the AHRQ Medical Office Survey on Patient Safety Culture.

Your inquiry was forwarded to Westat, the contractor who provides technical assistance for the safety culture surveys. We are happy to hear that you will be using the Medical Office Survey on Patient Safety Culture for your research project. Yes, you have AHRQ's permission to use the Medical Office Survey on Patient Safety Culture in English or translate it into Portuguese. The AHRQ safety culture surveys for hospitals, nursing homes, medical offices, and pharmacies are free and available for public use from the AHRQ Web site at: http://www.ahrq.gov/professionals/quality-patient-safety/patientsafetyculture/index.html. Select the Medical Office Survey on Patient Safety Culture and then you will find the surveys and support materials.

We request that any surveys used in Brazil note that the surveys were reprinted or translated from English with the permission of the United States Agency for Healthcare Research and Quality. Any research studies based on the survey results should give a source citation to the Medical Office SOPS Web page http://www.ahrq.gov/professionals/quality-patient-safety/patients afetyculture/medical-office/index.html .

Each survey has an accompanying Toolkit which contains the following materials:

- Survey Forms

- Survey Items and Dimensions

- A Survey User's Guide: Gives step-by-step instructions on how to select a sample, administer the survey and obtain high response rates, and how to analyze and report results.

o Survey feedback report PowerPoint@ template: Can be customized to display survey results to administrators and staff throughout the organization, and for presentation purposes.

- Data Entry and Analysis Tool: A data entry and analysis tool that works with Microsoft@ Excel and makes it easy to input your individual-level data from the survey. The tool then automatically creates tables and graphs to display your survey results. To request the tool for the hospital, medical office, or nursing home survey, send an E-mail to: DatabasesOnSafetyCulture@westat.com. 


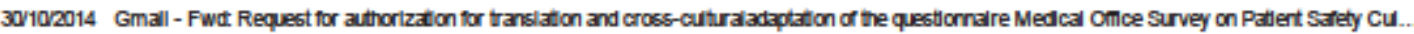

Since the release of the AHRQ Hospital Survey on Patient Safety Culture in November 2004, the number of international survey users has grown. This link http://www.ahrq.gov/professionals/quality-patientsafety/patientsafetyculture/pscintusers.html will give you information on international users, including languages into which the survey has been translated and guidelines for translation etc.

You may register for email updates from the AHRQ Web site by going to https://subscriptions.ahrq. gov/service/multi_subscribe. html?code=USAHRQ.

Choose from the following SOPS email subscription lists:

Surveys on Patient Safety Culture

․ Hospital Survey

ㅁ Medical Office Survey

․ Nursing Home Survey

․ Translations and International Use

If you need further information, please let us know.

Thank you.

Chris

Chris Gomes

AHRQ Surveys on Patient Safety Culture Technical Assistance

SafetyCultureSurveys@westat.com

1-888-324-9749

"Request for authorization for translation and cross-cultural adaptation of the questionnaire Medical Office Survey on Patient Safety Culture, "created by the Agency for Health Care Research and Quality (AHRQ)

My name is Marcia, I am a nurse. I perform my activities at the primary health care, currently in the coordination of the nursing staff of a health center of the State Secretariat of Health of the Federal District, Brazil.

I'm studying the academic masters in nursing at the University of Brasilia, and I have as object of study the Culture of Patient's Safety. so my research project is the translation and cross-cultural adaptation of the questionnaire "Medical Office Survey on Patient Safety Culture" created by the Agency for Health Care Research and Quality (AHRQ).

The intention of my contact is to request the authorization for use of the aforementioned questionnaire in my research, to adapt and make available an instrument that can be used in related searches on the culture of patient's safety in primary health care, to identify the vision of professionals concerning patient's safety. promoting the debate and reflection on the subject, in order to assist in the implementation of actions to improving the culture of patient's safety and the quality of care in health services.

In Brazil, the studies on patient's safety culture are still incipient. being essential to carry out investigations in the context of primary care, composing a body of knowledge of the subject in our country and that can be used as a justification for future studies, allowing intemational comparison among the studies developed using the questionnaire adapted and validated for the Brazilian context. In the academic environment, contribute to scientific production in the area of patient's safety in primary care, and little explored theme of great relevance today. In the execution of the study. there will be followed the ethical and legal precepts. The project will be submitted to the Research Ethics Committee of the State Secretariat of Health of the Federal District/SES/DF/FEPECS, in accordance with Resolution No. 466, December 12th, 2012. The instrument will be applied after informed consent, preserving the identity of the participants. 


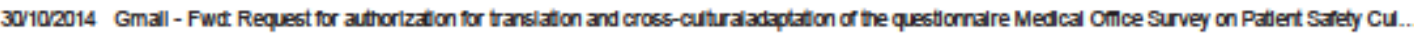

The translation and cross-cultural adaptation will be developed in the following five steps: Step 1: translation of the original instrument to the target language. Step 2: comparison of the two translated versions of the instrument (T1 and T2): synthesis I. Step 3: blind back-translation of the preliminary version translated the instrument T1-2. Step 4: comparison of the two versions of the instrument back-translated (B- T1 and B-T2): summary II. Step 5: test pilot of the pre-final version of the instrument in Portuguese with a monolingual sample: cognitive debriefing. Sample: the pre-test will be applied with $\mathbf{4 0}$ professionals from multidisciplinary team. working in three health centers in a Regional Health Secretariat of the Federal District. To examine deeply the instrument regarding the clarity of the instructions, response format and equivalence of content (content-related validity), will be using the content validity index and concordance, Kappa coefficient in the data analysis.

"For this project to be developed, I request permission from AHRQ to use in its entirety the questionnaire Medical Office Survey on Patient Safety Culture."

I thank for the given attention and I am counting with the understanding and help of the staff of the AHRQ, and I also congratulate for the excellent work that has been developing in the area of patient's safety.

"Best "regards"

"Márcia Timm*

marcia.timm@gmail.com

Brasilia - Federal District, Brazil.

Note: This email is sent with reference to Incident \#24618.

Please mention reference number 'ref\#24-24618' for further email communications.

Marcia Timm 
ANEXO B - Documento de Aprovação pelo Comitê de Ética

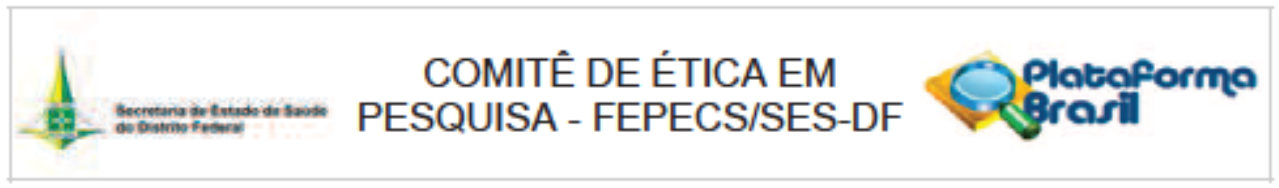

PARECER CONSUBSTANCIADO DO CEP

DADOS DO PROJETO DE PESQUISA

Título da Pesquisa: Cultura de Segurança do Paciente na Atenção Primária à Saúde: adaptação transcultural do questionário Medical Office Survey on Patient Safety Culture (MOSPSC)

Pesquisador: Marcia Timm

Área Temática:

Versäo: 1

CAAE: 31787314.0 .0000 .5553

Instituição Proponente: DISTRITO FEDERAL SECRETARIA DE SAUDE

Patrocinador Principal: Financiamento Próprio

\section{DADOS DO PARECER}

Número do Parecer: 688.060

Data da Relatoria: 16/06/2014

Apresentação do Projeto:

A pesquisa constitui-se projeto de Mestrado para o Programa de Pós Graduaçäo em Enfermagem da UnB desenvolvido por uma enfermeira do HRS.

Propõe uma adaptação transcultural do questionário Medical Office Survey on Patient Safety Culture (MOSPSC) criado pela Agency for Health Care Research and Quality (AHRQ), dos Estados Unidos, para mensurar a cultura de segurança do paciente nas equipes de atençäo primária a saúde no Brasil.

\section{Objetivo da Pesquisa:}

Objetivo Primário:

Desenvolver a adaptação do questionário Medical Office Survey on Patient Safety Culture da Agency for Health Care Research and Quality para mensurar a cultura de segurança do paciente nas equipes de atenção primária a saúde no Brasil.

Objetivos Secundários:

- Traduzir e realizar a adaptação transcultural do instrumento de pesquisa para avaliação da cultura de segurança do paciente na atenção primária à saúde:

* Validar o instrumento de pesquisa com aplicaçäo do pré-teste na atençäo primária a saúde.

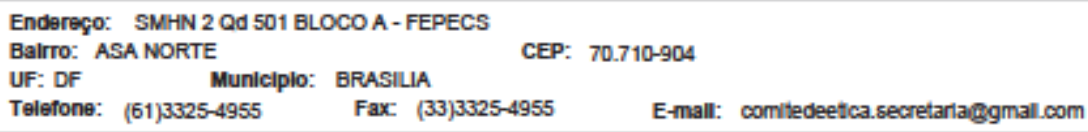




\section{COMITÊ DE ÉTICA EM PESQUISA - FEPECS/SES-DF \\ Qlatoforma erasi}

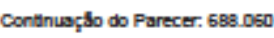

Avaliação dos Riscos e Benefícios:

Riscos: mínimos, embora, não descritos pela pesquisadora.

Beneficios: aplicaçäo prática na pesquisa da cultura de segurança do paciente e identificação de possíveis lacunas sobre o tema nos cenários de estudo, além de permitir a comparação internacional entre os estudos desenvolvidos utilizando-se o questionário adaptado e validado para o contexto brasileiro.

Comentários e Consideraçōes sobre a Pesquisa:

Estudo para tradução e validação de um questionário de segurança do paciente, o Medical Office Survey on Patient Safety Culture (MOSPSC),criado pela Agency for Health care Research and Quality (AHRQ), nos Estados Unidos. O questionário é constituido de 51 perguntas, que medem 12 dimensöes do construto da segurança do paciente.

O processo de trabalho envolve realização de uma traduçäo inglês/português e retrotradução português/inglês para minimizar as divergências entre as duas línguas. Depois, o questionário será aplicado a 40 profissionais de saúde de uma UBS de Sobradinho.

A beneficência do estudo foi demonstrada. Os riscos possivelmente säo mínimos porém, não foram descritos pela pesquisadora.

Planilha de orçamento foi apresentada e demonstra a viabilidade de execução do projeto.

Cronograma de execução apresentado.

Consideraçöes sobre os Termos de apresentação obrigatória:

Folha de Rosto: apresentada. Assinada pelo Diretor da CGSS.

Termo de Concordância: apresentado. Assinado pelo gerente do CSS n 3 e pelo diretor da CGSS.

TCLE: apresentado.

Curriculo da pesquisadora: apresentado.

Recomendaçöes:

Conclusões ou Pendências e Lista de Inadequaçöes:

Projeto em conformidade com a Resoluçäo 466/2012.

Situação do Parecer:

Aprovado

Necessita Apreciaçäo da CONEP:

Näo

Endereģo: SMHN 2 Qd 501 BLOCO A - FEPECS

BalrTo: ASA NORTE CEP: 70.710-904

UF: DF Municiplo: BRASILIA

Telefone: (61)3325-4955 Fax: (33)3325-4955

E-mall: comltedeetca.secretarlaggmal.com 


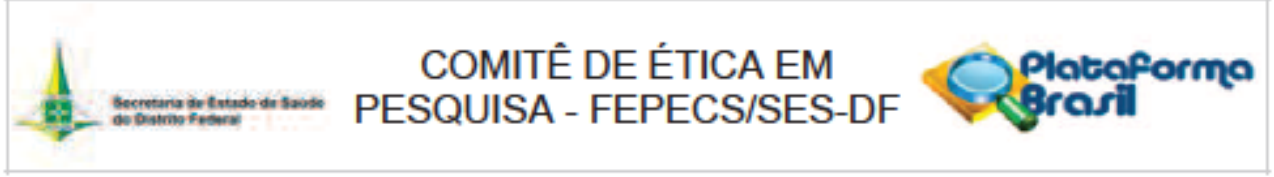

Contlnusçso do Parecer. 688.050

Consideraçöes Finais a critério do CEP:

BRASILIA, 16 de Junho de 2014

Assinado por:

luiz fernando galväo salinas

(Coordenador)

Endereço: SMHN 2 Qd 501 BLOCO A - FEPECS

BalrTo: ASA NORTE CEP: $70.710-904$

UF: DF Municipio: BRASILIA

Telefone: (61)3325-4955

Fax: (33) $3325-4955$

E-mall: comitedeetca.secretarlaggmal.com 
ANEXO C - Versão original do instrumento Medical Office Survey on Patient Safety Culture

\section{Medical Office Survey on Patient Safety}

\section{SURVEY INSTRUCTIONS}

Think about the way things are done in your medical office and provide your opinions on issues that affect the overall safety and quality of the care provided to patients in your office.

In this survey, the term provider refers to physicians, physician assistants, and nurse practitioners who diagnose, treat patients, and prescribe medications. The term staff refers to all others who work in the office.

- If a question does not apply to you or you don't know the answer, please check aDoes Not Apply or Don't Know."

- If you work in more than one office or location for your practice, when answering this survey answer only about the office location where you received this survey - do not answer about the entire practice.

- If your medical office is in a building with other medical offices, answer only about the specific medical office where you work-do not answer about any other medical offices in the building.

\section{SECTION A: List of Patient Safety and Quality Issues}

The following items describe things that can happen in medical offices that affect patient safety and quality of care. In your best estimate, how often did the following things happen in your medical office OVER THE PAST 12 MONTHS?

\section{Access to Care}

1. A patient was unable to get an appointment within $\mathbf{4 8}$ hours for an acute/serious problem

\section{Patient Identification}

2. The wrong chart/medical record was used for a patient.

Charts/Medical Records

3. A patient's chart/medical record was not available when needed

4. Medical information was filed, scanned, or entered into the wrong patient's chart/medical record.

Medical Equipment

5. Medical equipment was not working properly or was in need of repair or replacement.

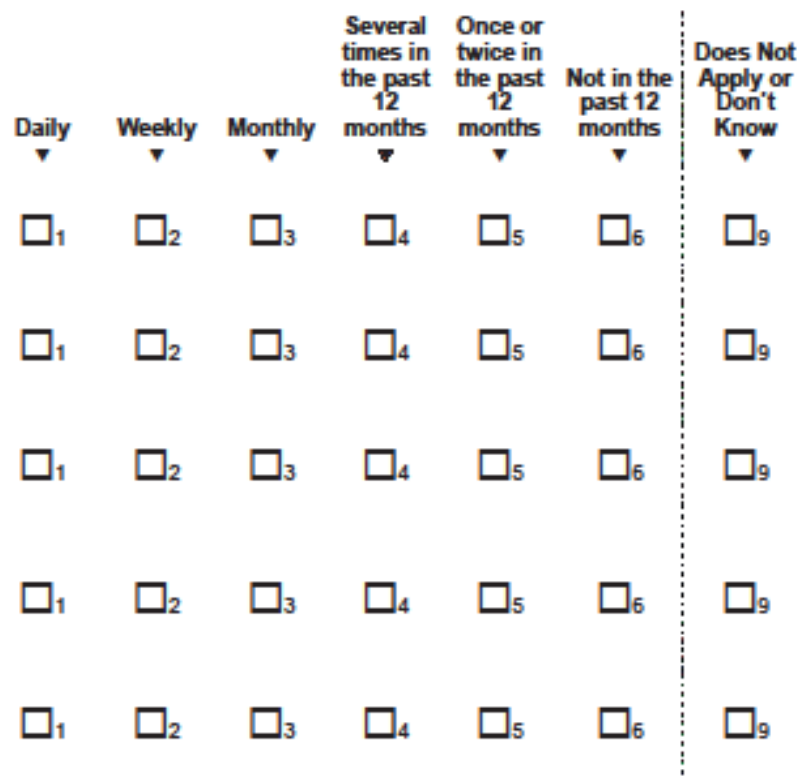




\section{SECTION A: List of Patient Safety and Quality Issues (continued)}

How often did the following things happen in your medical office OVER THERAST 12MONTHS?

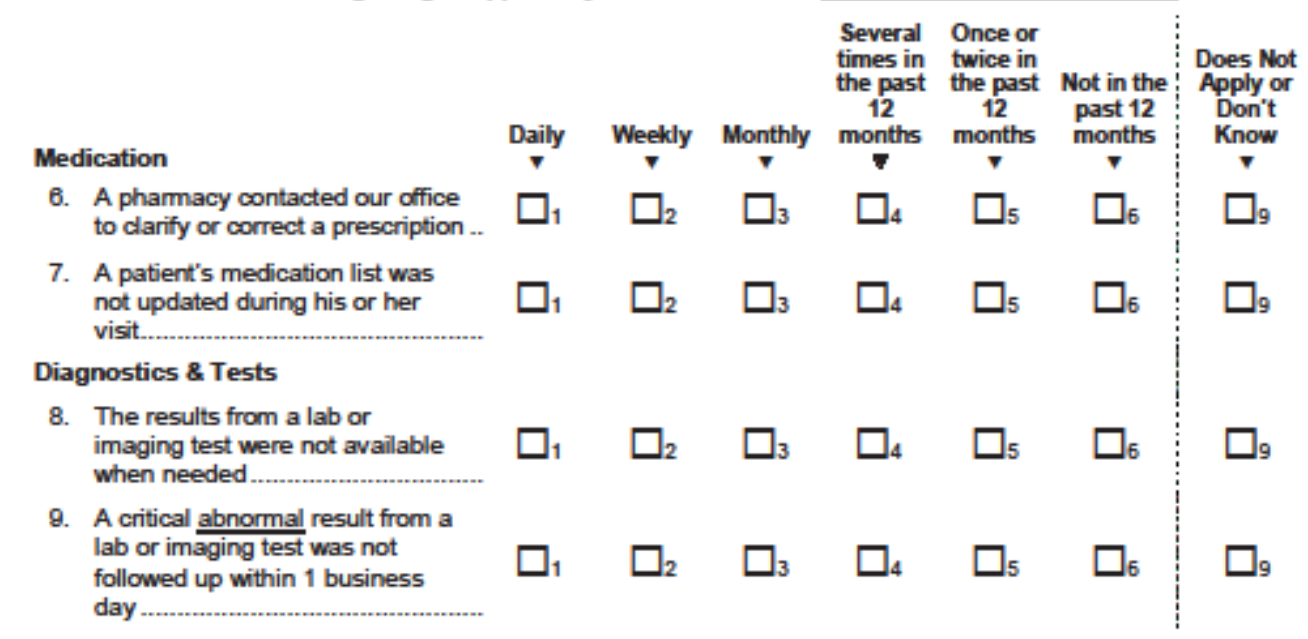

\section{SECTION B: Information Exchange With Other Settings}

Over the past 12 months, how often has your medical office had problems exchanaing accurate.complete. and timelv information with:

1. Outside labs/imaging centers?

\begin{tabular}{|c|c|c|c|c|c|c|}
\hline $\begin{array}{c}\text { Problems } \\
\text { daily } \\
\nabla\end{array}$ & $\begin{array}{c}\text { Problems } \\
\text { weekly } \\
7\end{array}$ & $\begin{array}{c}\text { Problems } \\
\text { monthly }\end{array}$ & $\begin{array}{l}\text { Problems } \\
\text { several } \\
\text { times } \\
\text { in the past } \\
12 \text { months } \\
\end{array}$ & $\begin{array}{l}\text { Problems } \\
\text { once or } \\
\text { twice } \\
\text { in the past } \\
12 \text { months } \\
\end{array}$ & $\begin{array}{l}\text { No } \\
\text { problems } \\
\text { in the } \\
\text { past } 12 \\
\text { months } \\
\text { v }\end{array}$ & $\begin{array}{c}\text { Does } \\
\text { Not } \\
\text { Apply or } \\
\text { Don't } \\
\text { Know } \\
\text { T }\end{array}$ \\
\hline & & & & & & \\
\hline & & & & & & \\
\hline & & & & & & \\
\hline & & & & & & \\
\hline & & & & & & \\
\hline
\end{tabular}


How much do you agree or disagree with the following statements?

1. When someone in this office gets really busy. others help out.

2. In this office, there is a good working relationship between staff and providers

3. In this office, we often feel rushed when taking care of patients

4. This office trains staff when new processes are put into place.

5. In this office, we treat each other with respect....

6. We have too many patients for the number of providers in this office.

7. This office makes sure staff get the on-the-job training they need

8. This office is more disorganized than it should be.

9. We have good procedures for checking that work in this office was done correctly.

10. Staff in this office are asked to do tasks they haven't been trained to do.

11. We have enough staff to handle our patient load..

12. We have problems with workfiow in this office .....

13. This office emphasizes teamwork in taking care of patients

14. This office has too many patients to be able to handle everything effectively.

15. Staff in this office follow standardized processes to get tasks done

\begin{tabular}{|c|c|c|c|c|c|}
\hline & & $\begin{array}{l}\text { Neither } \\
\text { Agree }\end{array}$ & & & \\
\hline Disagree & iagn & Disagree & Agree & Agree & Know \\
\hline$\square_{1}$ & $\square_{2}$ & $\square_{3}$ & $\square_{4}$ & $\square_{5}$ & $\square_{9}$ \\
\hline$\square_{1}$ & $\square_{2}$ & $\square_{3}$ & $\square_{4}$ & $\square_{5}$ & $\square_{9}$ \\
\hline$\square_{1}$ & $\square_{2}$ & $\square_{3}$ & $\square_{4}$ & $\square_{5}$ & $\square_{9}$ \\
\hline$\square_{1}$ & $\square_{2}$ & $\square_{3}$ & $\square_{4}$ & $\square_{5}$ & $\square_{9}$ \\
\hline$\square_{1}$ & $\square_{2}$ & $\square_{3}$ & $\square_{4}$ & $\square_{5}$ & $\square_{9}$ \\
\hline$\square_{1}$ & $\square_{2}$ & $\square_{3}$ & $\square_{4}$ & $\square_{5}$ & $\square_{9}$ \\
\hline$\square_{1}$ & $\square_{2}$ & $\square_{3}$ & $\square_{4}$ & $\square_{5}$ & $\square_{9}$ \\
\hline$\square_{1}$ & $\square_{2}$ & $\square_{3}$ & $\square_{4}$ & $\square_{5}$ & $\square_{9}$ \\
\hline$\square_{1}$ & $\square_{2}$ & $\square_{3}$ & $\square_{4}$ & $\square_{5}$ & $\square_{9}$ \\
\hline$\square_{1}$ & $\square_{2}$ & $\square_{3}$ & $\square_{4}$ & $\square_{5}$ & $\square_{9}$ \\
\hline$\square_{1}$ & $\square_{2}$ & $\square_{3}$ & $\square_{4}$ & $\square_{5}$ & $\square_{9}$ \\
\hline$\square_{1}$ & $\square_{2}$ & $\square_{3}$ & $\square_{4}$ & $\square_{5}$ & $\square_{9}$ \\
\hline$\square_{1}$ & $\square_{2}$ & $\square_{3}$ & $\square_{4}$ & $\square_{5}$ & $\square_{9}$ \\
\hline$\square_{1}$ & $\square_{2}$ & $\square_{3}$ & $\square_{4}$ & $\square_{5}$ & $\square_{9}$ \\
\hline$\square_{1}$ & $\square_{2}$ & $\square_{3}$ & $\square_{4}$ & $\square_{5}$ & $\square_{9}$ \\
\hline
\end{tabular}




\section{SECTION D: Communication and Followup}

\begin{tabular}{|c|c|c|c|c|c|c|}
\hline $\begin{array}{l}\text { low often } \\
\text { our medic }\end{array}$ & $\stackrel{\text { Never }}{\nabla}$ & Rarely & $\begin{array}{l}\text { Some- } \\
\text { times }\end{array}$ & $\begin{array}{l}\text { Most of } \\
\text { the time }\end{array}$ & Always & $\begin{array}{l}\text { Does Not } \\
\text { Apply or } \\
\text { Don't } \\
\text { Know } \\
\end{array}$ \\
\hline $\begin{array}{l}\text { 1. Providers in this office are open to staff ideas } \\
\text { about how to improve office processes.... }\end{array}$ & $\square_{1}$ & $\square_{2}$ & $\square_{3}$ & $\square_{4}$ & $\square_{5}$ & $\square_{9}$ \\
\hline $\begin{array}{l}\text { 2. Staff are encou } \\
\text { viewpoints in th }\end{array}$ & $\square_{1}$ & $\square_{2}$ & $\square_{3}$ & $\square_{4}$ & $\square_{5}$ & $\square_{9}$ \\
\hline $\begin{array}{l}\text { 3. This office reminds patients when they need to } \\
\text { schedule an appointment for preventive or } \\
\text { routine care }\end{array}$ & $\square_{1}$ & $\square_{2}$ & $\square_{3}$ & $\square_{4}$ & $\square_{5}$ & $\square_{9}$ \\
\hline $\begin{array}{l}\text { 4. Staff are afraid to ask questions when } \\
\text { something does not seem right.......... }\end{array}$ & $\square_{1}$ & $\square_{2}$ & $\square_{3}$ & $\square 4$ & $\square_{5}$ & $\square_{9}$ \\
\hline $\begin{array}{l}\text { 5. This office documents how well our chronic- } \\
\text { care patients follow their treatment plans .... }\end{array}$ & $\square_{1}$ & $\square_{2}$ & $\square_{3}$ & $\square_{4}$ & $\square_{5}$ & $\square_{9}$ \\
\hline $\begin{array}{l}\text { Our office follows up when we do not receive a } \\
\text { report we are expecting from an outside } \\
\text { provider }\end{array}$ & $\square_{1}$ & $\square_{2}$ & $\square_{3}$ & $\square_{4}$ & $\square_{5}$ & $\square_{9}$ \\
\hline $\begin{array}{l}\text { 7. Staff feel like their mistakes are held against } \\
\text { them. }\end{array}$ & $\square_{1}$ & $\square_{2}$ & $\square_{3}$ & $\square_{4}$ & $\square_{5}$ & $\square_{9}$ \\
\hline $\begin{array}{l}\text { 8. Providers and staff talk openly about office } \\
\text { problems }\end{array}$ & $\square_{1}$ & $\square_{2}$ & $\square_{3}$ & $\square_{4}$ & $\square_{5}$ & $\square_{9}$ \\
\hline $\begin{array}{l}\text { 9. This office follows up with patients who need } \\
\text { monitoring.... }\end{array}$ & $\square_{1}$ & $\square_{2}$ & $\square_{3}$ & $\square_{4}$ & $\square_{5}$ & $\square_{9}$ \\
\hline It is difficult to voice disagreement in this office.... & $\square_{1}$ & $\square_{2}$ & $\square_{3}$ & $\square_{4}$ & $\square_{5}$ & $\square_{9}$ \\
\hline $\begin{array}{l}\text { 11. In this office, we discuss ways to prevent errors } \\
\text { from happening again ..... }\end{array}$ & $\square_{1}$ & $\square_{2}$ & $\square_{3}$ & $\square_{4}$ & $\square_{5}$ & $\square_{9}$ \\
\hline $\begin{array}{l}\text { Staff are willing to report mistakes they } \\
\text { in this office .... }\end{array}$ & $\square_{1}$ & $\square_{2}$ & $\square_{3}$ & $\square_{4}$ & $\square_{5}$ & $\square_{9}$ \\
\hline
\end{tabular}




\section{SECTION E: Owner/Managing Partner/Leadership Support}

A. Are you an owner, a managing partner, or in a leadership position with responsibility for making financial decisions for your medical office?

\footnotetext{
$--\square$ Yes $\rightarrow$ Go to Section F

$\square_{2}$ No $\rightarrow$ Continue below
}

How much do you agree or disagree with the following statements about the owners/managing partners/leadership of your medical office?

1. They aren't investing enough resources to improve the quality of care in this office.

2. They overlook patient care mistakes that happen over and over

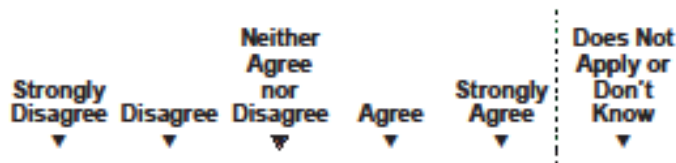

3. They place a high priority on improving patient care processes

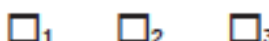

$\square_{1} \quad \square_{2}-\square_{3}$

$\square_{4}$

$\square_{5} \quad \square_{9}$

4. They make decisions too often based on what is best for the office rather than what is best for patients.

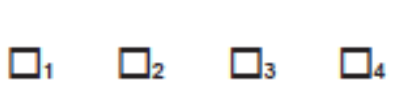

How much do you agree or disagree with the following statements?

1. When there is a problem in our office, we see if we need to change the way we do things

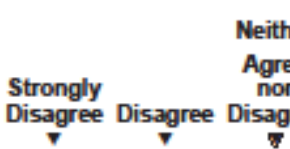

\section{Neither}

Our office processes are good at preventing mistakes that could affect patients.

$\underset{\nabla}{\nabla}$

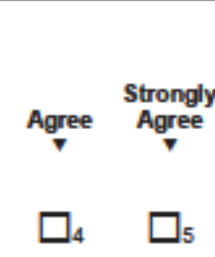

Mistakes happen more than they should in this office.<smiles>[TeH]</smiles>

. It is just by chance that we don't make more mistakes that affect our patients

5. This office is good at changing office processes to make sure the same problems don't happen again.

$\square_{1} \quad \square_{2} \quad \square_{3} \quad \square$

. In this office, getting more work done is more important than quality of care

After this office makes changes to improve the patient care process, we check to see if the changes worked. 


\section{Overall Ratings on Quality}

1. Overall, how would you rate your medical office on each of the following areas of health care quality?

\begin{tabular}{|c|c|c|c|c|c|c|}
\hline & & Poor & Fair & Good & Very good & $\underset{\nabla}{\text { Excellent }}$ \\
\hline $\begin{array}{l}\text { a. Patient } \\
\text { centered }\end{array}$ & $\begin{array}{l}\text { Is responsive to individual } \\
\text { patient preferences, needs, } \\
\text { and values... }\end{array}$ & $\square$ - & $\square_{2}$ & $\square 3$ & $\square 4$ & $\square_{5}$ \\
\hline b. Effective & $\begin{array}{l}\text { Is based on scientific } \\
\text { knowledge }\end{array}$ & $\square_{1}$ & $\square_{2}$ & $\square_{3}$ & $\square_{4}$ & $\square_{5}$ \\
\hline c. Timely & $\begin{array}{l}\text { Minimizes waits and potentially } \\
\text { harmful delays }\end{array}$ & $\square_{1}$ & $\square_{2}$ & $\square_{3}$ & $\square 4$ & $\square_{5}$ \\
\hline d. Efficient & $\begin{array}{l}\text { Ensures cost-effective care } \\
\text { (avoids waste, overuse, and } \\
\text { misuse of services)... }\end{array}$ & $\square$ & $\square_{2}$ & $\square 3$ & $\square 4$ & $\square_{5}$ \\
\hline e. Equitable & $\begin{array}{l}\text { Provides the same quality of } \\
\text { care to all individuals } \\
\text { regardless of gender, race. } \\
\text { ethnicity, socioeconomic } \\
\text { status, language, etc.... }\end{array}$ & $\square_{1}$ & $\square 2$ & $\square_{3}$ & $\square 4$ & $\square_{5}$ \\
\hline
\end{tabular}

\section{Overall Rating on Patient Safety}

2. Overall, how would you rate the systems and clinical processes your medical office has in place to prevent, catch, and correct problems that have the potential to affect patients?

$\begin{array}{ccccc}\begin{array}{l}\text { Poor } \\ \boldsymbol{\nabla}\end{array} & \begin{array}{c}\text { Fair } \\ \boldsymbol{\nabla}\end{array} & \begin{array}{c}\text { Good } \\ \boldsymbol{\nabla}\end{array} & \begin{array}{c}\text { Very good } \\ \mathbf{\nabla}\end{array} & \begin{array}{c}\text { Excellent } \\ \boldsymbol{\nabla}\end{array} \\ \square_{1} & \square_{2} & \square_{3} & \square_{4} & \square_{5}\end{array}$

\section{SECTION H: Background Questions}

1. How long have you worked in this medical office location?
$\square$ a. Less than 2 months
$\square$ d. 3 years to less than 6 years
$\square$ b. 2 months to less than 1 year
$\square$ e. 6 years to less than 11 years
$\square$ c. 1 year to less than 3 years
$\square$ f. 11 years or more

2. Typically, how many hours per week do you work in this medical office location?
$\square$ a. 1 to 4 hours per week
$\square$ d. 25 to 32 hours per week
$\square$ b. 5 to 16 hours per week
$\square$ e. 33 to 40 hours per week
$\square$ c. 17 to 24 hours per week
$\square$ f. 41 hours per week or more 


\section{SECTION H: Background Questions (continued)}

3. What is your position in this office? Check ONE category that best applies to your job.

$\square$ a. Physician (MD or DO)

$\square$ b. Physician Assistant, Nurse Practitioner, Clinical Nurse Specialist, Nurse Midwife, Advanced Practice Nurse, etc.

$\square$ c. Management

$$
\begin{array}{ll}
\text { Practice Manager } & \text { Business Manager } \\
\text { Office Manager } & \text { Nurse Manager } \\
\text { Office Administrator } & \text { Lab Manager } \\
& \text { Other Manager }
\end{array}
$$

d. Administrative or clerical staff

$\begin{array}{ll}\text { Insurance Processor } & \text { Front Desk } \\ \text { Billing Staff } & \text { Receptionist } \\ \text { Referral Staff } & \text { Scheduler (appointments, surgery, etc.) } \\ \text { Medical Records } & \text { Other administrative or clerical staff position }\end{array}$

Medical Records Other administrative or clerical staff position

$\square$ e. Nurse (RN), Licensed Vocational Nurse (LVN), Licensed Practical Nurse (LPN)

$\square$ f. Other clinical staff or clinical support staff
Medical Assistant
Technician (all types)
Nursing Aide
Therapist (all types)
Other dinical staff or clinical support staff

$\square$ g. Other position; please specify:

\section{SECTION I: Your Comments}

Please feel free to write any comments you may have about patient safety or quality of care in your medical office. 
ANEXO D - Características dos tradutores das etapas de tradução e retrotradução

\begin{tabular}{|l|l|c|}
\hline Instrumento Original: & \multicolumn{2}{|c|}{ Medical Office Survey on Patient Safety } \\
\hline \multicolumn{1}{|c|}{ Etapa } & \multicolumn{1}{|c|}{ Responsável } & Obs. \\
\hline Forward Translation 1 & Luana Guedes & \\
\hline Forward Translation 2 & Sabrina Mikael & \\
\hline Back Translation 1 & Maya Bellomo-Johnson & \\
\hline Back Translation 2 & Isabella Rennie Kenfield & \\
\hline Acompanhamento & Luísa Caliri & \\
\hline
\end{tabular}

Informação dos tradutores envolvidos:

\begin{tabular}{|l|l|}
\hline Nome completo: & Sabrina de Souza Elias Mikael \\
\hline Nacionalidade: & Brasileira \\
\hline Graduação: & Bacharelado em Enfermagem \\
\hline $\begin{array}{l}\text { Domínio da língua inglesa } \\
\text { (nativo/fluente): }\end{array}$ & Fluente \\
\hline $\begin{array}{l}\text { Domínio da língua portuguesa } \\
\text { (nativo/fluente): }\end{array}$ & Nativo \\
\hline Observações adicionais: & $\begin{array}{l}\text { Formada na Universidade de São Paulo - } \\
\text { USP, com diploma validado nos Estados } \\
\text { Unidos. }\end{array}$ \\
\hline
\end{tabular}

\begin{tabular}{|l|l|}
\hline Nome completo: & Luana Guedes de Oliveira \\
\hline Nacionalidade: & Brasileira \\
\hline Graduação: & Letras - Tradutor e Intérprete \\
\hline $\begin{array}{l}\text { Domínio da língua inglesa } \\
\text { (nativo/fluente): }\end{array}$ & Fluente \\
\hline $\begin{array}{l}\text { Domínio da língua portuguesa } \\
\text { (nativo/fluente): }\end{array}$ & Nativo \\
\hline Observações adicionais: & Tradutor especialista na área da saúde \\
\hline
\end{tabular}

\begin{tabular}{|l|l|}
\hline Nome completo: & Maya Bellomo-Johnson \\
\hline Nacionalidade: & Brasileira e Americana \\
\hline Graduação: & Psicologia \\
\hline $\begin{array}{l}\text { Domínio da língua inglesa } \\
\text { (nativo/fluente): }\end{array}$ & Nativo \\
\hline $\begin{array}{l}\text { Domínio da língua portuguesa } \\
\text { (nativo/fluente): }\end{array}$ & Nativo \\
\hline Observações adicionais: & $\begin{array}{l}\text { Especialização em Psicologia Clínica e } \\
\text { Formação em Tradução Português-Inglês } \\
\text { com 6 anos de experiência com tradução, } \\
\text { principalmente na área das ciências da } \\
\text { saúde e sociais. }\end{array}$ \\
\hline
\end{tabular}




\begin{tabular}{|l|l|}
\hline Nome completo: & Isabella Rennie Kenfield \\
\hline Nacionalidade: & Americana \\
\hline Graduação: & Graduada em antropologia e jornalismo \\
\hline $\begin{array}{l}\text { Domínio da língua inglesa } \\
\text { (nativo/fluente): }\end{array}$ & Nativo \\
\hline $\begin{array}{l}\text { Domínio da língua portuguesa } \\
\text { (nativo/fluente): }\end{array}$ & Fluente \\
\hline Observações adicionais: & $\begin{array}{l}\text { Mestrada em desenvolvimento } \\
\text { comunitário rural; Certificada em } \\
\text { interpretação simultânea médica. }\end{array}$ \\
\hline
\end{tabular}




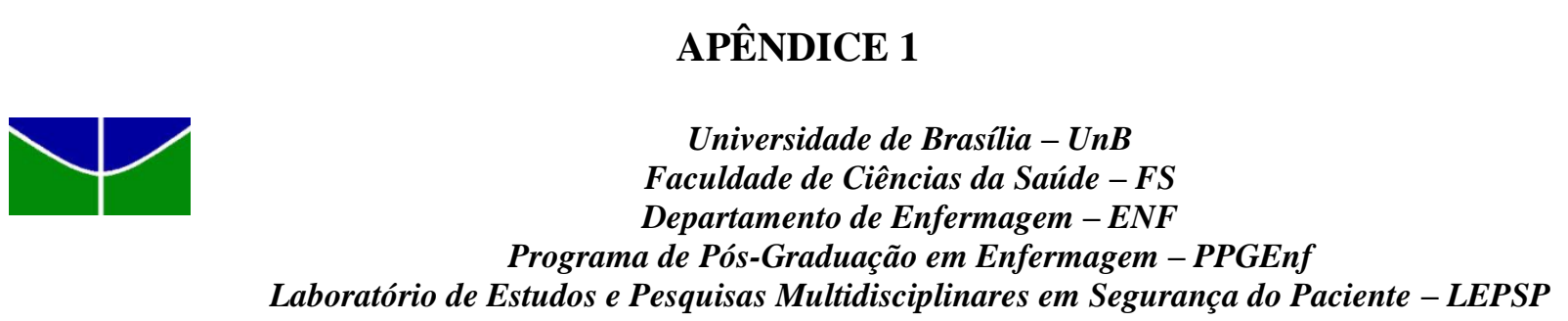

\section{Termo de Consentimento Livre e Esclarecido - TCLE}

Cultura de Segurança do Paciente na Atenção Primária à Saúde: adaptação transcultural do questionário Medical Office Survey on Patient Safety Culture (MOSPS).

O (a) Senhor(a) está sendo convidado(a) a participar da pesquisa acima identificada, que tem como objetivo, especificamente, traduzir, realizar a adaptação cultural e validar o questionário MOSPS da Agency for Health Care Research and Quality, para mensurar a cultura de segurança do paciente nas equipes de Atenção Primária à saúde no Brasil. Trata-se de um projeto de mestrado acadêmico desenvolvido junto ao PPGEnf da UnB.

O (a) senhor(a) receberá todos os esclarecimentos necessários antes e no decorrer da pesquisa, sendo assegurado o mais rigoroso sigilo através da omissão total de quaisquer informações que permitam identificá-lo(a).

Sua participação é voluntária, respondendo a um questionário que consta de 52 questões que medem 12 dimensões do construto segurança do paciente. O questionário será aplicado na Atenção Primária da Regional de Sobradinho, na data combinada, com um tempo estimado para seu preenchimento de 30 minutos. Não existe, obrigatoriamente, um tempo pré-determinado para responder o questionário. Será respeitado o tempo de cada um para respondê-lo. Informamos que o (a) Senhor (a) pode se recusar a responder qualquer questão que lhe traga constrangimento, podendo desistir de participar da pesquisa em qualquer momento sem nenhum prejuízo para o (a) senhor (a). A participação no estudo não acarretará custos para você e não será disponível nenhuma compensação financeira.

Esse estudo contribuirá para compreensão da cultura de segurança como primeiro passo para propor estratégias de intervenção na Atenção Primária, de modo a melhorar a qualidade dos serviços de saúde prestados no país. A participação na pesquisa poderá causar riscos mínimos, no entanto, lhe é garantida indenização diante de eventuais danos decorrentes da pesquisa.

Os resultados da pesquisa serão divulgados no ato de defesa da dissertação de mestrado e para Secretaria Estadual de Saúde do DF, podendo ser publicados posteriormente. Os dados e materiais utilizados na pesquisa ficarão sobre a guarda da pesquisadora responsável.

Se tiver qualquer dúvida em relação à pesquisa, por favor, telefone para Enfermeira Márcia Timm, na Clínica da Família de Sobradinho II da Secretaria Estadual de Saúde, telefone: 34830269 ou 99475222, no horário: das 7 às 18h ou pelo e-mail: marcia.timm@gmail.com.

Este projeto foi Aprovado pelo Comitê de Ética em Pesquisa da SES/DF. As dúvidas com relação à assinatura do TCLE ou os direitos do participante da pesquisa podem ser obtidos através do telefone (61) 3325-4955.

$\mathrm{Eu}$, fui informado (a) dos objetivos da pesquisa acima de maneira clara e detalhada e esclareci minhas dúvidas. Sei que em qualquer momento poderei solicitar novas informações e motivar minha decisão se assim o desejar. Desta forma, declaro, de forma livre e espontânea, que concordo em participar desse estudo. Recebi uma cópia deste termo de consentimento livre e esclarecido e me foi dada a oportunidade de ler e esclarecer as minhas dúvidas.

( ) Desejo conhecer os resultados desta pesquisa.

( ) Não desejo conhecer os resultados desta pesquisa.

Assinatura do participante da pesquisa

Brasília, $/ 2015$.
Pesquisadora Responsável

Márcia Timm - COREN - DF 80.073 


\section{APÊNDICE 2}

\section{Característica dos participantes}

1. Idade? anos

2. Gênero: $\square$ a. Feminino

b. Masculino

\section{Grau de instrução:}

$\square$ a. Ensino Médio Incompleto

$\square$ b. Ensino Médio Concluído

$\square$ c. Ensino Superior em andamento

$\square$ d. Ensino Superior concluído

$\square$ e. Especialização em andamento

$\square$ f. Especialização concluída

$\square$ g. Mestrado ou Doutorado em andamento

$\square$ h. Mestrado ou Doutorado concluído

4. Qual seu cargo neste serviço? Marque UMA categoria que melhor se aplica ao seu trabalho.

$\square$ Gerência $\quad \square$ Chefia de Enfermagem $\quad \square$ Terapeuta Ocupacional

$\square$ Enfermeiro $\square$ Médico $\quad \square$ Técnico de Enfermagem

$\square$ Administrador $\square$ Odontólogo $\square$ Agente Comunitário de Saúde

Nutricionista $\square$ Farmacêutico $\square$ TSB (Técnico em Saúde Bucal)

Psicólogo $\square$ Fisioterapeuta $\quad \square$ Técnico de Laboratório

Assistente Social

Equipe administrativa ( Recepção, Registros, agendamentos)

$\square$ Outro, de nível técnico. Por favor, especifique:

\section{Quantas horas semanais trabalha neste serviço?}

De uma a $4 \mathrm{~h}$ por semana

$\square$ De 5 a 16 h por semana

$\square$ De 17 a 24 h por semana

$\square$ De 25 a $32 \mathrm{~h}$ por semana

De 33 a $40 \mathrm{~h}$ 
6. No seu cargo/função, em geral você tem interação ou contato direto com pacientes?

a. Sim $\square$ b. Não

8. Há quanto tempo você trabalha na sua especialidade ou profissão atual?
$\square$ a. Menos de 1 ano
$\square$ d. 11 a 15 anos
$\square$ b. 1 a 5 anos
$\square$ e. 16 a 20 anos
c. 6 a 10 anos
$\square$ f. 21 anos ou mais

9. Há quanto tempo você trabalha neste serviço de saúde?

$\square$ a. Há menos de 2 meses

$\square$ b. De 2 meses a menos de 1 ano

$\square$ c. De 1 ano a menos de 3 anos $\square$ d. De 3 anos a menos de 6 anos

$\square$ e. De 6 anos a menos de 11 anos

$\square$ f. Há 11 anos ou mais 


\section{APÊNDICE 3}

\section{Comparação da primeira síntese T1-2 e após avaliação dos especialistas.}

\begin{tabular}{|c|c|}
\hline Versão síntese T1-2 & Versão após avaliação dos especialistas \\
\hline $\begin{array}{l}\text { Seção A: Lista de questões sobre } \\
\text { segurança do paciente e qualidade }\end{array}$ & $\begin{array}{l}\text { Seção A: Lista de questões sobre } \\
\text { segurança do paciente e qualidade }\end{array}$ \\
\hline $\begin{array}{l}\text { Os itens a seguir descrevem coisas que } \\
\text { podem acontecer em consultórios médicos } \\
\text { e que afetam a segurança do paciente e a } \\
\text { qualidade do cuidado. Pelos seus cálculos, } \\
\text { com que frequência as seguintes coisas } \\
\text { aconteceram em seu consultório médico } \\
\text { AO LONGO DOS ÚLTIMOS } 12 \text { MESES? } \\
\square \text { 1. Diariamente } \\
\square \text { 2. Semanalmente } \\
\square \text { 3. Mensalmente } \\
\square \text { 4. Várias vezes nos últimos } 12 \text { meses } \\
\square \text { 5. Uma ou duas vezes nos últimos } 12 \\
\text { meses } \\
\square \text { 6. Não aconteceu nos últimos } 12 \text { meses } \\
\square \text { 9. Não se aplica ou não sei } \\
\text { Acesso a Assistência }\end{array}$ & $\begin{array}{l}\text { Os itens a seguir descrevem situações que } \\
\text { podem ocorrer em serviços de saúde, } \\
\text { afetando a segurança do paciente e a } \\
\text { qualidade do cuidado. Pelos seus cálculos, } \\
\text { com que frequência os fatos listados } \\
\text { abaixo aconteceram em seu local de } \\
\text { trabalho NOS ÚLTIMOS } 12 \text { MESES? } \\
\square \text { 1. Diariamente } \\
\square \text { 2. Pelo menos uma vez na semana } \\
\square \text { 3. Pelo menos uma vez ao mês } \\
\square \text { 4. Várias vezes nos últimos } 12 \text { meses } \\
\square \text { 5. Uma ou duas vezes nos últimos } 12 \\
\text { meses } \\
\square 6 \text {. Não aconteceu nos últimos } 12 \text { meses } \\
\square 9 \text {. Não se aplica ou não sei } \\
\text { Acesso ao cuidado }\end{array}$ \\
\hline $\begin{array}{l}\text { 1. Um paciente não conseguiu uma } \\
\text { consulta em até } 48 \text { horas para um } \\
\text { problema sério/agudo. } \\
\text { Identificação do paciente }\end{array}$ & $\begin{array}{l}\text { 1. Um paciente não conseguiu uma } \\
\text { consulta em até } 48 \text { horas para um } \\
\text { problema sério/agudo. } \\
\text { Identificação do paciente }\end{array}$ \\
\hline $\begin{array}{l}\text { 2. Um prontuário/registro médico errado } \\
\text { foi utilizado para um paciente. }\end{array}$ & $\begin{array}{l}\text { 2. Um prontuário/registro errado foi } \\
\text { utilizado de outro paciente. }\end{array}$ \\
\hline Prontuários/registros médicos & Prontuários/registros \\
\hline $\begin{array}{l}\text { 3. O prontuário/registro médico de um } \\
\text { paciente não estava disponível quando } \\
\text { necessário. }\end{array}$ & $\begin{array}{l}\text { 3. O prontuário/registro de um paciente } \\
\text { não estava disponível quando } \\
\text { necessário. }\end{array}$ \\
\hline $\begin{array}{l}\text { 4. Informações médicas foram } \\
\text { arquivadas, digitalizadas ou inseridas } \\
\text { no prontuário/registro médico do } \\
\text { paciente errado. }\end{array}$ & $\begin{array}{l}\text { 4. Informações clínicas foram arquivadas, } \\
\text { digitalizadas ou inseridas no } \\
\text { prontuário/registro do paciente errado. }\end{array}$ \\
\hline Equipamento & Equipamento \\
\hline $\begin{array}{l}\text { 5. Um equipamento não estava } \\
\text { funcionando adequadamente ou } \\
\text { necessitava reparo ou substituição. }\end{array}$ & $\begin{array}{l}\text { 5. Um equipamento não funcionou } \\
\text { adequadamente ou necessitava } \\
\text { reparo ou substituição. }\end{array}$ \\
\hline $\begin{array}{l}\text { Medicação } \\
\text { 6. Uma farmácia entrou em contato com } \\
\text { o nosso consultório para esclarecer ou } \\
\text { corrigir uma prescrição }\end{array}$ & $\begin{array}{l}\text { Medicamento } \\
\text { 6. Um farmacêutico (a) entrou em contato } \\
\text { com a unidade de saúde para esclarecer } \\
\text { ou corrigir uma prescrição. }\end{array}$ \\
\hline $\begin{array}{l}\text { 7. A lista de medicamentos de um } \\
\text { paciente não foi atualizada durante a } \\
\text { sua consulta. }\end{array}$ & $\begin{array}{l}\text { 7. Os medicamentos utilizados de um } \\
\text { paciente não foram atualizados durante } \\
\text { a consulta. }\end{array}$ \\
\hline
\end{tabular}


Diagnósticos \& Exames

8. Os resultados de um exame laboratorial ou de imagem não estavam disponíveis quando necessário.

9. Um resultado crítico anormal de um exame laboratorial ou de imagem não foi acompanhado dentro de um dia útil.
Diagnósticos \& Testes

8. Os resultados de exames laboratoriais ou de imagem não estavam disponíveis quando necessário.

9. Um resultado anormal de um exame laboratorial ou de imagem não foi acompanhado/avaliado em tempo hábil.

\begin{tabular}{l}
\hline Versão síntese T1-2 \\
\hline Seção B: Troca de informações com outras \\
instituições \\
\hline Nos últimos 12 meses, com que frequência \\
o seu serviço de saúde apresentou \\
problemas relacionados à troca de \\
informações completas, precisas e pontuais \\
com:
\end{tabular}

1. Centros de imagem/laboratórios externos?

2. Outros serviços de saúde/médicos externos?

3. Farmácias?

4. Hospitais?

5. Outro? (Especificar):

$\square$ 1. Problemas diariamente

$\square$ 2. Problemas semanalmente

$\square$ 3. Problemas mensalmente

$\square$ 4. Vários problemas nos últimos 12 meses

$\square$ 5. Um ou dois problemas nos últimos 12 meses

$\square$ 6. Nenhum problema nos últimos 12 meses

$\square$ 9. Não se aplica ou não sei

\section{Versão após avaliação dos especialistas}

Seção B: Troca de informações com outras instituições

Nos últimos 12 meses, com que frequência o seu serviço de saúde apresentou problemas relacionados à troca de informações completas, precisas e pontuais com:

1. Centros de imagem/laboratórios externos?

2. Outros serviços de saúde/médicos externos?

3. Farmácias?

4. Hospitais?

5. Outro? (Especificar):

$\square$ 1. Problemas diariamente

$\square$ 2. Problema pelo menos uma vez na semana

$\square$ 3. Problema pelo menos uma vez ao mês

$\square$ 4. Vários problemas nos últimos 12 meses

$\square$ 5. Um ou dois problemas nos últimos 12 meses

$\square$ 6. Nenhum problema nos últimos 12 meses

$\square$ 9. Não se aplica ou não sei

\begin{tabular}{|l|l|}
\hline Versão síntese T1-2 & Versão após avaliação dos especialistas \\
\hline Seção C: Trabalhando em seu consultório & $\begin{array}{l}\text { Seção C: Trabalhando em seu serviço de } \\
\text { médico }\end{array}$ \\
\hline Quanto você concorda ou discorda das & Quanto você concorda ou discorda das \\
seguintes afirmações? & seguintes afirmações? \\
$\square$ 1. Discordo fortemente & $\square$ 1. Discordo totalmente \\
$\square$ 2. Discordo & $\square$ 2. Discordo \\
$\square$ 3. Não concordo nem discordo & $\square$ 3. Não concordo nem discordo \\
\hline
\end{tabular}




\begin{tabular}{|c|c|}
\hline $\begin{array}{l}\square \text { 4. Concordo } \\
\square \text { 5. Concordo fortemente } \\
\square 9 \text {. Não se aplica ou não sei } \\
\end{array}$ & $\begin{array}{l}\square \text { 4. Concordo } \\
\square \text { 5. Concordo totalmente } \\
\square 9 \text {. Não se aplica ou não sei } \\
\end{array}$ \\
\hline $\begin{array}{l}\text { 1. Quando alguém em seu consultório está } \\
\text { muito ocupado, as outras pessoas } \\
\text { ajudam. }\end{array}$ & $\begin{array}{l}\text { 1. Quando alguém em seu serviço está } \\
\text { muito ocupado, as outras pessoas ajudam. }\end{array}$ \\
\hline $\begin{array}{l}\text { 2. Neste consultório, há uma boa relação } \\
\text { de trabalho entre a equipe e os } \\
\text { provedores. }\end{array}$ & $\begin{array}{l}\text { 2. No seu serviço, há uma boa relação de } \\
\text { trabalho entre os médicos e demais } \\
\text { profissionais. }\end{array}$ \\
\hline $\begin{array}{l}\text { 3. Neste consultório, com frequência nos } \\
\text { sentimos apressados ao cuidar dos } \\
\text { pacientes. }\end{array}$ & $\begin{array}{l}\text { 3. Neste serviço frequentemente nos } \\
\text { sentimos apressados ao atender o } \\
\text { paciente. }\end{array}$ \\
\hline $\begin{array}{l}\text { 4. Este consultório treina a equipe quando } \\
\text { novos processos são colocados em uso }\end{array}$ & $\begin{array}{l}\text { 4. Seu serviço treina a equipe sempre que } \\
\text { novos processos são implantados. }\end{array}$ \\
\hline $\begin{array}{l}\text { 5. Neste consultório, tratamos uns aos } \\
\text { outros com respeito. }\end{array}$ & $\begin{array}{l}\text { 5. Neste serviço tratamos uns aos outros } \\
\text { com respeito. }\end{array}$ \\
\hline $\begin{array}{l}\text { 6. Temos pacientes demais para o número } \\
\text { de provedores neste consultório . }\end{array}$ & $\begin{array}{l}\text { 6. Neste serviço a quantidade de } \\
\text { pacientes é muito alta em relação ao } \\
\text { número } \\
\text { de médicos disponíveis. } \\
\end{array}$ \\
\hline $\begin{array}{l}\text { 7. Este consultório se certifica de que sua } \\
\text { equipe recebe a capacitação prática que } \\
\text { precisa. }\end{array}$ & $\begin{array}{l}\text { 7. Este serviço garante que sua equipe } \\
\text { receba atualizações necessárias ao } \\
\text { atendimento. }\end{array}$ \\
\hline $\begin{array}{l}\text { 8. Este consultório é mais desorganizado } \\
\text { do que deveria ser. }\end{array}$ & $\begin{array}{l}\text { 8. Neste serviço a desorganização é maior } \\
\text { do que o aceitável. }\end{array}$ \\
\hline $\begin{array}{l}\text { 9. Temos bons procedimentos para } \\
\text { verificar se o trabalho neste consultório } \\
\text { foi realizado corretamente. }\end{array}$ & $\begin{array}{l}\text { 9. Neste serviço temos procedimentos } \\
\text { para verificar se o trabalho foi realizado } \\
\text { corretamente. }\end{array}$ \\
\hline $\begin{array}{l}\text { 10. Os funcionários da equipe deste } \\
\text { consultório são solicitados a fazer } \\
\text { tarefas que não foram treinados para } \\
\text { realizar. }\end{array}$ & $\begin{array}{l}\text { 10. Os profissionais que trabalham neste } \\
\text { serviço são solicitados a realizar tarefas } \\
\text { para as quais não foram treinados. }\end{array}$ \\
\hline $\begin{array}{l}\text { 11. Nossa equipe é suficiente para cuidar } \\
\text { do número de pacientes }\end{array}$ & $\begin{array}{l}\text { 11. Neste serviço a quantidade de } \\
\text { profissionais da equipe é suficiente para } \\
\text { atender o número de pacientes }\end{array}$ \\
\hline $\begin{array}{l}\text { 12. Temos problemas com o fluxo de } \\
\text { trabalho neste consultório. }\end{array}$ & $\begin{array}{l}\text { 12. Neste serviço temos problemas com o } \\
\text { fluxo de trabalho. }\end{array}$ \\
\hline $\begin{array}{l}\text { 13. Este consultório enfatiza o trabalho } \\
\text { em equipe no cuidado aos pacientes. }\end{array}$ & $\begin{array}{l}\text { 13. Este serviço valoriza o trabalho em } \\
\text { equipe no cuidado aos pacientes. }\end{array}$ \\
\hline $\begin{array}{l}\text { 14. Este consultório tem pacientes demais } \\
\text { para ser capaz de cuidar de tudo } \\
\text { eficazmente. }\end{array}$ & $\begin{array}{l}\text { 14. Neste serviço há número maior de } \\
\text { pacientes que a capacidade para atendê- } \\
\text { los de maneira eficiente. }\end{array}$ \\
\hline $\begin{array}{l}\text { 15. A equipe deste consultório segue } \\
\text { processos padronizados para cumprir } \\
\text { tarefas. }\end{array}$ & $\begin{array}{l}\text { 15. A equipe deste serviço segue } \\
\text { processos padronizados para realizar suas } \\
\text { tarefas. }\end{array}$ \\
\hline
\end{tabular}




\begin{tabular}{|c|c|}
\hline Versão síntese T1-2 & Versão após avaliação dos especialistas \\
\hline $\begin{array}{l}\text { Seção D: Comunicação e } \\
\text { Acompanhamento }\end{array}$ & $\begin{array}{l}\text { Seção D: Comunicação e } \\
\text { acompanhamento }\end{array}$ \\
\hline $\begin{array}{l}\text { Com que frequência as seguintes coisas } \\
\text { acontecem em seu consultório médico? } \\
\square \text { 1. Nunca } \\
\square \text { 2. Raramente } \\
\square \text { 3. Às vezes } \\
\square \text { 4. Quase sempre } \\
\square \text { 5. Sempre } \\
\square \text { 9. Não se aplica ou não sei }\end{array}$ & $\begin{array}{l}\text { Com que frequência os fatos a seguir } \\
\text { ocorrem em seu serviço? } \\
\square \text { 1. Nunca } \\
\square \text { 2. Raramente } \\
\square \text { 3. Às vezes } \\
\square \text { 4. Quase sempre } \\
\square \text { 5. Sempre } \\
\square \text { 9. Não se aplica ou não sei }\end{array}$ \\
\hline $\begin{array}{l}\text { 1. Os provedores deste consultório são } \\
\text { abertos para as ideias da equipe sobre } \\
\text { como melhorar os processos do } \\
\text { consultório }\end{array}$ & $\begin{array}{l}\text { 1. Os médicos deste serviço estão abertos } \\
\text { para as ideias dos demais integrantes da } \\
\text { equipe sobre como melhorar os } \\
\text { processos de trabalho. }\end{array}$ \\
\hline $\begin{array}{l}\text { 2. A equipe é incentivada a expressar } \\
\text { pontos de vista alternativos neste } \\
\text { consultório }\end{array}$ & $\begin{array}{l}\text { 2. Neste serviço a equipe é incentivada a } \\
\text { expressar outros pontos de vista. }\end{array}$ \\
\hline $\begin{array}{l}\text { 3. Este consultório lembra os pacientes } \\
\text { quando eles precisam agendar uma } \\
\text { consulta para cuidado preventivo ou de } \\
\text { rotina }\end{array}$ & $\begin{array}{l}\text { 3. Neste serviço os pacientes sáa avisados } \\
\text { quando precisam agendar uma consulta } \\
\text { para cuidados preventivos ou de rotina. }\end{array}$ \\
\hline $\begin{array}{l}\text { 4. A equipe tem medo de fazer perguntas } \\
\text { quando algo não parece correto. }\end{array}$ & $\begin{array}{l}\text { 4. Neste serviço a equipe tem receio de } \\
\text { fazer perguntas quando algo não parece } \\
\text { correto }\end{array}$ \\
\hline $\begin{array}{l}\text { 5. Este consultório documenta a forma } \\
\text { como pacientes crônicos seguem seu } \\
\text { plano de tratamento. }\end{array}$ & $\begin{array}{l}\text { 5. O seu serviço registra a maneira como } \\
\text { pacientes crônicos seguem seu plano de } \\
\text { tratamento }\end{array}$ \\
\hline $\begin{array}{l}\text { 6. Nosso consultório faz o } \\
\text { acompanhamento quando não recebemos } \\
\text { um relatório que estamos esperando de } \\
\text { um provedor externo. }\end{array}$ & $\begin{array}{l}\text { 6. Nosso serviço faz acompanhamento } \\
\text { quando não recebemos um relatório que } \\
\text { estamos esperando de outro serviço. }\end{array}$ \\
\hline $\begin{array}{l}\text { 7. A equipe sente que seus erros são } \\
\text { usados contra ela. }\end{array}$ & $\begin{array}{l}\text { 7. A equipe deste serviço acredita que } \\
\text { seus erros possam ser usados contra si. }\end{array}$ \\
\hline $\begin{array}{l}\text { 8. Os prestadores e funcionários falam } \\
\text { abertamente sobre os problemas do } \\
\text { consultório. }\end{array}$ & $\begin{array}{l}\text { 8. A equipe fala abertamente sobre os } \\
\text { problemas do seu serviço. }\end{array}$ \\
\hline $\begin{array}{lccc}\text { 9. Este consultório } & \text { acompanha } & \text { os } \\
\text { pacientes } & \text { que } & \text { precisam } & \text { de } \\
\text { monitoramento. } & & \\
\end{array}$ & $\begin{array}{l}\text { 9. Este serviço acompanha os pacientes } \\
\text { que precisam de monitoramento. }\end{array}$ \\
\hline $\begin{array}{l}\text { 10. É difícil expressar opiniões diferentes } \\
\text { neste consultório. }\end{array}$ & $\begin{array}{l}\text { 10. Neste serviço é difícil expressar } \\
\text { opiniões diferentes. }\end{array}$ \\
\hline $\begin{array}{l}\text { 11. Neste consultório, discutimos formas } \\
\text { de evitar que erros aconteçam } \\
\text { novamente. }\end{array}$ & $\begin{array}{l}\text { 11. Neste serviço discutimos maneiras de } \\
\text { evitar que erros aconteçam novamente. }\end{array}$ \\
\hline $\begin{array}{l}\text { 12. Os funcionários estão dispostos a } \\
\text { reportar os erros que observam neste } \\
\text { consultório }\end{array}$ & $\begin{array}{l}\text { 12. Os funcionários estão dispostos a } \\
\text { relatar erros que observam neste } \\
\text { serviço. }\end{array}$ \\
\hline
\end{tabular}




\begin{tabular}{|c|c|}
\hline Versão síntese T1-2 & Versão após avaliação dos especialistas \\
\hline $\begin{array}{l}\text { Seção E: Apoio do proprietário/sócio } \\
\text { diretor/líder }\end{array}$ & $\begin{array}{lrr}\text { Seção } & \text { E: } & \text { Apoio } \\
\text { gestores/administradores/líderes }\end{array}$ \\
\hline $\begin{array}{l}\text { Quanto você concorda ou discorda das } \\
\text { seguintes afirmações sobre os } \\
\text { proprietários/sócios diretores/líderes do } \\
\text { seu consultório médico? } \\
\square \text { 1.Discordo fortemente } \\
\square \text { 2. Discordo } \\
\square \text { 3. Não concordo nem discordo } \\
\square \text { 4. Concordo } \\
\square \text { 5. Concordo fortemente } \\
\square 9 \text {. Não se aplica ou não sei }\end{array}$ & $\begin{array}{l}\text { Quanto você concorda ou discorda das } \\
\text { seguintes afirmações sobre os } \\
\text { gestores/líderes do seu serviço? } \\
\square \text { 1. Discordo totalmente } \\
\square \text { 2. Discordo } \\
\square \text { 3. Não concordo nem discordo } \\
\square \text { 4. Concordo } \\
\square \text { 5. Concordo totalmente } \\
\square \text { 9. Não se aplica ou não sei }\end{array}$ \\
\hline $\begin{array}{l}\text { 1. Eles não estão investindo recursos } \\
\text { suficientes para melhorar a qualidade do } \\
\text { cuidado neste consultório. }\end{array}$ & $\begin{array}{l}\text { 1. Eles não estão investindo recursos } \\
\text { suficientes para melhorar a qualidade } \\
\text { do } \\
\text { cuidado neste serviço. }\end{array}$ \\
\hline $\begin{array}{l}\text { 2. Eles ignoram erros que se repetem no } \\
\text { cuidado aos pacientes. }\end{array}$ & $\begin{array}{l}\text { 2. Eles ignoram erros que se repetem no } \\
\text { cuidado aos pacientes. }\end{array}$ \\
\hline $\begin{array}{llcc}\text { 3. Eles dão alta } & \text { prioridade } & \text { ao } \\
\text { aprimoramento dos } & \text { processos } & \text { de } \\
\text { cuidado aos pacientes. } & & \\
\end{array}$ & $\begin{array}{l}\text { 3. Eles dão prioridade ao aprimoramento } \\
\text { dos processos de cuidado aos } \\
\text { pacientes. }\end{array}$ \\
\hline $\begin{array}{l}\text { 4. Eles, com muita frequência, tomam } \\
\text { decisões baseadas no que é melhor para } \\
\text { o consultório e não o que é melhor para } \\
\text { pacientes. }\end{array}$ & $\begin{array}{l}\text { 4. Eles frequentemente tomam decisões } \\
\text { baseadas no que é melhor para o } \\
\text { serviço e não o que é melhor para os } \\
\text { pacientes. }\end{array}$ \\
\hline
\end{tabular}

\begin{tabular}{|c|c|}
\hline Versão síntese T1-2 & Versão após avaliação dos especialistas \\
\hline Seção F: Seu consultório médico & Seção F: Seu serviço de saúde \\
\hline $\begin{array}{l}\text { Quanto você concorda ou discorda das } \\
\text { seguintes afirmações? } \\
\square \text { 1. Discordo fortemente } \\
\square \text { 2. Discordo } \\
\square \text { 3. Não concordo nem discordo } \\
\square \text { 4. Concordo } \\
\square \text { 5. Concordo fortemente } \\
\square \text { 9. Não se aplica ou não sei. }\end{array}$ & $\begin{array}{l}\text { Quanto você concorda ou discorda das } \\
\text { seguintes afirmações? } \\
\square \text { 1. Discordo totalmente } \\
\square \text { 2. Discordo } \\
\square \text { 3. Não concordo nem discordo } \\
\square \text { 4. Concordo } \\
\square \text { 5. Concordo totalmente } \\
\square \text { 9. Não se aplica ou não sei }\end{array}$ \\
\hline $\begin{array}{l}\text { 1. Quando existe um problema em nosso } \\
\text { consultório, verificamos se é preciso } \\
\text { mudar a forma como fazemos as coisas. }\end{array}$ & $\begin{array}{l}\text { 1. Quando há um problema em nosso } \\
\text { serviço avaliamos se é necessário mudar } \\
\text { a maneira como fazemos as coisas. }\end{array}$ \\
\hline $\begin{array}{l}\text { 2. Nossos processos são bons em prevenir } \\
\text { erros que poderiam afetar os pacientes. }\end{array}$ & $\begin{array}{l}\text { 2. Nossos processos são adequados para } \\
\text { prevenir erros que poderiam afetar os } \\
\text { pacientes. }\end{array}$ \\
\hline $\begin{array}{l}\text { 3. Erros acontecem com mais frequência } \\
\text { do que deveriam neste consultório. }\end{array}$ & $\begin{array}{l}\text { 3. Neste serviço, erros acontecem com } \\
\text { mais frequência do que deveriam. }\end{array}$ \\
\hline $\begin{array}{l}\text { 4. É apenas por acaso que nós não } \\
\text { cometemos mais erros que afetam } \\
\text { nossos pacientes. }\end{array}$ & $\begin{array}{l}\text { 4.É apenas por acaso que nós não } \\
\text { cometemos mais erros que afetam } \\
\text { nossos pacientes. }\end{array}$ \\
\hline
\end{tabular}




\begin{tabular}{|c|c|}
\hline $\begin{array}{c}\text { 5. Este consultório é bom em mudar } \\
\text { processos para garantir que os mesmos } \\
\text { problemas não voltem a ocorrer. }\end{array}$ & $\begin{array}{c}\text { 5. Este serviço é eficiente em modificar } \\
\text { processos de trabalho para prevenir que } \\
\text { os mesmos problemas se repitam. }\end{array}$ \\
\hline $\begin{array}{c}\text { 6. Neste consultório, realizar maior } \\
\text { quantidade de tarefas é mais importante } \\
\text { que a qualidade do cuidado prestado. }\end{array}$ & $\begin{array}{c}\text { 6. Neste serviço a quantidade de atividades } \\
\text { realizadas é mais importante que a } \\
\text { qualidade do cuidado prestado. }\end{array}$ \\
\hline $\begin{array}{l}\text { 7. Após mudanças realizadas neste } \\
\text { consultório para melhorar o processo de } \\
\text { atendimento ao paciente, verificamos se } \\
\text { as mudanças funcionaram. }\end{array}$ & $\begin{array}{l}\text { 7. Neste serviço, após realizarmos } \\
\text { mudanças para melhorar o processo de } \\
\text { atendimento ao paciente, avaliamos se } \\
\text { elas funcionaram. }\end{array}$ \\
\hline
\end{tabular}

\begin{tabular}{|c|c|}
\hline Versão síntese T1-2 & Versão após avaliação dos especialistas \\
\hline Seção G: Avaliação Geral & Seção G: Avaliação Geral \\
\hline Avaliação Geral - em Qualidade & Avaliação global da qualidade \\
\hline $\begin{array}{l}\text { 1. No geral, como você classificaria o seu } \\
\text { consultório médico em cada uma das } \\
\text { seguintes áreas de qualidade de cuidados } \\
\text { de saúde? } \\
\square \text { 1. Pobre } \\
\square \text { 2. Razoável } \\
\square \text { 3. Bom } \\
\square \text { 4. Muito bom } \\
\square \text { 5. Excelente }\end{array}$ & $\begin{array}{l}\text { 1. No geral, como você classificaria este } \\
\text { serviço de saúde em cada uma das } \\
\text { seguintes áreas de qualidade de cuidados } \\
\text { de saúde? } \\
\square \text { 1. Ruim } \\
\square \text { 2. Razoável } \\
\square \text { 3. Bom } \\
\square \text { 4. Muito bom } \\
\square \text { 5. Excelente }\end{array}$ \\
\hline $\begin{array}{l}\text { a. Centrado no paciente: É sensível às } \\
\text { preferências } \\
\text { individuais, }\end{array}$ & $\begin{array}{l}\text { a. Centrado no paciente: É sensível às } \\
\text { preferências } \\
\text { individuais, }\end{array}$ \\
\hline $\begin{array}{l}\text { necessidades e valores dos } \\
\text { pacientes. }\end{array}$ & $\begin{array}{l}\begin{array}{l}\text { necessidades e valores dos } \\
\text { pacientes. }\end{array} \\
\text { acien }\end{array}$ \\
\hline $\begin{array}{l}\text { b. Efetivo: É baseado no } \\
\text { conhecimento científico. }\end{array}$ & $\begin{array}{l}\text { b. Efetivo: É baseado } \\
\text { conhecimento científico. }\end{array}$ \\
\hline $\begin{array}{l}\text { c. Pontual: Minimiza esperas e } \\
\text { atrasos potencialmente prejudiciais. }\end{array}$ & $\begin{array}{l}\text { c. Pontual: Minimiza esperas e } \\
\text { atrasos potencialmente prejudiciais. }\end{array}$ \\
\hline $\begin{array}{l}\text { d. Eficiente: Garante um cuidado de } \\
\text { bom custo-benefício (evita o } \\
\text { desperdício, uso excessivo e uso } \\
\text { incorreto de serviços). }\end{array}$ & $\begin{array}{l}\text { d. Eficiente: Garante um cuidado de } \\
\text { bom custo-benefício (evita o } \\
\text { desperdício, uso excessivo e } \\
\text { incorreto de serviços). }\end{array}$ \\
\hline $\begin{array}{l}\text { e. Imparcial: Fornece a mesma } \\
\text { qualidade de cuidado a todos os } \\
\text { indivíduos, independentemente de } \\
\text { sexo, raça, etnia, status } \\
\text { socioeconômico, língua, etc.. }\end{array}$ & $\begin{array}{l}\text { e. Equitativo: Fornece a mesma } \\
\text { qualidade de cuidados a todos os } \\
\text { indivíduos, independentemente de } \\
\text { gênero, etnia, status } \\
\text { socioeconômico, idioma, etc... }\end{array}$ \\
\hline Avaliação global da segurança do paciente & Avaliação global da segurança do paciente \\
\hline $\begin{array}{l}\text { 2. No geral, como você classificaria os } \\
\text { sistemas e processos clínicos que o seu } \\
\text { consultório utiliza para prevenir, } \\
\text { identificar e corrigir problemas que } \\
\text { tenham o potencial de afetar pacientes? } \\
\square \text { 1. Pobre } \\
\square \text { 2. Razoável }\end{array}$ & $\begin{array}{l}\text { 2. No geral, como você classificaria os } \\
\text { sistemas e processos clínicos que o seu } \\
\text { serviço utiliza para prevenir, identificar e } \\
\text { corrigir problemas que tenham o potencial } \\
\text { de afetar pacientes? } \\
\square \text { 1. Ruim } \\
\square \text { 2. Razoável }\end{array}$ \\
\hline
\end{tabular}




\begin{tabular}{|l|l|}
\hline$\square 3$. Bom & $\square 3$. Bom \\
$\square$ 4. Muito bom & $\square 4$. Muito bom \\
$\square$ 5. Excelente & $\square 5$. Excelente \\
\hline
\end{tabular}

\begin{tabular}{|c|c|}
\hline Versão síntese T1-2 & Versão após avaliação dos especialistas \\
\hline $\begin{array}{l}\text { Seção H: Questões sobre a prática } \\
\text { profissional }\end{array}$ & $\begin{array}{l}\text { Seção H: Questões sobre a prática } \\
\text { profissional }\end{array}$ \\
\hline $\begin{array}{l}\text { 1. Há quanto tempo você trabalha neste } \\
\text { consultório médico? } \\
\square \text { a. Há menos de } 2 \text { meses } \\
\square \text { b. De } 2 \text { meses a menos de } 1 \text { ano } \\
\square \text { c. De } 1 \text { ano a menos de } 3 \text { anos } \\
\square \text { d. De } 3 \text { anos a menos de } 6 \text { anos } \\
\square \text { e. De } 6 \text { anos a menos de } 11 \text { anos } \\
\square \text { f. Há } 11 \text { anos ou mais }\end{array}$ & $\begin{array}{l}\text { 1. Há quanto tempo você trabalha neste } \\
\text { serviço? } \\
\square \text { a. Há menos de } 2 \text { meses } \\
\square \text { b. De } 2 \text { meses a menos de } 1 \text { ano } \\
\square \text { c. De } 1 \text { ano a menos de } 3 \text { anos } \\
\square \text { d. De } 3 \text { anos a menos de } 6 \text { anos } \\
\square \text { e. De } 6 \text { anos a menos de } 11 \text { anos } \\
\square \text { f. Há } 11 \text { anos ou mais }\end{array}$ \\
\hline $\begin{array}{l}\text { 2. Normalmente, quantas horas por } \\
\text { semana você trabalha neste consultório } \\
\text { médico? } \\
\square \text { a. De } 1 \text { a } 4 \text { horas por semana } \\
\square \text { b. De } 5 \text { a } 16 \text { horas por semana } \\
\square \text { c. De } 17 \text { a } 24 \text { horas por semana } \\
\square \text { d. De } 25 \text { a } 32 \text { horas por semana } \\
\square \text { e. De } 33 \text { a } 40 \text { horas por semana } \\
\square \text { f. } 41 \text { horas por semana ou mais }\end{array}$ & $\begin{array}{l}\text { 2. Normalmente, quantas horas por } \\
\text { semana você trabalha neste serviço? } \\
\square \text { a. De } 1 \text { a } 4 \text { horas por semana } \\
\square \text { b. De } 5 \text { a } 16 \text { horas por semana } \\
\square \text { c. De } 17 \text { a } 24 \text { horas por semana } \\
\square \text { d. De } 25 \text { a } 32 \text { horas por semana } \\
\square \text { e. De } 33 \text { a } 40 \text { horas por semana } \\
\square \text { f. } 41 \text { horas por semana ou mais }\end{array}$ \\
\hline $\begin{array}{l}\text { Qual é o seu cargo neste consultório? } \\
\text { Marque UMA categoria que melhor se } \\
\text { aplica ao seu trabalho. } \\
\square \text { a. Médico } \\
\square \text { b. Enfermeiro especialista, enfermeiro } \\
\text { obstetra, } \\
\square \text { c. Gerência - Gerente do consultório, } \\
\text { Administrador do consultório, Gerente de } \\
\text { enfermagem, Gerente de laboratório, Outro } \\
\text { gerente. } \\
\square \text { d. Equipe administrativa - Encarregado } \\
\text { dos convênios médicos, Equipe de } \\
\text { cobrança, Equipe de referência, Registros } \\
\text { médicos, Recepção, Recepcionista, } \\
\text { Encarregado dos agendamentos (consultas, } \\
\text { cirurgia, etc.), Outro cargo administrativo. } \\
\square \text { e. Enfermeiro, técnico de enfermagem, } \\
\text { auxiliar de enfermagem. } \\
\square \text { f. Outro pessoal clínico ou pessoal de } \\
\text { apoio clínico, Técnicos (todos os tipos), } \\
\text { Terapeutas (todos os tipos), Outro cargo } \\
\text { clínico ou de apoio clínico. } \\
\square \text { g. Outra posição; por favor especifique: }\end{array}$ & $\begin{array}{l}\text { Qual é o seu cargo neste serviço? Marque } \\
\text { UMA categoria que melhor se aplica ao } \\
\text { seu trabalho. } \\
\square \text { a. Médico } \\
\square \text { b. Enfermeiro } \\
\square \text { c. Gerência - Administrador, Gerente } \\
\text { de Enfermagem, Gerente de laboratório, } \\
\text { Outro gerente__ } \\
\square \text { d. Equipe administrativa - } \\
\text { Registros médicos, Recepção, } \\
\quad \text { Recepcionista, Encarregado dos } \\
\quad \text { agendamentos (consultas, exames, } \\
\quad \text { cirurgia, etc.), Outro cargo } \\
\text { administrative. } \\
\square \text { e. Técnico de Enfermagem } \\
\square \text { f. Outro pessoal clínico: Técnico de } \\
\text { Laboratório, Técnico em Saúde } \\
\text { Bucal } \\
\square \text { Odontólogo } \\
\square \text { Fisioterapeuta } \\
\square \text { Nutricionista } \\
\square \text { Farmacêutico }\end{array}$ \\
\hline
\end{tabular}




\begin{tabular}{|l|l|}
\hline & $\square$ Psicólogo \\
& $\square$ Terapeuta Ocupacional \\
$\square$ Assistente Social \\
$\square$ Agente Comunitário de Saúde \\
$\square$ Outra posição, de nível técnico. Por \\
& favor, especifique: \\
\hline
\end{tabular}




\section{APÊNDICE 4}

Versão final do instrumento traduzido e adaptado

\section{Pesquisa sobre Cultura de Segurança do Paciente para Atenção Primária}

\section{INSTRUÇÕES DA PESQUISA}

Pense sobre a maneira como as coisas são feitas no serviço de saúde onde você trabalha e dê sua opinião sobre questões que afetam a segurança e a qualidade do cuidado prestado aos pacientes.

Se uma questão não se aplica a você ou se você não sabe a resposta, por favor, marque "Não se aplica ou não sei".

Se você trabalha em mais de um serviço de saúde, ao responder esta pesquisa, responda apenas sobre o local onde você a recebeu; não responda sobre sua prática de forma geral.

Se você trabalha em um local que possui outros serviços de saúde, responda somente em relação ao seu próprio local de trabalho.

\section{SEÇÃO A: Lista de questões sobre segurança do paciente e qualidade}

Os itens a seguir descrevem situações que podem ocorrer em serviços de saúde, afetando a segurança do paciente e a qualidade do cuidado. Pelos seus cálculos, com que frequência os fatos listados abaixo aconteceram em seu local de trabalho NOS ÚLTIMOS 12 MESES?

\section{Acesso ao cuidado}

1. Um paciente não conseguiu uma consulta em até 48 horas para um problema sério/agudo.

\section{Identificação do Paciente}

\section{No atendimento de um} paciente foi utilizado um prontuário/registro de outro paciente.

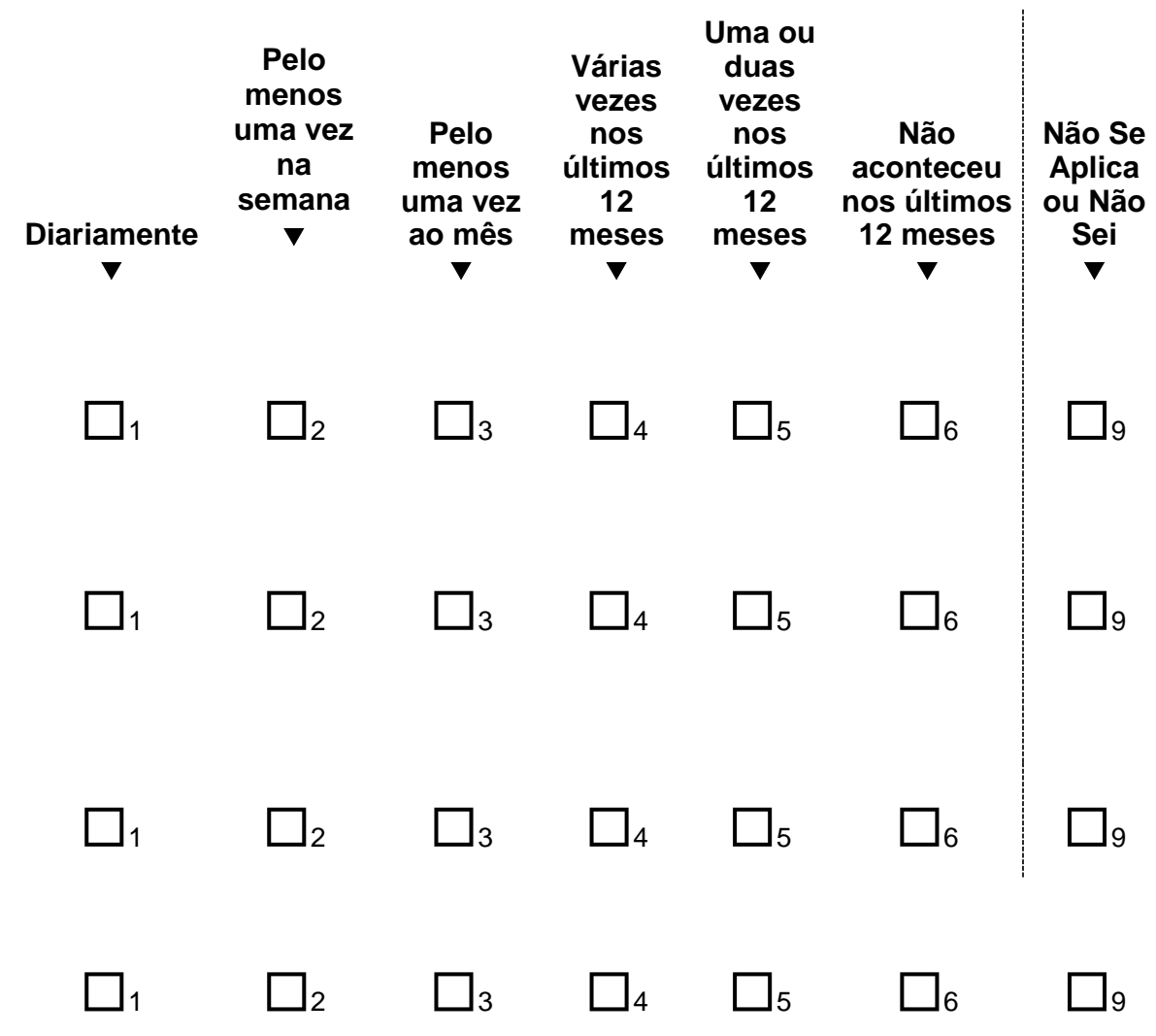

\section{Prontuários/registros}

3. O prontuário/registro de um paciente não estava disponível quando necessário.

4. Informações clínicas de um paciente foram arquivadas, digitalizadas ou inseridas no prontuário/registro de outro paciente. 


\section{Equipamento}

5. Um equipamento necessário ao atendimento não funcionou adequadamente ou necessitava reparo ou substituição.
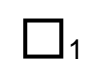

$\square_{2}$

$\square 3$

$\square 4$

$\square_{5}$

$\square 6$

$\square 9$

SEÇÃO A: Lista de questões sobre segurança do paciente e qualidade (continuação)

\section{Medicamento}

6. O paciente retornou à unidade de saúde para esclarecer ou corrigir uma prescrição.

7. Os medicamentos utilizados por um paciente não foram revisados pelo profissional de saúde durante sua consulta.

\section{Diagnósticos \& Testes}

8. Os exames laboratoriais ou de imagem não foram realizados quando necessário.

9. Os resultados de exames laboratoriais ou de imagem não estavam disponíveis quando necessário.

10. Um resultado anormal de um exame laboratorial ou de imagem não foi acompanhado/avaliado em tempo hábil.

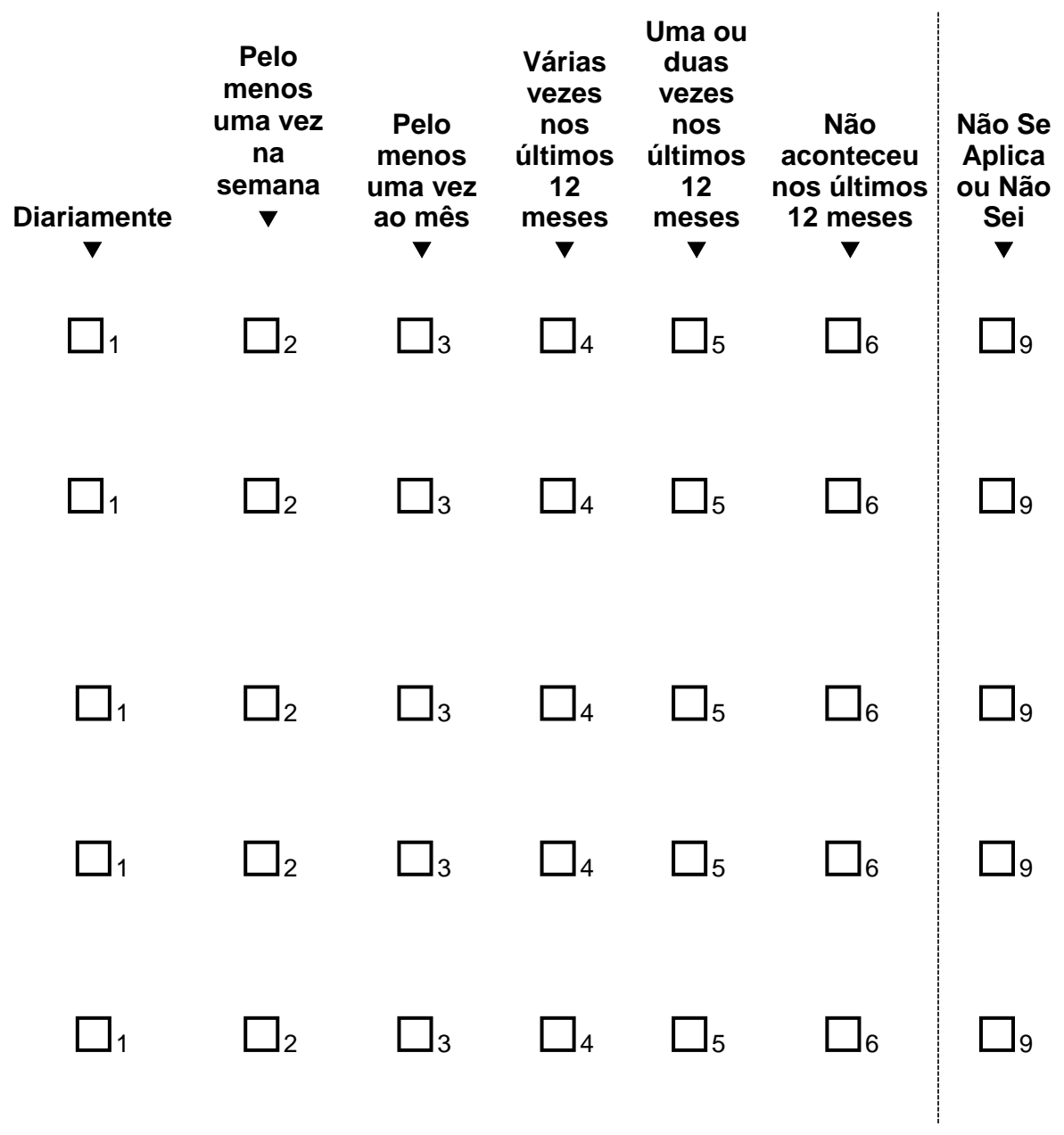


Nos últimos 12 meses, com que frequência este serviço de saúde apresentou problemas relacionados à troca de informações completas, precisas e pontuais com:

1. Centros de

imagem/laboratórios da

\begin{tabular}{|c|c|c|c|c|c|c|}
\hline $\begin{array}{c}\text { Problemas } \\
\text { diariamente } \\
\nabla\end{array}$ & $\begin{array}{c}\text { Problem } \\
\text { a pelo } \\
\text { menos } \\
\text { uma vez } \\
\text { na } \\
\text { semana } \\
\nabla\end{array}$ & $\begin{array}{c}\text { Problema } \\
\text { pelo } \\
\text { menos } \\
\text { uma vez } \\
\text { ao mês } \\
\\
\nabla\end{array}$ & $\begin{array}{c}\text { Vários } \\
\text { problema } \\
\text { s nos } \\
\text { últimos } 12 \\
\text { meses } \\
\nabla\end{array}$ & $\begin{array}{l}\text { Um ou dois } \\
\text { problemas } \\
\text { nos últimos } \\
12 \text { meses }\end{array}$ & $\begin{array}{c}\text { Nenhum } \\
\text { problema } \\
\text { nos } \\
\text { últimos } \\
12 \text { meses } \\
\nabla\end{array}$ & $\begin{array}{c}\text { Não se } \\
\text { Aplica ou } \\
\text { Não Sei } \\
\nabla\end{array}$ \\
\hline$\square$ 唯 & $\square_{2}$ & $\square_{3}$ & $\square_{4}$ & $\square_{5}$ & $\square_{6}$ & $\square_{9}$ \\
\hline$\square_{1}$ & $\square_{2}$ & $\square_{3}$ & $\square_{4}$ & $\square_{5}$ & $\square_{6}$ & $\square_{9}$ \\
\hline$\square_{1}$ & $\square_{2}$ & $\square_{3}$ & $\square_{4}$ & $\square_{5}$ & $\square_{6}$ & $\square_{9}$ \\
\hline$\square_{1}$ & $\square_{2}$ & $\square_{3}$ & $\square_{4}$ & $\square_{5}$ & $\square_{6}$ & $\square_{9}$ \\
\hline$\square_{1}$ & $\square_{2}$ & $\square_{3}$ & $\square_{4}$ & $\square_{5}$ & $\square_{6}$ & $\square_{9}$ \\
\hline
\end{tabular}

2 Outros şa saúde? saúde/médicos da rede de atenção à saúde?

3. Farmácias?

4. Hospitais?

Outros? Por favor, especifique:

\section{SEÇÃO C: Trabalhando neste serviço de saúde}

\section{Quanto você concorda ou discorda com as seguintes afirmações?}

1. Quando alguém neste serviço está muito ocupado, outros colegas ajudam.

2. Neste serviço há uma boa relação de trabalho entre os médicos e demais profissionais.

3. Neste serviço frequentemente nos sentimos apressados ao atender 0 paciente.

4. Este serviço treina a equipe sempre que novos processos são implantados.

5. Neste serviço tratamos uns aos outros com respeito.

6. Neste serviço a quantidade de pacientes é muito alta em relação ao número de médicos disponíveis.

\begin{tabular}{|c|c|c|c|c|c|}
\hline $\begin{array}{c}\text { Discordo } \\
\text { Totalmente } \\
\nabla\end{array}$ & $\underset{\nabla}{\text { Discordo }}$ & $\begin{array}{c}\text { Não } \\
\text { Concordo } \\
\text { Nem } \\
\text { Discordo } \\
\nabla\end{array}$ & $\begin{array}{c}\text { Concordo } \\
\nabla\end{array}$ & $\begin{array}{c}\text { Concordo } \\
\text { Totalmente } \\
\nabla\end{array}$ & $\begin{array}{c}\text { Não se } \\
\text { Aplica } \\
\text { ou Não } \\
\text { Sei } \\
\nabla\end{array}$ \\
\hline$\square_{1}$ & $\square_{2}$ & $\square_{3}$ & $\square_{4}$ & $\square_{5}$ & $\square_{9}$ \\
\hline$\square_{1}$ & $\square_{2}$ & $\square_{3}$ & $\square_{4}$ & $\square_{5}$ & $\square_{9}$ \\
\hline$\square_{1}$ & $\square_{2}$ & $\square_{3}$ & $\square_{4}$ & $\square_{5}$ & $\square_{9}$ \\
\hline$\square_{1}$ & $\square_{2}$ & $\square_{3}$ & $\square_{4}$ & $\square_{5}$ & $\square 9$ \\
\hline$\square_{1}$ & $\square_{2}$ & $\square_{3}$ & $\square_{4}$ & $\square_{5}$ & $\square_{9}$ \\
\hline$\square_{1}$ & $J_{2}$ & $\square_{3}$ & $\square_{4}$ & $\square_{5}$ & $\square_{9}$ \\
\hline
\end{tabular}


7. Este serviço garante que sua equipe receba atualizações necessárias ao atendimento.

8. Neste serviço a desorganização é maior que o aceitável.

9. Neste serviço há procedimentos para verificar se o trabalho foi realizado corretamente.

10. Os profissionais que trabalham neste serviço são solicitados a realizar tarefas para as quais não foram treinados.

11. Neste serviço a quantidade de profissionais da equipe é suficiente para atender o número de pacientes.

12. Neste serviço há problemas com o fluxo de trabalho.

13. Este serviço valoriza o trabalho em equipe no cuidado aos pacientes.

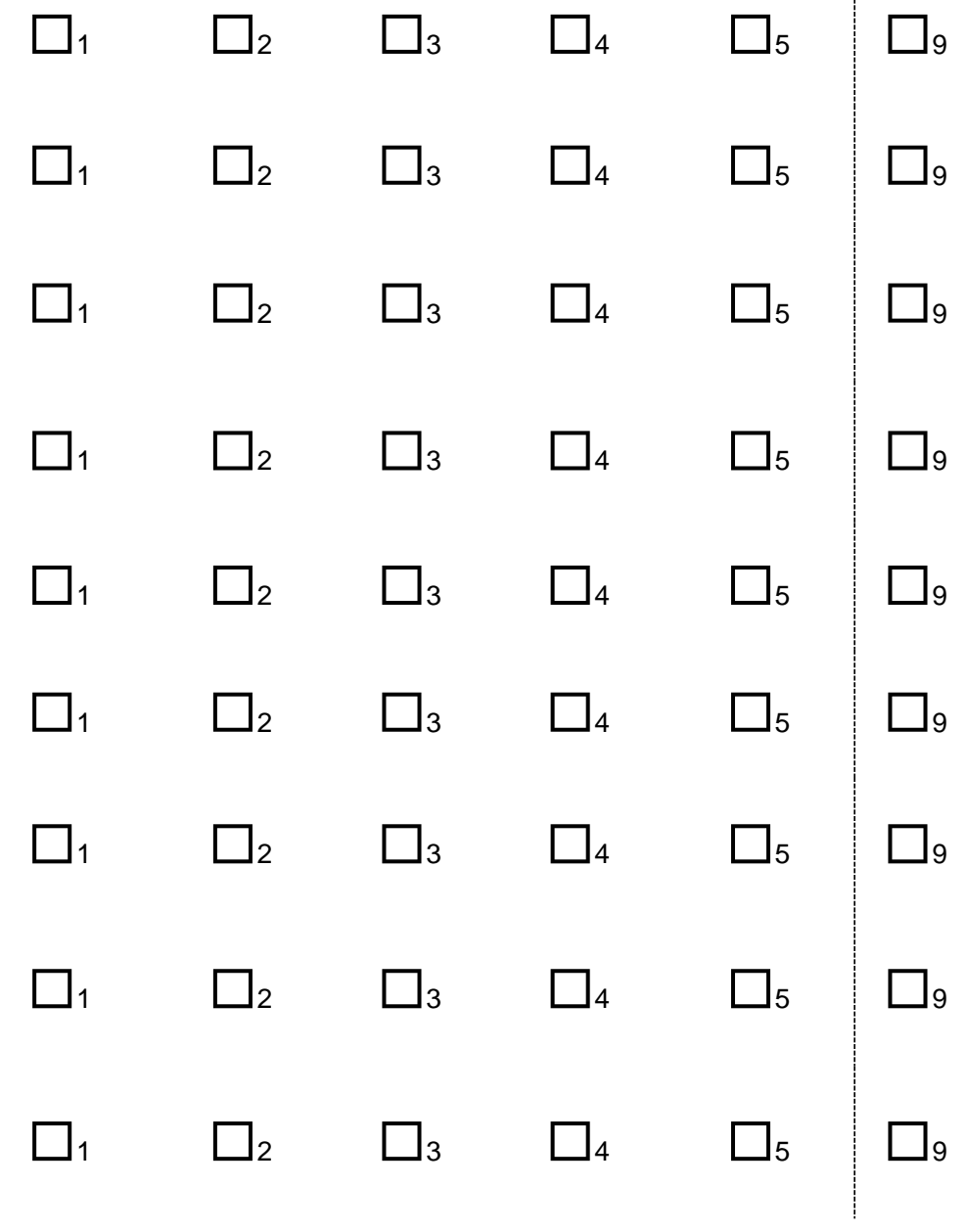

14. Neste serviço há número maior de pacientes que a capacidade para atendêlos de maneira eficiente.

15. A equipe deste serviço segue processos padronizados para realizar suas atividades.

\section{SEÇÃO D: Comunicação e Acompanhamento}

Com que frequência os fatos a seguir ocorrem neste serviço?

1. Os médicos deste serviço estão abertos para as ideias dos demais integrantes da equipe sobre como melhorar os processos de trabalho.

2. Neste serviço a equipe é incentivada a expressar outros pontos de vista.

3. Neste serviço os pacientes são avisados quando precisam agendar uma consulta para cuidados preventivos ou de rotina.

4. Neste serviço a equipe tem receio de fazer perguntas quando algo não parece correto.

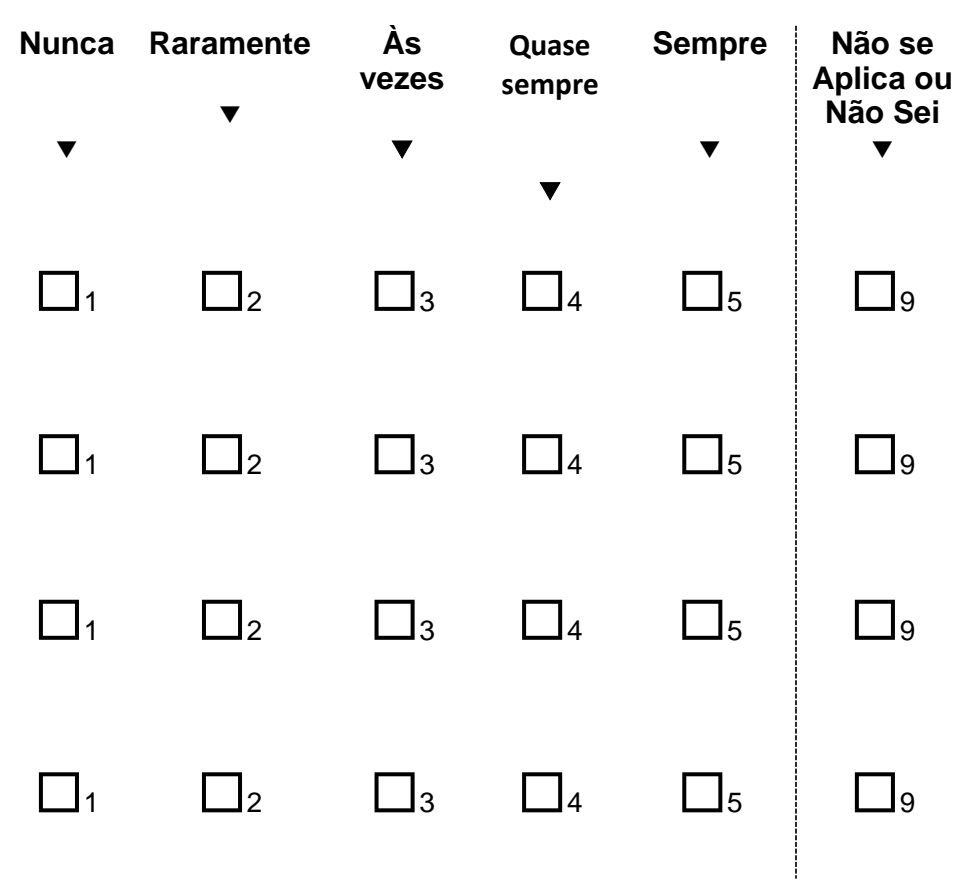


5. Este serviço registra a maneira como pacientes crônicos seguem o plano de tratamento.

6. Este serviço faz acompanhamento quando não recebe um relatório esperado de outro serviço.

7. A equipe deste serviço acredita que seus erros possam ser usados contra si.

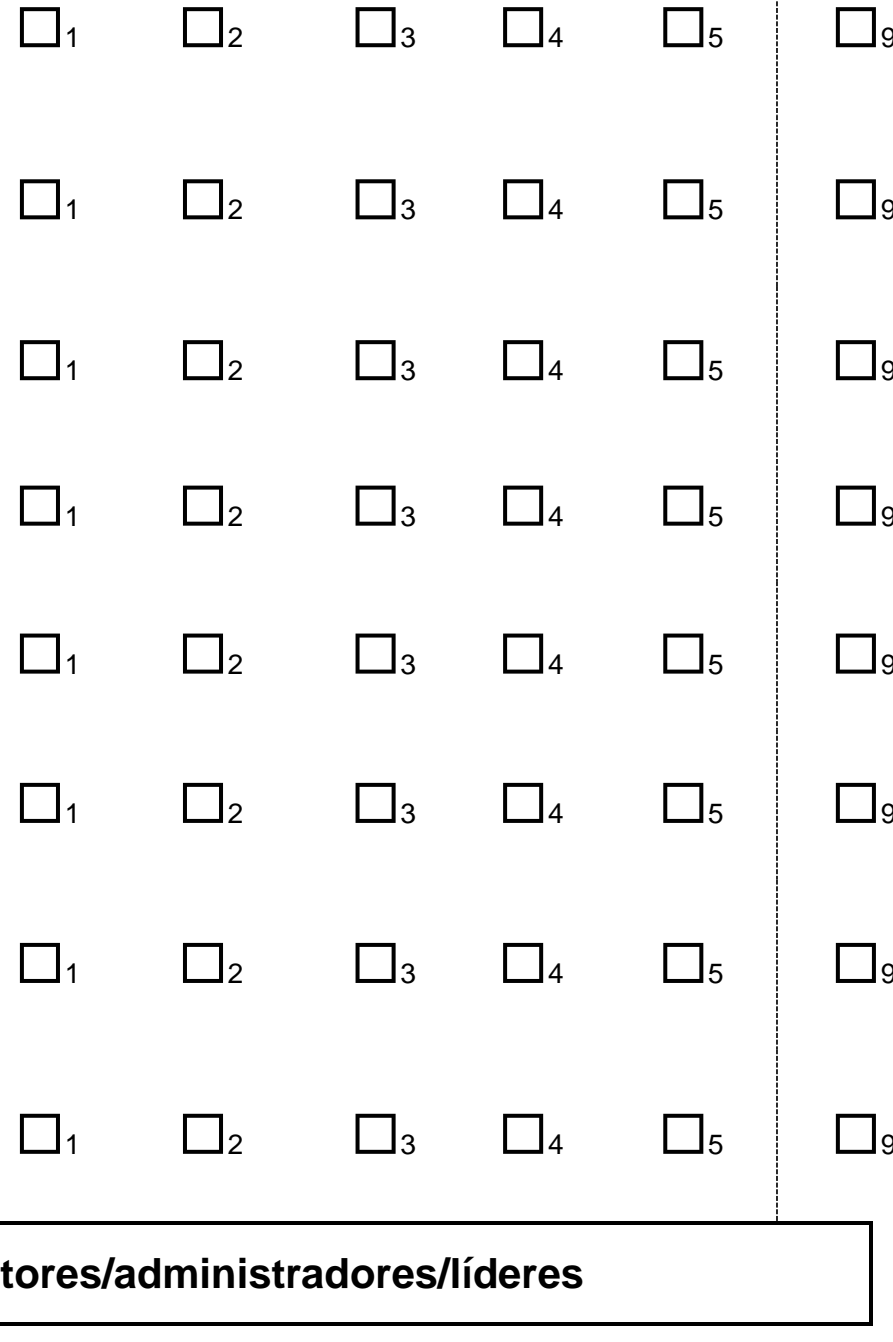

8. A equipe fala abertamente sobre os problemas neste serviço.

9. Este serviço acompanha os pacientes que precisam de monitoramento.

10. Neste serviço é difícil expressar opiniões diferentes.

11. Neste serviço discutimos maneiras de evitar que erros aconteçam novamente.

12. Os funcionários estão dispostos a relatar erros que observam neste serviço.

\section{SEÇÃO E: Apoio de gestores/administradores/líderes}

A. Você é gestor/administrador ou tem algum cargo de liderança com responsabilidade para tomar decisões financeiras pelo serviço?

\section{Sim $\rightarrow$ Vá para Seção $\boldsymbol{F}$}

Não $\rightarrow$ Continue abaixo

Quanto você concorda ou discorda das seguintes afirmações sobre os gestores/líderes do seu serviço?

1. Eles não estão investindo recursos suficientes para melhorar a qualidade do cuidado neste serviço.

\begin{tabular}{|c|c|c|c|c|c|}
\hline $\begin{array}{c}\text { Discordo } \\
\text { Totalmente } \\
\nabla\end{array}$ & $\underset{\nabla}{\text { Discordo }}$ & $\begin{array}{c}\text { Não } \\
\text { Concordo } \\
\text { nem } \\
\text { Discordo } \\
\nabla\end{array}$ & $\underset{\nabla}{\text { Concordo }}$ & $\begin{array}{c}\text { Concordo } \\
\text { Totalmente } \\
\nabla\end{array}$ & $\begin{array}{c}\text { Não se } \\
\text { Aplica } \\
\text { ou } \\
\text { Não } \\
\text { Sei } \\
\nabla\end{array}$ \\
\hline$\square_{1}$ & $\square_{2}$ & $\square_{3}$ & $\square_{4}$ & $\square_{5}$ & $\square 9$ \\
\hline$\square_{1}$ & $\square_{2}$ & $\square_{3}$ & $\square_{4}$ & $\square_{5}$ & $\square_{9}$ \\
\hline$\square_{1}$ & $\square_{2}$ & $\square_{3}$ & $\square_{4}$ & $\square_{5}$ & $\square_{9}$ \\
\hline$\square_{1}$ & $\square_{2}$ & $\square_{3}$ & $\square_{4}$ & $\square_{5}$ & $\square_{9}$ \\
\hline
\end{tabular}

2. Eles ignoram erros que se repetem no cuidado aos pacientes.

3. Eles dão prioridade à melhoria dos processos de atendimento aos pacientes.

4. Eles frequentemente tomam decisões baseadas no que é melhor para o serviço e não no que é melhor para os pacientes. 
Quanto você concorda ou discorda das seguintes afirmações?

1. Quando há um problema em nosso serviço avaliamos se é necessário mudar a maneira como fazemos as coisas.

2. Nossos processos de trabalho são adequados para prevenir erros que poderiam afetar os pacientes.

3. Neste serviço acontecem erros com mais frequência do que deveriam.

4. É apenas por acaso que não cometemos mais erros que afetam nossos pacientes.

5. Este serviço é eficiente em modificar processos de trabalho para prevenir que problemas se repitam.

6. Neste serviço a quantidade de atividades realizadas é mais importante que a qualidade do cuidado prestado.

7. Neste serviço, após realizarmos mudanças para melhorar o processo de atendimento ao paciente, avaliamos se elas funcionam.

\begin{tabular}{|c|c|c|c|c|c|}
\hline $\begin{array}{c}\text { Discordo } \\
\text { Totalmente } \\
\nabla\end{array}$ & $\underset{\nabla}{\text { Discordo }}$ & $\begin{array}{c}\text { Não } \\
\text { Concordo } \\
\text { Nem } \\
\text { Discordo } \\
\nabla\end{array}$ & Concordo & $\begin{array}{c}\text { Concordo } \\
\text { Totalmente } \\
\nabla\end{array}$ & $\begin{array}{c}\text { Não se } \\
\text { Aplica } \\
\text { ou Não } \\
\text { Sei } \\
\nabla\end{array}$ \\
\hline$\square_{1}$ & $\square_{2}$ & $\square_{3}$ & $\square_{4}$ & $\square_{5}$ & $\square_{9}$ \\
\hline$\square_{1}$ & $\square_{2}$ & $\square_{3}$ & $\square_{4}$ & $\square_{5}$ & $\square_{9}$ \\
\hline$\square_{1}$ & $\square_{2}$ & $\square_{3}$ & $\square_{4}$ & $\square_{5}$ & $\square_{9}$ \\
\hline$\square_{1}$ & $\square_{2}$ & $\square_{3}$ & $\square_{4}$ & $\square_{5}$ & $\square_{9}$ \\
\hline$\square_{1}$ & $\square_{2}$ & $\square_{3}$ & $\square_{4}$ & $\square_{5}$ & $\square_{9}$ \\
\hline$\square_{1}$ & $\square_{2}$ & $\square_{3}$ & $\square_{4}$ & $\square_{5}$ & $\square_{9}$ \\
\hline$\square_{1}$ & $\square_{2}$ & $\square_{3}$ & $\square_{4}$ & $\square_{5}$ & $\square_{9}$ \\
\hline
\end{tabular}




\section{SEÇÃO G: Avaliação global}

\section{Avaliação global da qualidade}

1. No geral, como você classificaria este serviço de saúde em cada uma das seguintes áreas de qualidade de cuidados de saúde?

a. Centrado É sensível às preferências no individuais, necessidades e paciente: valores dos pacientes.

b. Efetivo: É baseado no conhecimento científico.

c. Pontual:

Minimiza esperas e atrasos potencialmente prejudiciais.

d. Eficiente: Garante um cuidado de bom custo-benefício (evita o desperdício, uso excessivo e incorreto de serviços).

e. Imparcial:
Fornece a mesma qualidade de cuidados a todos os indivíduos, independentemente de gênero, etnia, status socioeconômico, idioma, etc...

$\begin{array}{ccc}\text { Ruim } & \text { Razoável } & \text { Bom } \\ \boldsymbol{\nabla} & \boldsymbol{\nabla} & \boldsymbol{\nabla}\end{array}$

Muito Bom

Excelente

$\square_{1}$

$\square 2$

$\square_{3}$

$\square_{4}$

$\square 5$

$\square 1$

$\square 2$

$\square 3$

$\square_{4}$

$\square 5$

$\square 1$

$\square 2$

$\square 3$

$\square_{4}$

$\square 5$

$\square 1$

$\square 2$

$\square 3$

$\square_{4}$<smiles>C1C[AsH]C1</smiles> 


\section{SEÇÃO H: Questões sobre a prática profissional}

1. Há quanto tempo você trabalha neste serviço?
$\square$ a. Há menos de 2 meses
$\square$ d. De 3 anos a menos de 6 anos
$\square$ b. De 2 meses a menos de 1 ano
$\square$ e. De 6 anos a menos de 11 anos
$\square$ c. De 1 ano a menos de 3 anos
$\square$ f. Há 11 anos ou mais

2. Normalmente, quantas horas por semana você trabalha neste serviço?
$\square$ a. 1 a 4 horas por semana
$\square$ d. 25 a 32 horas por semana
$\square$ b. 5 a 16 horas por semana
$\square$ e. 33 a 40 horas por semana
$\square$ c. 17 a 24 horas por semana
$\square$ f. 41 horas por semana ou mais

3. Qual é o seu cargo neste serviço? Marque UMA categoria que melhor se aplica ao seu trabalho.

$\square$ a. Médico

$\square$ b. Enfermeiro

$\square$ c. Gerência

Administrador

Gerente de Enfermagem

Gerente de laboratório

Outro gerente

$\square$ d. Equipe administrativa

Registros médicos

Recepção

Recepcionista

$\square$ e. Técnico de Enfermagem

$\square$ f. Outro pessoal clínico:

Técnico de Laboratório

Técnico em Saúde Bucal
$\square$ Odontólogo
$\square$ Fisioterapeuta
$\square$ Nutricionista
$\square$ Farmacêutico
$\square$ Psicólogo
$\square$ Terapeuta Ocupacional
$\square$ Assistente Social
$\square$ Agente Comunitário de Saúde
$\square$ Outra função. Por favor, especifique:

\section{SEÇÃO I - Seus comentários}

Por favor sinta-se à vontade para fazer os comentários que você queira sobre segurança $e$ qualidade assistencial no serviço onde você trabalha. 